\title{
GLOSSINOTOECHIIDAE (BRAQUIÓPODOS UNCINULOIDEOS) DEL DEVÓNICO DE LA CORDILLERA CANTÁBRICA (N DE ESPAÑA)
}

\author{
Jenaro L. GARCÍA-ALCALDE \\ Departamento de Geología (Area de Paleontología) de la Universidad de Ovie- \\ do. c/ Jesús Arias de Velasco, s/n, 33005 Oviedo. \\ email: jalcalde@geol.uniovi.es
}

García-Alcalde, J. L. 2008. Glossinotoechiidae (braquiópodos uncinuloideos) del Devónico de la Cordillera Cantábrica (N de España). [Devonian Glossinotoechiidae (Brachiopoda, Uncinuloidea) of the Cantabrian Mountains (N Spain).] Revista Española de Paleontología, 23 (2), 237-266. ISSN 0213-6937

\section{EXTENDED ABSTRACT}

Glossinotoechiidae Havlíček, 1992 is a well-delimited uncinuloid family originated at the upper part of the Silurian (Ludlowian, after Savage, 2002, or in the Wenlockian, after Havlíček, 1992). It diversified abundantly along the Lower Devonian and disappeared at the beginning of the Middle Devonian (lower Eifelian). Havlíček (1959, 1961 , 1983, 1992) presented detailed and complete studies on the taxa included in the family, especially on the Bohemian ones. Savage (2002) rejected Hostimex Havlíček, 1982 and Markitoechia Havlíček, 1959 from it.

Most taxa of Glossinotoechiidae have usually been included between the Uncinulidae Rzhonsnitskaia, 1956 and Hebetoechiidae Havlíček, 1960. The Glossinotoechiidae shares a number of common features with those families, i.e. the tendency to develop geniculate shell (bycyclic growth) and marginal spines in adult (concha alta) stages. Havlíček (1992) stressed the main differences among the three families in especial the development of a more or less long and high ventral marginal rim (double geniculation) in glossinotoechiid shells. GarcíaAlcalde (1999a) included questionably in it his new genus Lebanzuella. But revaluation of the Lebanzuella characters, specially the coarse ornamentation, smooth umbo, multilobed, longitudinally striated cardinal process and lack of connectivum, compel us now to ascribe it to a new, still non proposed Uncinuloidea, (Hebetoechiidae?) subdivision. García-Alcalde (submitted) suggests the forms he classified earlier as Markitoechia sp., could be ascribed to Voskopitoechia Havlíček, 1992 (Hebetoechiinae).

Despite the great stratigraphical importance and relative abundance in Lower Devonian successions, the Cantabrian Mountains glossinotoechiids have barely received attention. Barrois (1882) proposed a new species, Rhynchonella kayseri, of the upper part of the Emsian, later included in Glossinulus. But classic authors as Comte (1938: Uncinulus kayseri; 1959: Uncinulus princeps, U. henrici and U. kayseri) and other later authors as Westbroek (1967: Glossinulus (Glossinotoechia) latus, Markitoechia lebanza) or García-Alcalde (in García-Alcalde et al., 1979: Glossinulus mimicus; in Arbizu et al., 1979: Glossinulus mimicus, Eoglossinotoechia gr. sylphidea, Glossinotoechia cf. chlupaci; 1995: Tridensilis intermedia, Glossinulus mimicus; 1996: Glossinulus mimicus, Markitoechia spp; 2001: Glossinulus mimicus, Chlupacitoechia intermedia), confined themselves just either to species listing or to brief and partial morphological comments. Schumann (1965) constituted an outstanding exception. This author analyzed the morphology and systematics of several Cantabrian glossinotoechiid forms, i.e. Glossinotoechia henrici (Barrande, 1847), G. sanctimichaelis (Kayser, 1889), G. lata n. sp, and G. kayseri (Barrois, 1882). The Schumann's paper is yet a necessary and useful reference even if their classifications must be revised. Figured Schumann's specimens are anterolaterally rimmed a feature that occurs in Chlupacitoechia Havlíček, 1992 and in Glossinulus Schmidt, 1942 but never in Glossinotoechia that shows a complete double geniculation along the ventral margin. Thus, the so-called Glossinotoechia henrici and G. sanctimichaelis in Schumann (1965: 70, 72 Pl. 4 figs. 1,9) could be better identified as Chlupacitoechia intermedia (Brice, 1981), as suggested for the former species by Brice (1981: 198). G. lata Schumann, 1965, a very transverse form that occurs together "G. henrici", is represented for very scant material, most part of it constituted by internal, crushed moulds. It is difficult at the present to know the origin of the forms figured as Glossinotoechia kayseri by Schumann (op. cit.: 80, Pl. 4 figs. 4-5) but they differ considerably of the named species in the general shape and faint development of the umbo region, medial dorsal depression and ventral elevation. The term "hypotypoide" (recto hypotypoid) as applied to both figured specimens, is not enlightening at all because the rather confused usage of it. Probably the specimens come from the Fundpunkt 1 (Schumann op. cit.: 96) corresponding to the last tiers of the La Vid Group, near Argovejo (Prov. of León), upper Emsian. In these levels, at the Leon area, 
Chlupacitoechia intermedia and Ch. lavidana occur (but not Glossinulus kayseri) to which could, respectively, belong questionably the discussed specimens.

In the present paper two new glossinotoechiid species are proposed, Eoglossinotoechia puertoana n. sp, and Chlupacitoechia lavidana n. sp. Chlupacitoechia intermedia (Brice, 1981) is also identified and described from several localities in the Southern Cantabrian Mountains. Glossinulus kayseri, earlier synonymized to the typespecies of the genus, G. mimicus (Barrande, 1879) by several authors (Drot, 1964; Arbizu et al. 1979; GarciaAlcalde et al., 1979; García-Alcalde 1995, 1996, 2001) is considered herein as a separate species and an emended diagnosis, lectotype, stratum typicum and locus typicus, are proposed for it.

In the Cantabrian Mountains, Chlupacitoechia occurs in the lower part of the upper Emsian (dacryoconarid Nowakia cancellata and conodont Polygnathus laticostatus Biozones), represented by great, thick, with weak double geniculation shells (Ch. lavidana n. sp.). These features suggest close affinities with evolved Devonian Eoglossinotoechia (i.e. E. marocanensis Drot, 1964). A little higher, but still in the same biozones, Chlupacitoechia intermedia (Brice, 1981) occur. This species is smaller and lower than Ch. lavidana but with stronger double geniculation. The genus Glossinulus could arise from a Chlupacitoechia species close to Ch. intermedia, developing the typical low median fold in the ventral valve and a stronger median dorsal depression. The above phylogenetic relationships were more or less outlined both by Westbroek (1967: 73-81, Figs. 80-81) and Brice (1981: 199-200). The former author evolved directly forms of Chlupacitoechia [Glossinulus (Glossinotoechia) latus] from Eoglossinotoechia (E. sylphidea), and the latter considers Ch. intermedia as the Glossinulus ancestor.

The Devonian Cantabrian Glossinotoechiidae species lived in relatively deep, shelf environments with predominant fine, siliciclastic sedimentation with short periods of carbonate production, attached through the thin pedicles to shell or other bottom skeletal fragments. The bottom instability induced the massive colonization of the glossinotoechiid and co-existent brachiopod shells by epizoan, probably in comensalist relationships with their hosts. Number of small tabulate corals (among them, the curious Nord-Gondwanan Hyostragulum Marek \& Galle, 1976, but also auloporid, and others), bryozoan, serpulid and minute inarticulate brachiopods pile up on the glossinotoechiid shells near the commissures, sometimes sealing them, that would give rise to the death of the hosts and perhaps of the symbionts themselves.

It has been suggested Eoglossinotoechia Havlíček, 1959 would be a cosmopolitan form (i.e. Savage, 2002) but unquestionable Eoglossinotoechia species occur in the North-Gondwanan paleogeographic realm alone as does Chlupacitoechia. The species of Glossinotoechia Havlíček, 1959 and Glossinulus, inhabited mainly the North-Gondwanan realm but colonized the Sibiro-Baltic realm as well.

All the Cantabrian Glossiinotoechiidae occur in the Asturo-Leonian shelf area. The older forms (Chlupacitoechia lavidana n. sp. and Ch. intermedia) occur in lenticular carbonate intervals into the relatively deeper shaly succession of the Valporquero Formation (Figs. 9-10). The co-existent fauna encompasses off-shore dacryoconarids (Nowakia cancellata, Styliolinidae, and so on), small brachiopods as Lissatrypa, Dalejodiscus, Dalejina, ?Rugoleptaena, and "Cyathaxonia Fauna" solitary rugose corals. Eoglossinotoechia puertoana n. sp, and Glossinulus kayseri inhabited likewise in relatively deep mudstone intervals interbedded between shallower biostromal reef layers (Figs. 4, 19, 21).

The detailed paleogeographic distribution of the Cantabrian glossinotoechiids is striking. As referred to above, none of them occurs far from the Asturo-Leonian area, but they lack likewise in the easternmost part of it in the Valsurbio and San Martin-Ventanilla regions. Older forms seem exclusive of the province of Leon (Fig. 1). Eoglossinotoechia puertoana n. sp, occurs both in Leon (Santa Lucia Formation, members III and IV, upper part of the Polygnathus costatus patulus Biozone and lower part of the P. c.partitus) and in Asturias (Moniello Formation, upper Member). However, the species is much more abundant in Leon than in Asturias. Glossinulus kayseri, typical and ubiquitous in Asturias is known at the present in a sole locality of the Leon province (Arroyo de El Puerto, near Santa Lucía, Figs. 1-2) at the oldest part of his life-scope. Reasons for this odd paleogeographic distribution pattern are unclear. Anyway they do not depend exclusively on the basin depth. Indeed the Glossinotoechiidae extend in the Esla River region (Leon) along the bathymetric facies A to D (García-Alcalde et al, 2002: Fig. 6.5) corresponding to shallow to relatively deep conditions that are just the general conditions for the most part of the Asturian Devonian outcrops. Perhaps the distribution of Chlupacitoechia lavidana and Ch. intermedia would be rather related to tropical storms, allowing the rise and growth of suitable substrata for those species in the way suggested, among others for Stel (1976) and García-Alcalde (1999b), that would be best available in Leon than in Asturias due to the intensity and course of the triggered sea currents. On the other hand, the distribution of Glossinulus kayseri and Eoglossinotoechia puertoana n. sp, could be related to the evolution of the reef ecosystem they inhabited.

Keywords: Articulate brachiopods, Glossinotoechiidae, Devonian, Cantabrian Mountains, Paleobiogeography, Systematics. 


\section{RESUMEN}

Se revisa la sistemática y paleobiogeografía de los Glossinotoechiidae (Braquiópodos Articulados Uncinuloideos) del Devónico Inferior y parte inicial del Devónico Medio de la Cordillera Cantábrica (N de España). Se describen especies de los géneros Eoglossinotoechia, Chlupacitoechia y Glossinulus, dos de ellas nuevas: E. puertoana $\mathrm{n}$. sp. (finales del Emsiense superior y comienzos del Eifeliense inferior) y Chlupacitoechia lavida$n a$ n. sp. (parte baja del Emsiense superior). Glossinulus kayseri (Barrois, 1882), habitualmente incluida en la sinonimia de G. mimicus (Barrande, 1879), es reivindicada como especie autónoma, propia del ámbito paleogeográfico nord-gondwánico y se facilita una diagnosis enmendada y se designa lectotipo y localidad y estrato típicos para ella. Chlupacitoechia intermedia (Brice, 1981) incluye formas que autores anteriores clasificaron como Glossinotoechia henrici, G. sanctimichaelis y G. lata e, incluso, algunas de las formas determinadas como Glossinotoechia kayseri. Lebanzuella García-Alcalde, 1999, anteriormente incluido en Glossinotoechiidae, es reasignado a un taxon uncinuloideo diferente, aún por definir, quizás de la Familia Hebetoechiidae. Formas clasificadas en listas faunísticas como Markitoechia sp. son reasignadas a Voskopitoechia Havlíček, 1992, un género de la Subfamilia Hebetoechiinae. Los Glossinotoechiidae cantábricos habitaron medios de plataforma relativamente profundos, caracterizados por una sedimentación siliciclástica fina. Los representantes de la familia aparecen sólo en el dominio Astur-Leonés de la Cordillera Cantábrica (nunca en el Palentino) salvo en su parte más oriental, al este del río Esla, donde faltan también. Las formas más antiguas (Chlupacitoechia lavidana y Ch. intermedia) son exclusivas de la provincia de León. Eoglossinotoechia puertoana n. sp. aparece en Asturias y León, pero es mucho más abundante en la segunda provincia que en la primera. Glossinulus kayseri, ubicua en la Formación Moniello de Asturias, donde fue señalada prácticamente en todos los niveles de la última mitad del Emsiense superior sólo se encontró, hasta hoy, en una localidad leonesa, cercana a Santa Lucía, en la parte más antigua de su ámbito de distribución. Esta distribución podría estar relacionada con la acción de huracanes y tormentas tropicales, en lo que se refiere a las formas más antiguas, y con la evolución del ecosistema arrecifal, para las más modernas.

\section{Palabras clave: Braquiópodos articulados, Glossinotoechiidae, Devónico, Cordillera Cantábrica, Paleobio- geografía, Sistemática.}

\section{INTRODUCCIÓN}

Los Glossinotoechiidae Havlíček, 1992, constituyen un compacto y bien delimitado grupo de rinconélidos uncinuloideos, originado en el Silúrico que se diversificó abundantemente en el curso del Devónico Inferior y se extinguió a comienzos del Devónico Medio, en el Eifeliense inferior.

La Familia comparte con los Uncinulidae Rzhonsnitskaia, 1956 y Hebetoechiidae Havlíček, 1960, donde fueron habitualmente incluidos sus taxones, la tendencia a desarrollar conchas geniculadas (crecimiento bicíclico) y espinas marginales en los estadios adultos (Havlíček, 1992). Los Glossinotoechiidae tienen, sin embargo contorno muy diferente y poseen casi siempre conectivo en la parte anterior del septalio, ausente, por ejemplo, en los Hebetoechiidae. Esta última familia presenta, además, conchas no aladas (es decir, carentes de reborde marginal ventral, más o menos extenso y alto; doble geniculación, de Havlíček, 1992), costación mucho más grosera que las otras dos y suele carecer de apófisis cardinal o desarrollarla de manera incipiente como rellenos conchíferos, a veces lobulados. Entre los Uncinulidae existen taxones con conchas débilmente aladas pero las apófisis cardinales son multilobuladas, frecuentemente muy anchas y espesas, con numerosas laminillas verticales, que difieren de las habituales en
Glossinotoechiidae, linguiformes y estrechas desarrolladas, sobre todo, en altura. La aparición de alas en la valva ventral es un fenómeno frecuente entre los Glossinotoechiidae, que se acusa, en especial, en las formas más recientes de la familia, del Praguiense en adelante.

Los estudios más intensos y completos referentes a la familia, se deben a Havlíček (1959, 1961, 1983, 1992), principalmente en el ámbito bohémico, de tal manera que tanto la propia familia, como la mayoría de sus géneros (Hostimex, Glossinotoechia, Chlupacitoechia, Eoglossinotoechia y Markitoechia - considerado un Uncinulidae por Savage, 2002-) fueron descritos y analizados concienzudamente por dicho autor.

Hostimex Havlícek, 1982 y Markitoechia Havlíček, 1959, fueron rechazados de la familia por Savage (2002). García-Alcalde (1999a) incluyó en la familia, con ciertas dudas, a su nuevo género Lebanzuella. La reevaluación de los caracteres, en especial la grosera costación, desarrollada con frecuencia por delante del umbo, el carácter estrófico incipiente de la charnela, el tipo de apófisis cardinal, ancha, multilobulada posterior y bilobulada anteriormente, con altas laminillas verticales y la ausencia de conectivo nos hacen pensar ahora que pertenecería, más bien, a una subdivisión, quizás sin proponer aún, de Uncinuloidea (Hebetoechiidae?). García-Alcalde (submitted), sugiere también que las formas que denominó anteriormente en listas de fauna 
como Markitoechia sp., podrían encajar mejor, en Voskopitoechia Havlíček, 1992 (Voskopitoechia chlupaci n. sp.), un Hebetoechiinae del Praguiense de la Cordillera Cantábrica.

A pesar de su interés estratigráfico y abundancia relativa en el Devónico de la Cordillera Cantábrica, el grupo recibió en general poca atención. Barrois (1882) propuso una nueva especie, Rhynchonella kayseri, de la parte alta del Emsiense, hoy incluida en el género Glossinulus. Pero autores clásicos como Comte (1938: Uncinulus kayseri; 1959: Uncinulus princeps, U. henrici y U. kayseri) y otros posteriores como Westbroek [1967: Glossinulus (Glossinotoechia) latus, Markitoechia lebanza] o García-Alcalde (en García-Alcalde et al., 1979: Glossinulus mimicus; en García-Alcalde et al., 1979: Glossinulus mimicus, Eoglossinotoechia gr. sylphidea, Glossinotoechia cf. chlupaci; 1995: Tridensilis intermedia, Glossinulus mimicus; 1996: Glossinulus mimicus, Markitoechia spp.; 2001: Glossinulus mimicus, Chlupacitoechia intermedia), se limitaron a señalar la presencia de formas de Glossinotoechiidae, en listas de fósiles y/o breves comentarios de texto. Una excepción notable la constituye Schumann (1965) quien, en el contexto de un trabajo extenso sobre los Rhynchonelloidea del Devónico de la Cordillera Cantábrica, analizó la morfología y sistemática de numerosas formas cantábricas de la familia: Glossinotoechia henrici (Barrande, 1847), G. sanctimichaelis (Kayser, 1889), G. lata n. sp. y G. kayseri (Barrois, 1882). Este trabajo continúa siendo una referencia necesaria y útil aunque las clasificaciones deban revisarse. Así, G. henrici, de Schumann, carece de la doble geniculación peduncular completa, característica de la especie bohémica (que es, justamente, el tipo del género Glossinotoechia) y podría tratarse, más bien, de un representante de Chlupacitoechia intermedia, como sugirió la propia autora de la especie (Brice, 1981: 198). La forma clasificada como Glossinotoechia sanctimichaelis por Schumann (op. cit.: 72), es una forma alada antero-lateralmente, perteneciente también a Chlupacitoechia intermedia. Glossinotoechia lata Schumann, 1965, corresponde igualmente al género Chlupacitoechia (ver Havlíček, 1992: 101); dicha especie se basó en material escaso y deformado, sobre todo moldes internos, del Grupo de La Vid, recogido cerca de Felmin (León), en el valle del río Torío, y su única característica distintiva respecto a las formas típicas de Chlupacitoechia intermedia parece ser su carácter marcadamente transverso. Sin embargo, las poblaciones de $\mathrm{Ch}$. intermedia, en todas las localidades que muestreamos a lo largo de la Cordillera Cantábrica, comprenden formas transversas, a veces bastante transversas y otras, más o menos equidimensionales estableciendo una transición morfológica con las típicamente alargadas de Ch. intermedia. El propio autor de Ch. lata indica que coexiste con formas de lo que él denominaba Glossinotoechia henrici que, como ya se dijo antes, son $C h$. intermedia. De todos modos, dado lo precario del material en que está basada la especie Ch. lata, es difícil afir- mar si se trata o no con seguridad de variantes extremas del desarrollo de $C h$. intermedia; si así fuera, habría que considerar a $\mathrm{Ch}$. intermedia como sinónima de Ch. lata. Por último, una parte de las formas determinadas como Glossinotoechia kayseri, por Schumann (1965: 80, Fundpunkt 1 Schichtglied 16), podrían igualmente pertenecer a Chlupacitoechia intermedia (ver Brice, 1981: 202), de acuerdo con su posición estratigráfica, mientras que el resto, en particular las del Fundpunkt 5, corresponderían a la especie nominada, del género Glossinulus. No resulta evidente en el trabajo cual es la procedencia de los ejemplares figurados por Schumann (1965: pl. 4 figs. 4-5) bajo la denominación "Glossinotoechia kayseri", pero ambos difieren considerablemente de la especie nominada tanto en la forma general y débil desarrollo de la región umbonal, como en el escaso desarrollo de la depresión media dorsal y de la elevación media ventral. El término "hipotipoide" que se aplica a ambas figuras tampoco aclara nada, debido al sentido ambiguo del mismo. Dichos ejemplares, probablemente vienen del llamado Fundpunkt 1 (op. cit.: 96), del tercio superior del Grupo La Vid, cerca de Argovejo (León), del Emsiense superior. Según nuestras observaciones, en esa posición estratigráfica aparecen en la provincia de León Chlupacitoechia intermedia y Ch. lavidana n. sp. pero nunca Glossinulus kayseri. De manera que los ejemplares figurados por Schumann corresponderían, con ciertas dudas, a una de aquellas especies, pero no a ésta.

En el presente trabajo, se proponen, dos nuevas especies: Eoglossinotoechia puertoana n. sp. y Chlupacitoechia lavidana $\mathrm{n}$. sp. y se describe material asignable a Chlupacitoechia intermedia (Brice, 1981) y a Glossinulus kayseri (Barrois, 1882) del área tipo y de otras localidades cantábricas, todas del Emsiense superior.

\section{PALEOBIOGEOGRAFÍA}

Se ha sugerido que Eoglossinotoechia Havlíček, 1959 sería una forma cosmopolita (i.e. Savage in Savage et al., 2002), pero, igual que ocurre con Chlupacitoechia Havlíček, 1992, Markitoechia Havlíček, 1959 y Hostimex Havlíček, 1982, las especies indudables del género son exclusivamente nord-gondwánicas. Glossinotoechia Havlíček, 1959 y Glossinulus Schmidt, 1942, principalmente nord-gondwánicos, colonizaron también el ámbito sibiro-báltico.

En la Cordillera Cantábrica, el género Chlupacitoechia, apareció hacia la parte baja del Emsiense superior (Biozonas de Nowakia cancellata y Polygnathus laticostatus) (Fig. 10), con formas grandes y altas de alas ventrales poco desarrolladas (Chlupacitoechia lavidana n. sp.), características que lo aproximan a algunas formas modernas de Eoglossinotoechia (por ejemplo, a E. marocanensis Drot, 1964), y algo más tarde, en la misma biozona y edad, lo hizo Chlupacitoechia intermedia (Brice, 1981) (Fig. 10), de menor tamaño y altura cuyas alas ventrales, aún débiles, 
son más desarrolladas que las de la especie anterior. Glossinulus podría, quizás, derivar de alguna forma próxima a Chlupacitoechia intermedia, con la convexidad media de la valva ventral y la depresión media dorsal mucho más acusadas. Las relaciones filogenéticas señaladas fueron, en cierto modo, esbozadas por Westbroek (1967: 73-81, Figs. 80-81) y Brice (1981: 199-200). El primer autor hace derivar directamente formas de Chlupacitoechia [Glossinulus (Glossinotoechia) latus, en el referido trabajo] de Eoglossinotoechia (E. sylphidea) y el segundo considera que $C h$. intermedia es la forma ancestral de Glossinulus.

Las especies cantábricas de Chlupacitoechia habitaron medios de plataforma relativamente profundos, con sedimentación predominante siliciclástica fina y breves períodos de producción carbonatada, fijándose en el fondo sobre fragmentos de conchas o de otros organismos. El carácter inestable del fondo se evidencia en el hecho de que tanto las conchas de los Glossinotoechiiidae como las de otros braquiópodos coexistentes suelen estar masivamente colonizadas por epizoos, que evitarían de esta manera la muerte por asfixia, además de establecer relaciones posiblemente comensalistas con sus huéspedes. Numerosos tabulados (entre ellos, la curiosa forma nord-gondwánica
Hyostragulum Marek \& Galle, 1976, pero también aulopóridos y otros), briozoos, serpúlidos y pequeños braquiópodos articulados se acumularon cerca de las comisuras de las conchas, sellándolas a veces, lo que produciría la muerte del huésped y, quizás, la de los propios simbiontes, empantanados en el fino légamo sedimentario.

Los Glossinotoechiidae de la Cordillera Cantábrica, pertenecen todos al ámbito paleogeográfico Astur-Leonés, de plataforma somera, aunque las formas de la parte baja del Emsiense superior (Chlupacitoechia lavidana n. sp. y, Ch. intermedia) suelen desarrollarse, como ya se dijo, en intervalos de mayor productividad carbonatada dentro de la sucesión pizarrosa, relativamente más profunda, de la Formación Valporquero (Fig. 10). Dichas formas coexistieron con faunas de ámbitos pelágicos, como dacrioconáridos (Nowakia cancellata, Styliolinidae, etc.), braquiópodos de pequeño tamaño como Lissatrypa, Dalejodiscus, Daleji$n a$, ?Rugoleptaena, etc. y corales rugosos solitarios de la "Fauna de Cyathaxonia". Por su parte, Eoglossinotoechia puertoana n. sp. y Glossinulus kayseri son formas que se desarrollaron igualmente en intervalos de sedimentación fangolítica, relativamente más profundos, intercalados en sucesiones arrecifales biostromales someras.

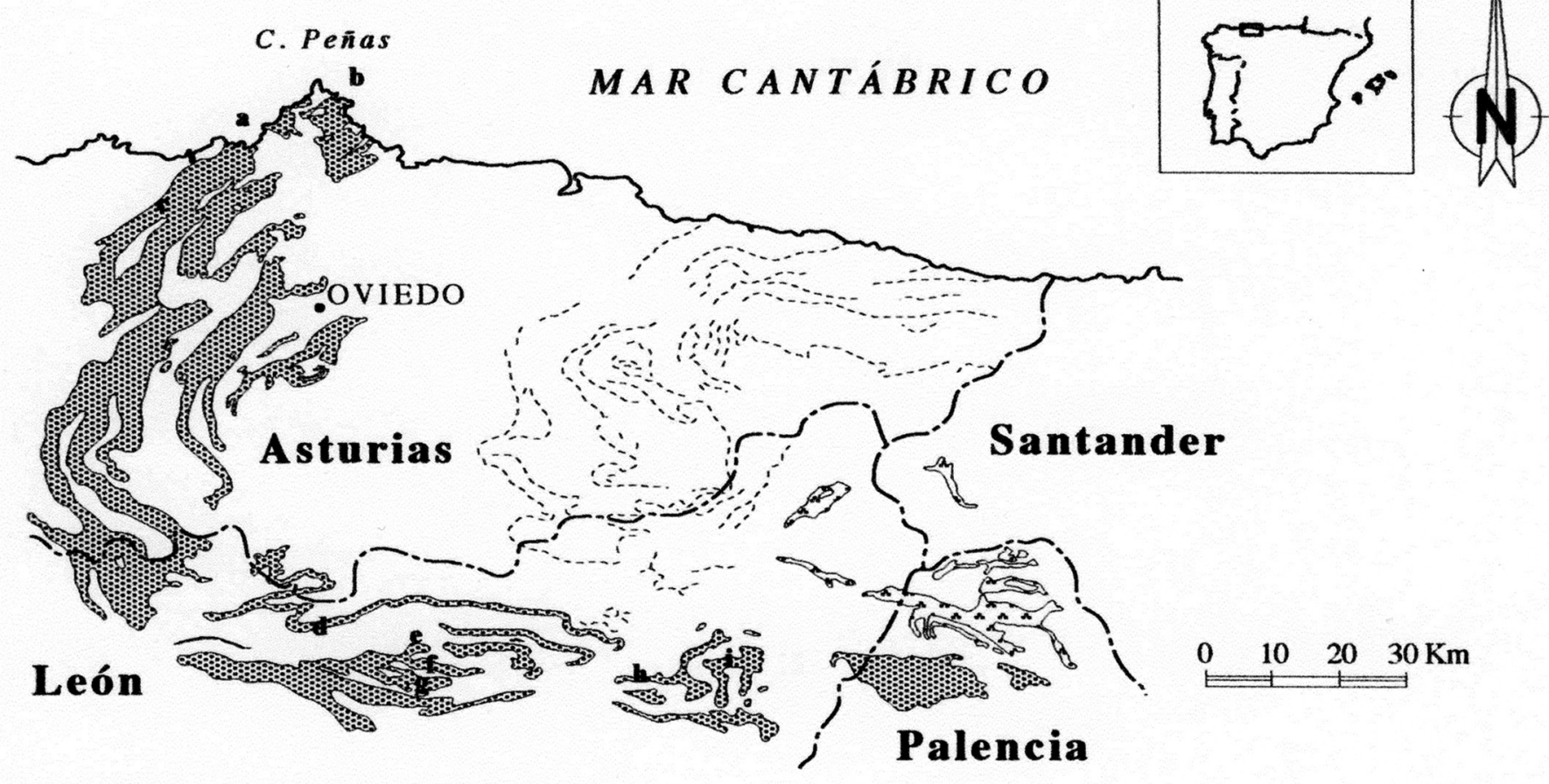

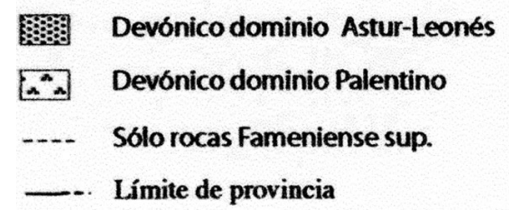

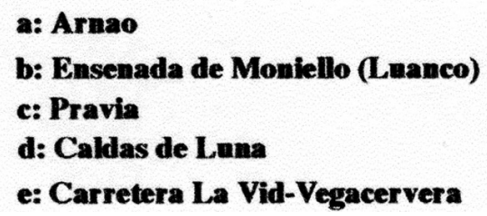

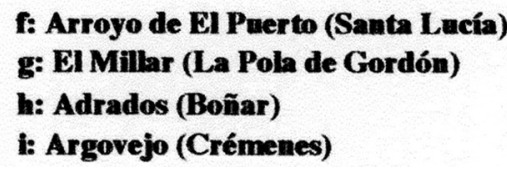

f: Arroyo de El Puerto (Santa Lucía)

h: Adrados (Boñar)

i: Argovejo (Crémenes)

Figura 1. Afloramientos devónicos de la Cordillera Cantábrica y situación de las localidades principales citadas en el trabajo. The Cantabrian Mountains Devonian, setting of the main worked localities. 
La distribución paleogeográfica de detalle de los diferentes taxones de la familia en la Cordillera Cantábrica, es muy curiosa. Como ya se dijo, ninguno de ellos aparece fuera del dominio Astur-Leonés, pero faltan también en la región más oriental del dominio, al este de la región del Esla (áreas del Valsurbio y San Martin-Ventanilla, en Palencia) (Fig. 1). Las formas de la parte baja del Emsiense Superior: Chlupacitoechia lavidana n. sp. y Ch. interme- dia, parecen exclusivas de la provincia de León. Por su parte, Eoglossinotoechia puertoana n. sp., abundante en casi todos los yacimientos de la parte alta del Emsiense superior-Eifeliense más bajo, en León (Fm. Santa Lucía, miembros III y IV, mitad superior de la Biozona de conodontos Polygnathus costatus patulus y base de la de $P$. c. partitus; cf. García-López \& Sánz-López, 2002), aparece también, en similar posición estratigráfica, pero como for-

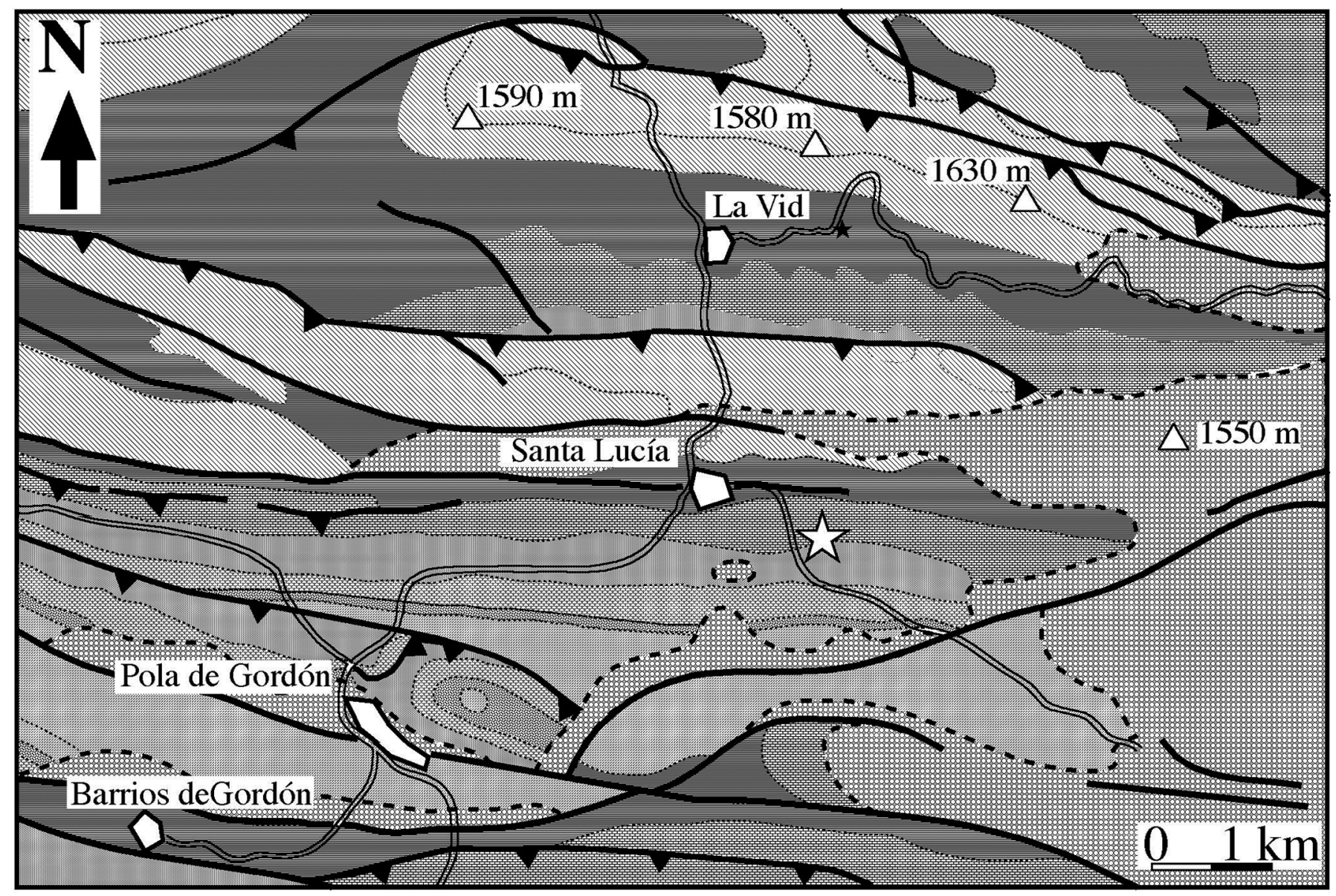

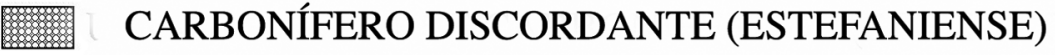
CARBONÍFERO INFERIOR Y MEDIO

Areniscas del Devónico Superior

Formación Portilla (Givetiense)

$\square$ Formación Huergas (Eifeliense inf.-Givetiense inf.)

Formación Santa Lucía (Emsiense sup.-Eifeliense inf.)

Grupo La Vid (Lochkoviense-Emsiense sup.) CÁMBRICO-DEVÓNICO BASAL
1 Corte $C^{a}$ La Vid-Vegacervera (Estratotipo Chlupacitoechia lavidana n.sp.

….... Contacto normal

- . . Disconformidad

- Falla

$\boldsymbol{\nabla}$ Cabalgamiento

$\approx$ Carretera

$\oslash$ Pueblo o villa

$\triangle$ Pico

放

Figura 2. Mapa geológico de la region del río Bernesga, donde se situán las localidades típicas de Chlupacitoechia lavidana n. sp. y Eoglossinotoechia puertoana n. sp. (modificado de García-Alcalde, 2004).

Geological map of the Bernesga River area where type-localities for Chlupacitoechia lavidana $n$. sp, and Eoglossinotoechia puertoana $n$. sp occur (modified from García-Alcalde, 2004). 
ma poco abundante, en Asturias (Fm. Moniello, Miembro Superior: por ejemplo, en Arnao y en la ensenada de Moniello, Fig. 1). Finalmente, Glossinulus kayseri, tan característica en la Formación Moniello, desde el Emsiense superior a prácticamente la base del Eifeliense, sólo apareció, hasta hoy, en una localidad leonesa, en la parte baja de su ámbito de distribución (sucesión del arroyo de El Puerto, cerca de Santa Lucía, Figs. 1-2, tercio superior del Miembro I de la Fm. Santa Lucía, transición de las biozonas de conodontos Polygnathus serotinus-Polygnathus costatus patulus; García-López \& Sánz-López, 2002).

Las razones de ésta distribución no son evidentes. En cualquier caso, no dependen exclusivamente de la profundidad de la cuenca. En efecto, en las áreas de los ríos Luna al Esla, en la provincia de León, los Glossinotoechiidae ocupan facies batimétricas A-D (Garcia-Alcalde et al., 2002: Fig. 6.5), propias de cuencas muy someras a relativamente profundas, el mismo intervalo en que se desarrolla el grueso del área de afloramiento devónico en Asturias. Quizás, la distribución de Chlupacitoechia lavidana y Ch. intermedia, dependió más de los flujos marinos provocados por tempestades tropicales, que permitirían el desarrollo de substratos adecuados para ser colonizados por dichas especies, en la forma sugerida por Stel (1976) y García-Alcalde (1999b), de manera preferente en unas áreas que en otras. Por su parte, la distribución de Glossinulus kayseri y Eoglossinotoechia puertoana n. sp. podría estar relacionada con el grado o el tipo de desarrollo del ecosistema arrecifal, donde ambas proliferaron.

\section{SISTEMÁTICA}

Superfamilia Uncinuloidea Rzhonsnitskaia, 1956 Familia Glossinotoechiidae Havlíček, 1992

\section{Género Eoglossinotoechia Havlíček, 1959}

Especie-tipo: Eoglossinotoechia cacuminata Havlíček, 1959, Lochkoviense.

Diagnóstico: Conchas pequeñas, triangulares, biconvexas con márgenes anterior y laterales truncados. Gancho inclinado a suberecto, foramen pequeño, placas deltidiales grandes, conjuntas. Sin pliegue medio dorsal ni seno medio ventral; lengüieta extensa, rectangular. Costillas finas, de sección redondeada comenzando en los ápices, aplanadas y hendidas medianamente en los paries geniculatus. Espinas marginales cortas. Placas dentales bien desarrolladas, sub-paralelas; campo muscular ventral fuertemente impreso. Septo medio dorsal alto y largo; septalio pequeño relleno con el material conchífero de la apófisis cardinal; placas cardinales unidas por un conectivo; apófisis cardinal multilobulada posteriormente, linguiforme y bilobulada o trilobulada anteriormente.
Discusión: Como ya se dijo más arriba, Eoglossinotoechia presenta muchos caracteres comunes con los otros taxones de la Familia Glossinotoechiidae: Glossinotoechia y Glossinulus, hasta el punto de que algunas de sus especies fueron incluidas variablemente en uno $\mathrm{u}$ otro, principalmente en el primero (ver, por ejemplo, Drot, 1964, Schumann, 1965). Las revisiones de Havlícek $(1983,1992)$ pusieron en evidencia que Glossinotoechia Havlíček, 1959 comprende conchas muy altas, con doble geniculación completa: el estadio de concha plana termina mediante el desarrollo de un reborde marginal elevado (geniculación ventral), seguido por un repentino cambio en la dirección de crecimiento originando la geniculación dorsal, típica del estadio de concha alta en los especímenes maduros. El género Chlupacitoechia Havlíček, 1992, que agrupa especies del Emsiense incluidas antes en Eoglossinotoechia, Glossinotoechia y Glossinulus (C. chlupaci, C. lata, C. intermedia), presenta también doble geniculación, pero restringida a los márgenes antero-laterales de la valva ventral. Por su parte, Glossinulus Schmidt, 1942, también con doble geniculación incipiente en los márgenes antero-laterales, se diferencia del resto de géneros de la familia, en la morfología general de la concha, con seno ventral provisto de pliegue medio y pliegue dorsal con depresión media, muy marcados.

Eoglossinotoechia, se originó probablemente en el Silúrico Superior, pero las especies mejor conocidas son del Lochkoviense y Praguiense (Devónico Inferior; Havlíček, 1992), con la excepción de Eoglossinotoechia marocanensis Drot, 1964, del Emsiense Superior de Marruecos. Chatterton (1973: 120) propuso E. linki n. sp., en las calizas con Receptaculites y Warroo de la Fm. Taemas, en Australia [en la opinión del autor del taxon, de edad Emsiense superior $\mathrm{y}$, con dudas, Eifeliense inferior, aunque Talent et al. (2001), la consideran más bien del Emsiense inferior], pero se trata de una forma dudosa (ver Talent et al., 2001: 160), debido a la presencia de seno ventral y pliegue dorsal bien desarrollados. Las citas, también en niveles altos del Devónico Inferior, de Eoglossinotoechia taymirica y diferentes subespecies de la especie en la antigua Unión Soviética (Nikiforova, 1960; Alekseeva, 1967; Nikolaev \& Rzhonsnitskaia, 1967; Tcherkesova, 1968; por ejemplo) corresponden a géneros de otras familias, particularmente a Taimyrrhynx Havlíček, 1983 (un Uncinulidae).

La distribución paleogeográfica del género, excluidas las citas erróneas o dudosas, era, hasta hoy, Bohemia y Marruecos (Havlíček, 1992) y, con dudas, Nevada (Johnson et al., 1973: E. ? cf. cacuminata) y Australia (Lenz \& Johnson, 1985: E. catombalensis). E. puertoana n. sp. representa, por tanto, la segunda especie claramente postPraguiense del género, propia, además, de un dominio nord-gonwánico, la Cordillera Cantábrica, diferente de aquellos en que se citó, con seguridad, anteriormente. 
Eoglossinotoechia puertoana $\mathrm{n}$. sp.

Figs. 2-8

. pars 1959 Uncinulus kayseri Barrois; Comte, 394 Tab. II.

v. 1979 Eoglossinotoechia gr. sylphidea; García-Alcalde et al., 15 Fig. 11.

? 1979 Glossinotoechia cf. chlupaci; García-Alcalde et al., 15 .
Derivatio nominis: Propia de el Arroyo de El Puerto, localidad típica de la especie.

Material: 187 ejemplares. Holotipo DPO 39102 (Fig. 8.a1-5), 6 Paratipos DPO 39106, 39109, 39110, 39114, 39118, 39121 (Fig. 8.d-h) y otros 27 ejemplares DPO 38991-38996, 39101, 39103-39105, 39107-39108, 39111-39113, 39115-39117, 39119$39120,39144-39150$, procedentes del estrato y localidad tipicos, 31 ejemplares, DPO 39095-39100, 39125-39143, 39165-39170
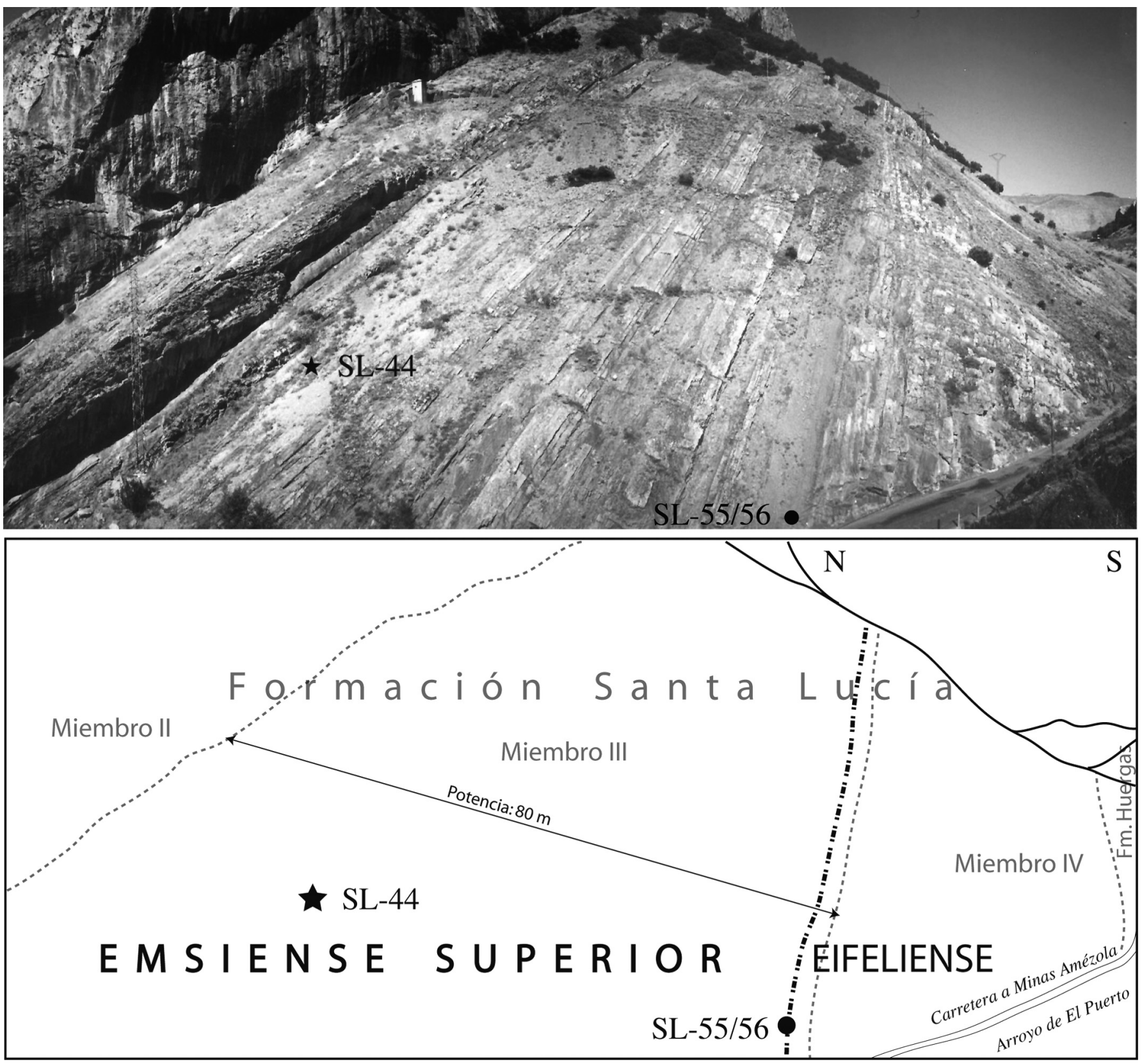

Figura 3. Localidad típica de Eoglossinotoechia puertoana n. sp., en la carretera de Santa Lucía a las minas de carbón a cielo abierto de Amézola (provincia de León), a lo largo del arroyo de El Puerto y estrato típico en el nivel SL-44 del miembro III de la Formación Santa Lucía. Límite operativo Emsiense/Eifeliense, en el nivel SL-55/56.

Eoglossinotoechia puertoana n. sp. type-locality, at the Santa Lucía-Amézola Coal Mines road (province of Leon), along the El Puerto creek, and species stratoype, at the level SL-44 of the III Member of the Santa Lucía Formation. Working Emsian-Eifelian boundary (level SL-55/56). 


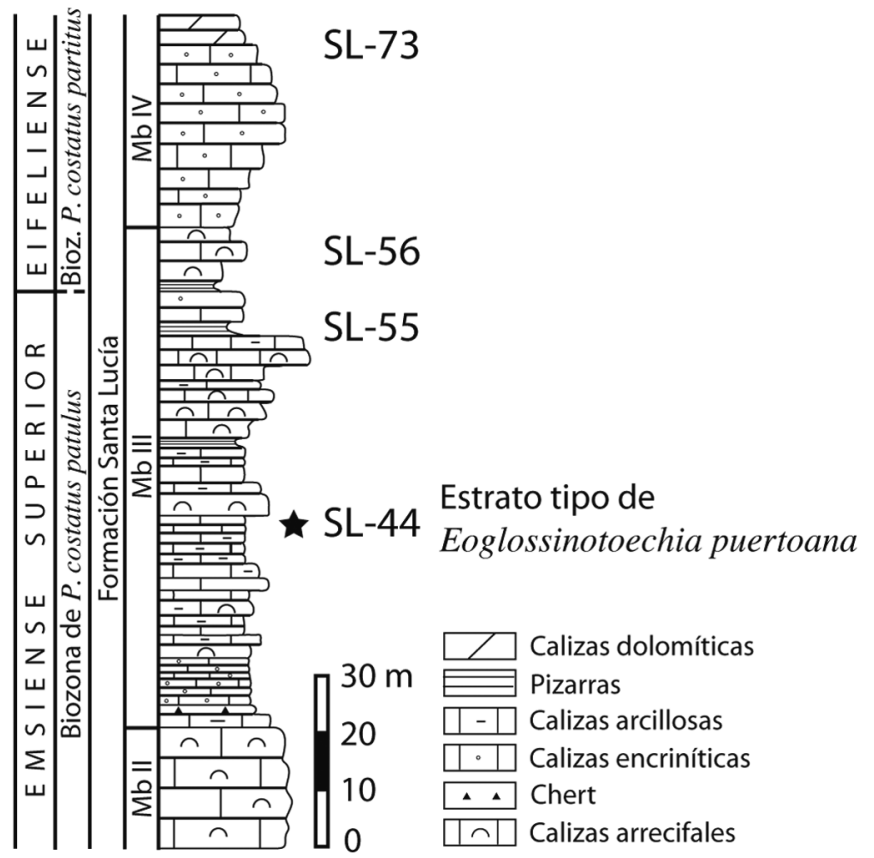

Figura 4. Estrato-tipo de Eoglossinotoechia puertoana n. sp. Eoglossinotoechia puertoana $n$. sp. stratotype.

procedentes de la misma localidad, pero de un nivel diferente, SL-55/56; 11 ejemplares, DPO 39072-39079, 39122-39124, de la misma localidad, yacimiento I-8, quizás del mismo nivel anterior o algo por debajo. 56 ejemplares, DPO 39081-39094, 3915139164, 39190-39200, 39220-39234, 39255-39256 procedentes de diversos yacimientos de la región leonesa (E1 Millar, I-37, Aviados I-69, Barrios de Gordón I-20, Argovejo M-AR-SL-5) de la parte alta del Miembro III de la Formación Santa Lucía (Emsiense terminal-Eifeliense inicial?). 36 ejemplares en variable estado de conservación, DPO 39201-39219, 39238-39254 procedentes del Miembro III de la Fm. Santa Lucía, Emsiense terminal o Eifeliense inicial) en Ciñera (Pola de Gordón, prov. de León), yacimiento denominado "El Regodón" I-13. 19 ejemplares, DPO 39171-39188, 39257 de dos yacimientos de la región asturiana (Arnao C-129 y Moniello M-920) también de la parte alta de la Formación Moniello (Emsiense terminal-Eifeliense inicial?). El ejemplar DPO 39086, se figura en Fig. 8b; el DPO 39093, en Fig. 8.d. Los DPO 39234 y 39253 fueron seccionado en serie para mostrar la estructura interna (ver Figs. 6-7).

Localidad y estrato-tipo: Corte a lo largo del Arroyo de El Puerto, ESE del pueblo de Santa Lucía (León, $\mathrm{N}$ de España). Formación Santa Lucía, parte alta del Miembro III, nivel SL-44 (Figs. 1-4), Emsiense terminal. Intervalo Faunistico 16 (García-Alcalde, 1996). El estrato-tipo de la especie corresponde al extremo inferior de su distribución estratigráfica, que alcanza probablemente el Eifeliense inferior; se trata de un nivel con una elevada diversidad faunística, comprendiendo, al menos, 41 especies de braquiópodos (grupo dominante con 23 especies), crinoideos (9 especies), trilobites, corales, briozoos, rostroconchos, bivalvos, gasterópodos y poliquetos.

Diagnosis: Small, sub-pentagonal, rather low, dorsi-biconvex, more long than large shells with maximum width in the anterior quarter of length. Evenly convex valves with truncated anterior and lateral sides, and rounded edges. Inclined beak apical angle ca. $70^{\circ}$. Mesothyrid to permesothyrid ventral foramen, strong, medially folded, deltidium. Ventral sinus and dorsal fold are either lacking or very faintly developed. Relatively low, trapezoidal tongue. Denticulated commissures, uniplicate anterior commissure, short marginal spines. Shell entirely ornate by radial (ca. 35 elements at the commissure, 8/7 in the middle part, $27 / 28$ on the sides), rarely divided ribs that start at the
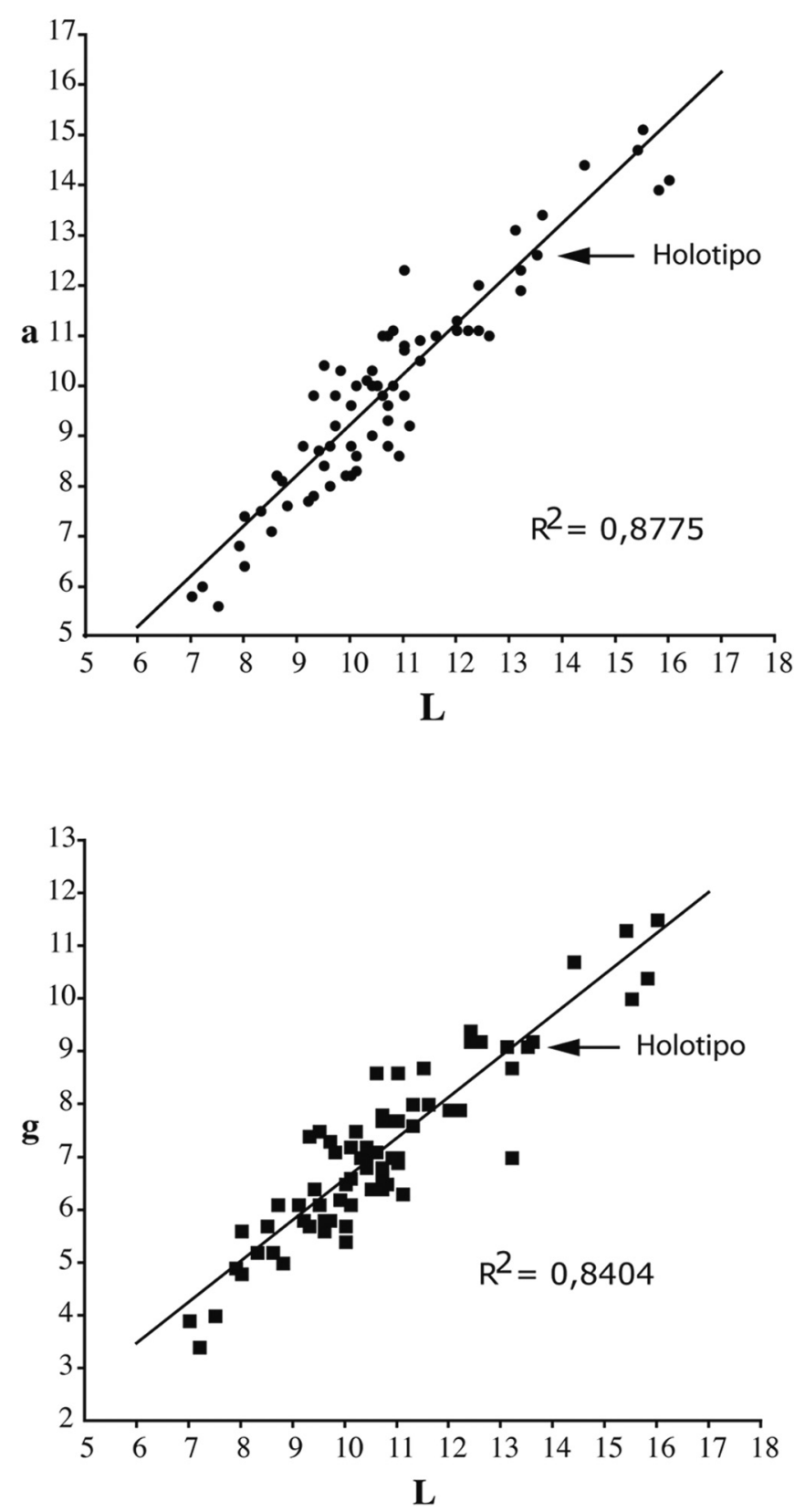

Figura 5. Diagramas de dispersión longitud/anchura (L/a) y longitud/grosor (L/g) de Eoglossinotoechia puertoana $\mathrm{n}$. sp.

Eoglossinotoechia puertoana $n$. sp. Length/Width (L/a) and Length/Thickness $(\mathrm{L} / \mathrm{g}$ ) dispersion diagrams. 
valve beaks; fine, convex ribs along the shell disc, larger and flattened, longitudinally grooved to accommodate the marginal spines and covered by minute chevron-like striae, on paries geniculatus. Short, concave, dental plates, bounding narrow, free lateral cavities. Long, high dorsal median septum, small septalium, filled posteriorly by a high, longitudinally striated cardinal process and roofed over anteriorly by a free, thin, convex connectivum.

Diagnosis: Conchas pequeñas, alargadas, de contorno subpentagonal con la máxima anchura en el cuarto anterior de la longitud; concha dorsi-biconvexa, no muy alta; valvas regularmente convexas con bordes laterales y frontales truncados y aristas redondeadas. Gancho inclinado, ángulo apical en torno a $70^{\circ}$, foramen mesotírido a permesotírido limitado basalmente por un deltidio plegado medianamente. Sin seno ventral ni pliegue dorsal desarrollados, salvo de forma muy débil en la parte anterior de la concha. Lengüeta no muy alta, trapezoidal. Comisura denticulada, espinas marginales cortas, comisura frontal uniplegada. Concha cubierta de costillas finas y convexas, salvo en los paries geniculatus, donde se aplanan y presentan hendiduras longitudinales en la parte media y una fina estriación en zigzag; espacios intercostales agudos, mucho más estrechos; las costillas nacen en los ápices de las valvas y son, sobre todo, simples, aunque hay algunas divisiones; en el frente desembocan, por término medio, 35 costillas, $8 / 7$ en la parte media, 27/28 en los flancos. Placas den- tales cortas pero bien singularizadas. Septo medio dorsal alto y largo, soportando un septalio pequeño posteriormente relleno por una apófisis cardinal alta y pectinada, que se extiende lateralmente sobre las placas cardinales, cubierto anteriormente por un conectivo delgado, convexo, libre de callotest.

Descripción: Conchas pequeñas (Lmax: 16,3 mm; promedio: 11 $\mathrm{mm}$ ), de contorno sub-pentagonal a triangular, alargadas a equidimensionales, incluso ligeramente más anchas que largas (promedio a/L: 0,93), con la máxima anchura situada en el cuarto anterior de la longitud (Fig. 5). Valvas regularmente convexas, la dorsal más que la ventral, y bordes laterales y frontales truncados formando paredes verticales con aristas redondeadas; las regiones postero-laterales, están, además, ligeramente deprimidas formando sendas superficies lunulares. Región umbonal estirada posteriormente, con gancho débilmente inclinado y ángulo apical oscilando entre $40^{\circ}$ y $90^{\circ}$ (promedio: $70^{\circ}$ ); foramen mesotírido a permesotírido, circular, limitado basalmente por un deltidio fuerte, plegado en su parte media.

Conchas dorsi-biconvexas, no muy altas (promedio g: $7 \mathrm{~mm}$; g/L: 0,65) (Fig. 5), con el grosor máximo de la valva ventral hacia la mitad de la longitud y el de la dorsal muy cerca del borde truncado, pero no en el propio borde. Comisuras denticuladas, la frontal uniplegada; lengüeta trapezoidal bien desarrollada, pero no muy alta, dirigida dorsalmente. Seno ventral apenas desarrollado en la parte anterior de la valva hacia la base de la lengüeta, ancho y de fondo convexo; pliegue dorsal inexistente, o evidenciado por un débil resalte en la región anterior de la valva, de techo convexo o aplanado, sin depresión media.
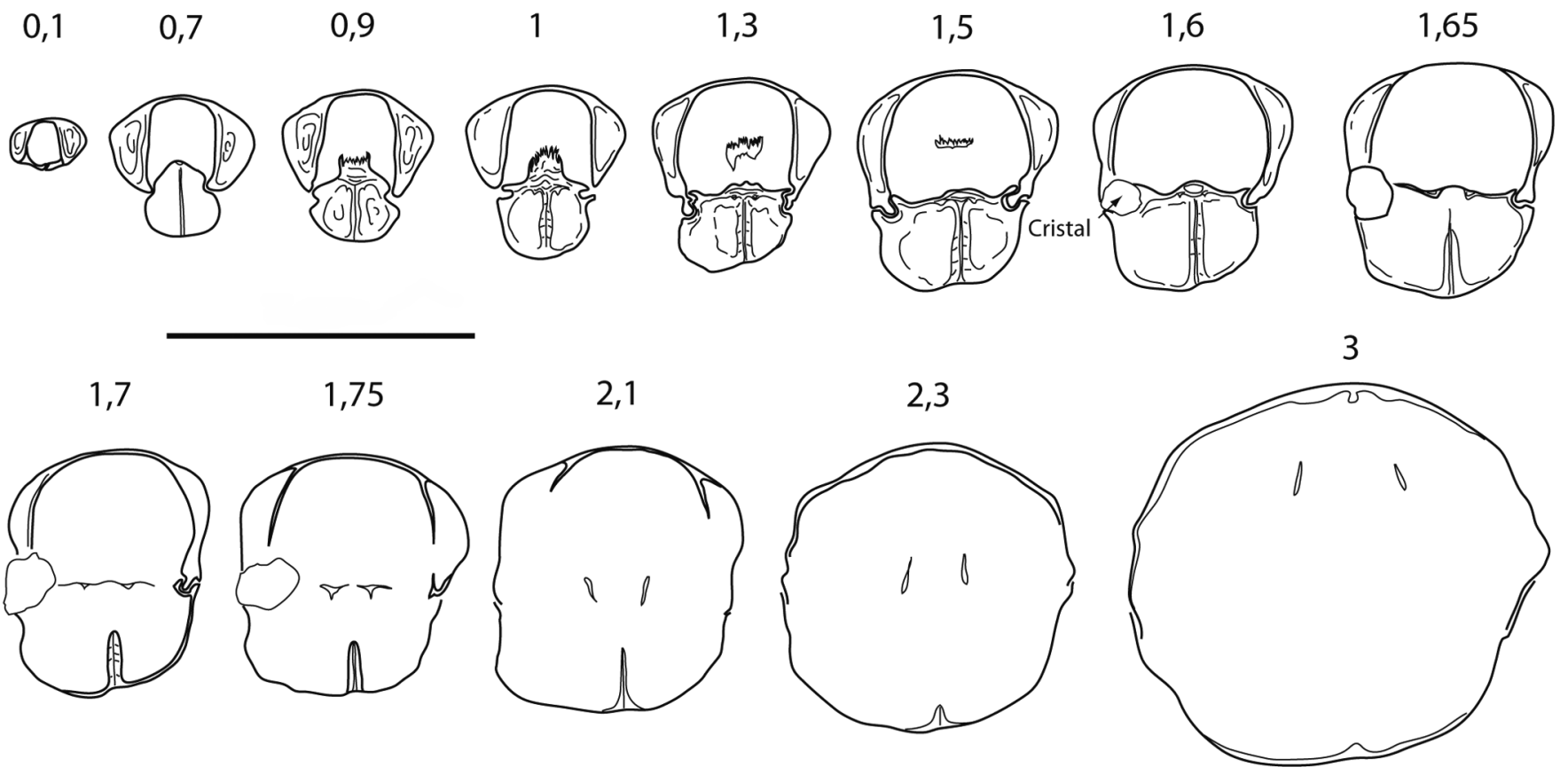

Figura 6. Secciones seriadas de Eoglossinotoechia puertoana n. sp. DPO 39234. Distancias medidas al ápice ventral (la barra horizontal representa $5 \mathrm{~mm}$ ).

Eoglossinotoechia puertoana n. sp. DPO 39234 serial sections. Distances measured in mm from the shell apex (horizontal bar $5 \mathrm{~mm}$ ). 
Superficie de ambas valvas cubierta por finas costillas, suavemente convexas, salvo en los paries geniculatus, donde ensanchan, se aplanan, muestran una fina estriación en zigzag paralela a los bordes de la comisura y están, además, acanaladas longitudinalmente en su parte media para la articulación de espinas marginales de tipo B (Westbroek, 1967), no muy largas (las hendiduras no alcanzan los bordes truncados) (Fig. 8.b4). Las costillas son bastante rectas salvo en las zonas truncadas laterales donde se doblan postero-lateralmente; espacios intercostales agudos, mucho más estrechos que las costillas; las costillas son generalmente muy finas y simples en la región juvenil (neánica) pero al comenzar la fase efébica se producen algunas bifurcaciones, nunca numerosas, sobre todo en las zonas que desembocarán en las márgenes de la lengüeta, aunque existen también algunas divisiones por delante y en otras partes de la concha; resulta difícil distinguir, entre las costillas de la zona de la lengüeta, la existencia de parietales. La fórmula costal en la parte media de la concha oscila entre $5 / 4$ y $14 / 13$, (promedio 8/7, para más del $15 \%$ de ejemplares; fórmulas entre $7 / 6$ y 9/8, ambas inclusive, presentes en más del $60 \%$ de los ejemplares de la muestra); el número total de costillas en la comisura varia de 20 a 55 (promedio 35).

Lamelas de crecimiento distantes, irregularmente distribuidas; con cierta frecuencia, una de ellas, bastante fuerte, representa la frontera entre las regiones neánica y efébica, donde aparecen la mayor parte de bifurcaciones; otras lamelas bien marcadas por delante de la anterior, suelen ser también origen de ramificaciones.

Caracteres internos: Placas dentales, cortas, finas y cóncavas, abriéndose algo hacia delante, delimitando cavidades apicales
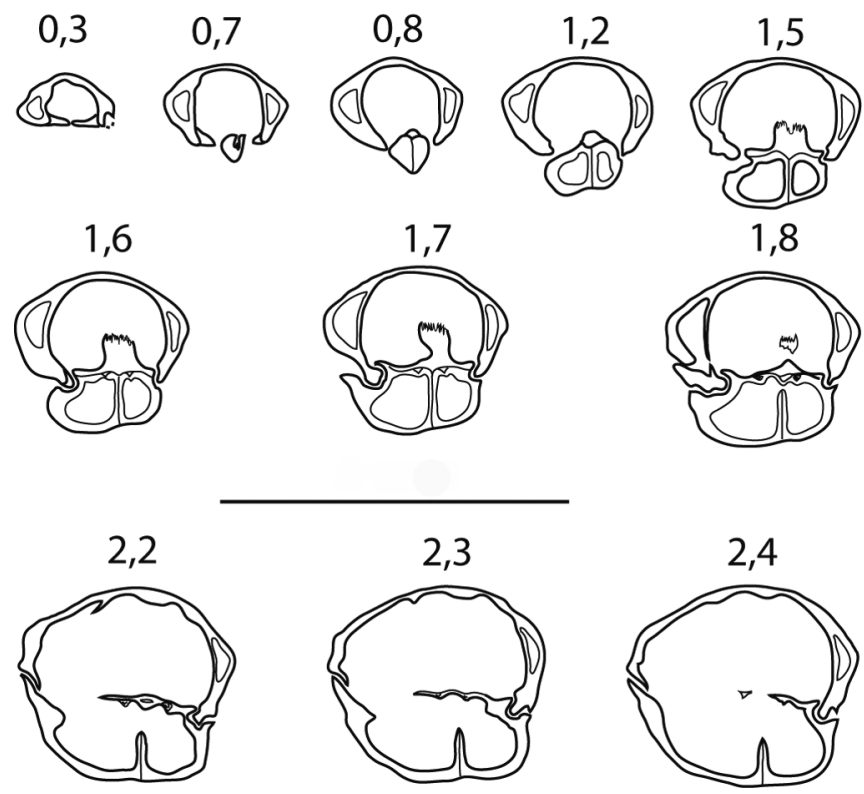

Figura 7. Secciones seriadas de Eoglossinotoechia puertoana n. sp. DPO 39253. Distancias medidas al ápice ventral (la barra horizontal representa $5 \mathrm{~mm}$ ).

Eoglossinotoechia puertoana n. sp, DPO 39253 serial sections. Distances measured in $\mathrm{mm}$ from the shell apex (horizontal bar $5 \mathrm{~mm}$ ). pequeñas, pero bien desarrolladas; dientes cardinales pequeños, denticulados; campo muscular débilmente impreso, con un débil miofragma medio, desarrollado sobre todo más allá de la zona de articulación (Figs. 6-7). Valva dorsal con un septalio reducido y poco profundo, apoyado en un septo medio largo, alto y fino, que alcanza la mitad o más de la longitud de la valva; placas cardinales aplanadas, discretas en la parte posterior de la valva y unidas anteriormente por un conectivo, algo convexo, que se prolonga más allá del punto en que el septo medio se despega de las placas septaliales. Placas cardinales y septalio ocultos en su mayor parte bajo concha secundaria que forma una apófisis cardinal pectinada, bastante alta, con laminillas finas y numerosas, que desaparece hacia el inicio del conectivo (Figs. 6-7). Cruras prolongándose unos milímetros hacia delante en el plano de la comisura, doblándose abruptamente en dirección ventral en sus extremos distales (Fig. 6). Cavidades glenoideas denticuladas bien desarrolladas, con crestas internas sobresaliendo algo de la plataforma cardinal (Fig. 7). Squamae y glottae muy bien desarrolladas.

Observaciones ontogenéticas: Las conchas neánicas, generalmente de longitud inferior a $7 \mathrm{~mm}$, son biconvexas, de comisuras cortantes, contorno triangular, bajas ( $\mathrm{g} / \mathrm{L}$ menor de 0,5$)$, bastante alargadas (a/L: 0,8 o menos), con ápice pinzado (ángulo apical menor de $60^{\circ}$ ) y gancho recto, carecen totalmente de seno ventral y pliegue dorsal y la ornamentación está compuesta por costillas rectas y simples en número inferior a 30 (estadio de concha plana). Entre 7 y $9 \mathrm{~mm}$ de longitud comienza la fase efébica (estadio de concha alta), se desarrollan paries geniculatus y algunas costillas, sobre todo en las regiones medio-laterales, se dividen. En el curso del desarrollo posterior, el contorno tiende a hacerse pentagonal, casi equidimensional $(\mathrm{a} / \mathrm{L}$ alrededor de la unidad), y el perfil lateral dorsi-biconvexo y relativamente más alto (g/L alcanzando 0,8 en las conchas mayores), crecen en altura los paries geniculatus, aumenta el ángulo apical (hasta cerca de $90^{\circ}$ o algo más) y el gancho llega a hacerse sub-erecto, las costillas de los flancos se doblan postero-lateralmente en los márgenes truncados, se producen nuevas ramificaciones y el número total de elementos radiales aumenta hasta alcanzar en los estadios de desarrollo más avanzados (longitud máxima cercana a $17 \mathrm{~mm}$ ) un número total en la comisura entre 40 y 50.

Discusión: Nuestra especie se parece bastante a Eoglossinotoechia marocanensis Drot, 1964, del Emsiense superior de Marruecos, en el aspecto general, pero es algo más pequeña, más baja, la fórmula costal media comprende menos costillas, las aristas de la región truncada son menos vivas y la altura máxima de la valva dorsal se encuentra bastante detrás del margen anterior. E. ? linki Chatterton, 1973, del Emsiense de Taemas, Australia, tiene seno ventral y pliegue dorsal desarrollados anteriormente con una débil depresión media sobre el pliegue dorsal, las costillas nacen por delante de los ápices, son poco numerosas (20 a 28), la apófisis cardinal y el septo medio dorsal son mucho más bajos. De hecho, las características reseñadas, 


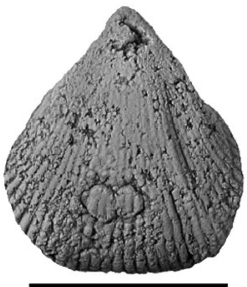

a1

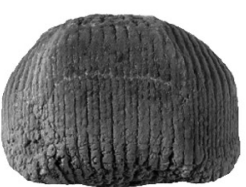

a4

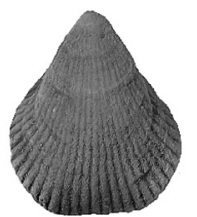

e1

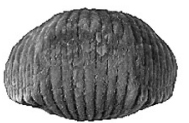

e4

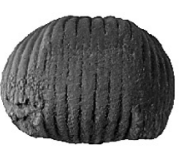

g1

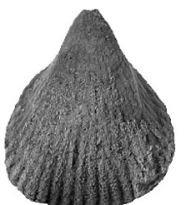

g3

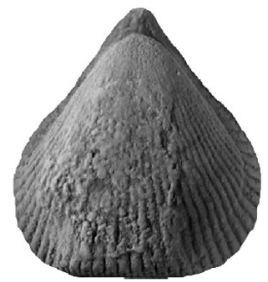

a2

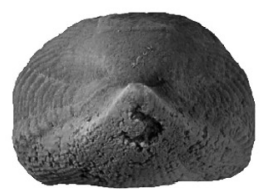

a5

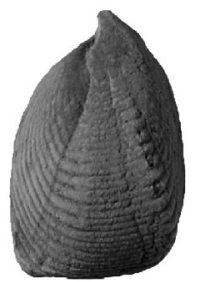

a3

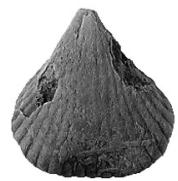

c1

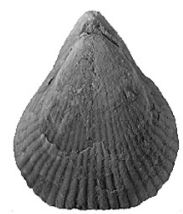

e2

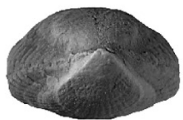

e5

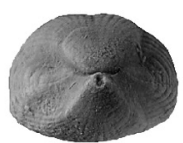

g2

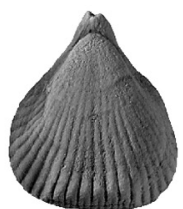

g4
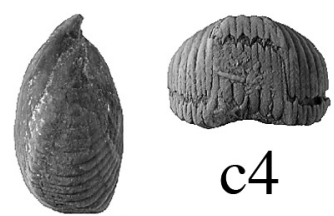

c4

e3

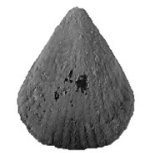

f1
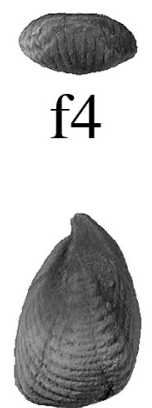

g5

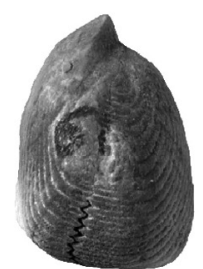

b1

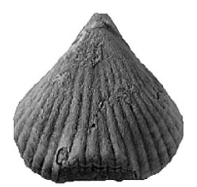

c2
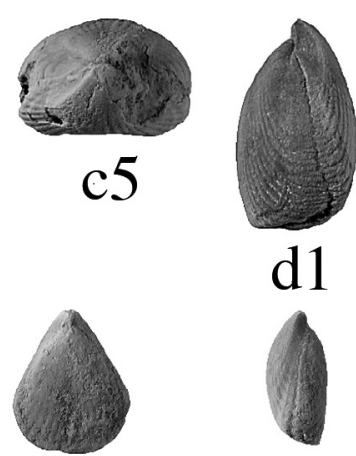

f2
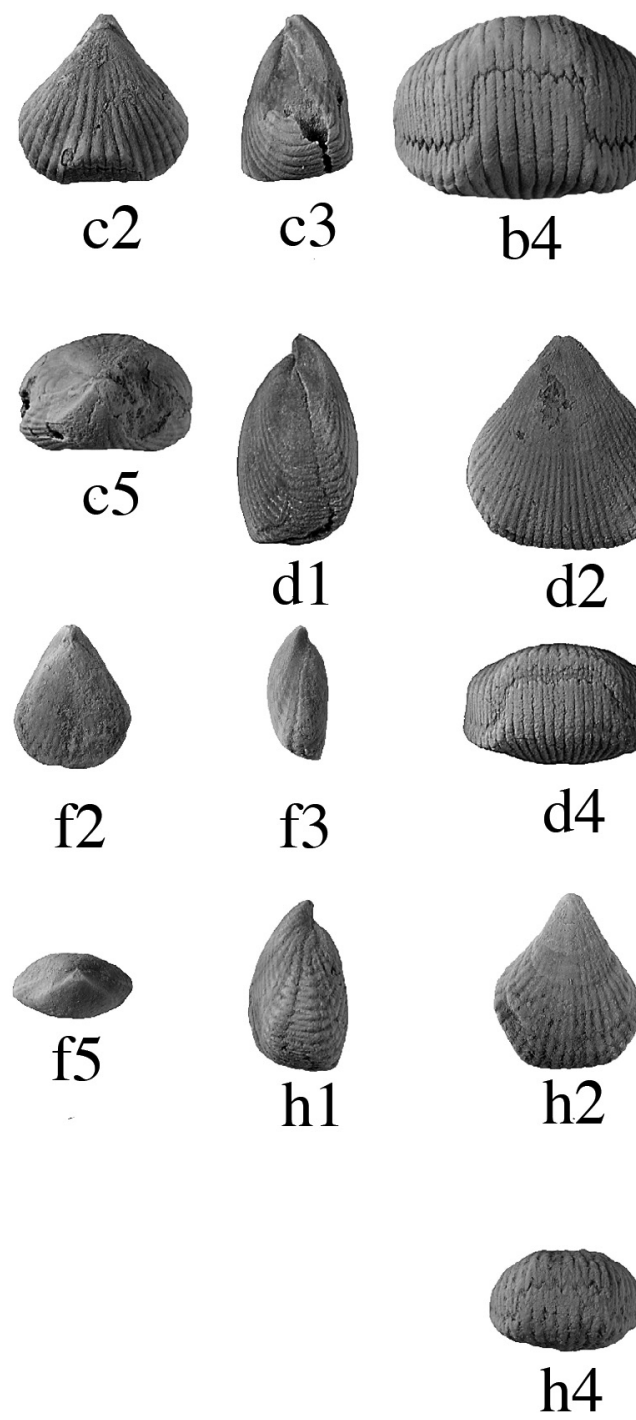

c3

b4

d2

f3

d4

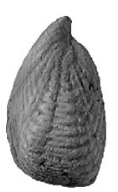

h1

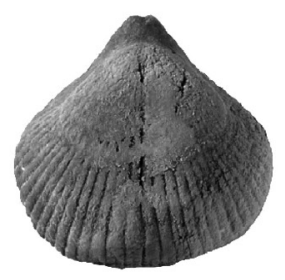

b3
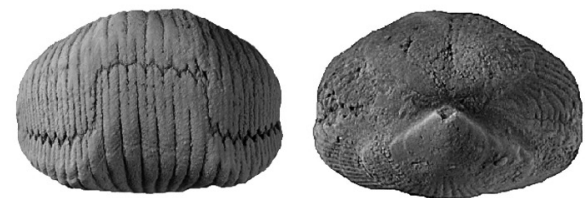

b5
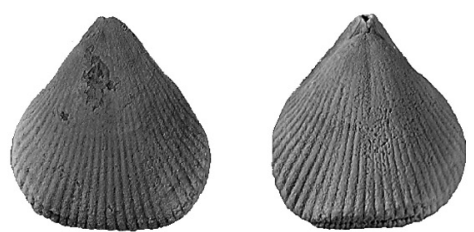

d3
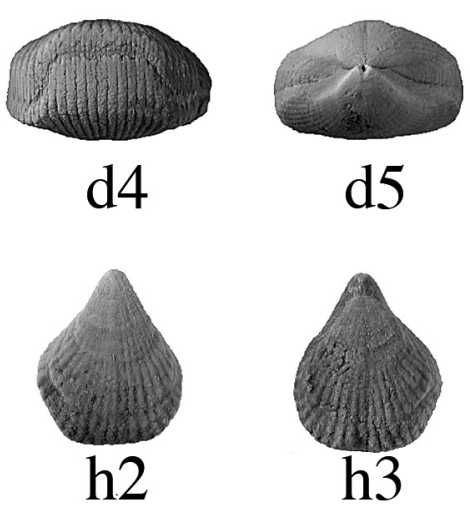

d5

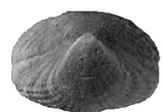

h5

Figura 8. Eoglossinotoechia puertoana n. sp. (todas las figuras se blanquearon con óxido de magnesio. Las barras horizontales representan $10 \mathrm{~mm}$ ). a1-5: Holotipo DPO 39102, vistas ventral, dorsal, lateral, anterior y posterior. b1-5: Ejemplar DPO 39086, procedente de Argovejo, vistas lateral, ventral, dorsal, anterior y posterior. c1-5: Ejemplar DPO 39093, procedente de Argovejo, vistas ventral, dorsal, lateral, anterior y posterior. d1-5: Paratipo DPO 39110, vistas lateral, ventral, dorsal, anterior y posterior. e1-5: Paratipo DPO 39109, vistas ventral, dorsal, lateral, anterior y posterior. f1-5: Paratipo DPO 39121, vistas ventral, dorsal, lateral, anterior y posterior. g1-5: Paratipo DPO 39114, vistas anterior, posterior, ventral, dorsal y lateral. h1-5: Paratipo DPO 39118, vistas lateral, ventral, dorsal, anterior y posterior.

Eoglossinotoechia puertoana $n$. sp. (the figures have been whitened with magnesium oxide. Horizontal bars: 10 mm). a1 -5: Holotype DPO 39102, ventral, dorsal, lateral, anterior, and posterior views. b1 -5: DPO 39086, coming from Argovejo, lateral, ventral, dorsal, anterior, and posterior views. c1-5: DPO 39093, coming from Argovejo, ventral, dorsal, lateral, anterior, and posterior views. d1-5: Paratype DPO 39110, lateral, ventral, dorsal, anterior, and posterior views. e1-5: Paratype DPO 39109, ventral, dorsal, lateral, anterior, and posterior views. f1-5: Paratype DPO 39121, ventral, dorsal, lateral, anterior, and posterior views. g1-5: Paratype DPO 39114, anterior, posterior, ventral, dorsal, and lateral views. h1-5: Paratype DPO 39118, lateral, ventral, dorsal, anterior, and posterior views. 
sobre todo las externas, hacen dudosa la pertenencia de la forma australiana al género Eoglossinotoechia.

Las formas referidas como Eoglossinotoechia gr. sylphidea, en la caliza de Santa Lucia, en la provincia de León (García-Alcalde et al., 1979: 15, Fig. 11) corresponden a la nueva especie. La referencia en la misma publicación a Glossinotoechia cf. chlupaci (op . cit.: 15) podría corresponder también a un ejemplar aplastado de la nueva especie, pero no se pudo encontrar el ejemplar correspondiente en las colecciones del Departamento de Geología de Oviedo, por lo que la referencia es dudosa.

\section{Chlupacitoechia Havlíček, 1992}

Especie-tipo: Uncinulus (Glossinulus) chlupaci Havlíček, 1956.

\section{Chlupacitoechia lavidana n. sp.} Figs. 9-15

\section{v. pars 1996 Tridensilis intermedia; García-Alcalde, Figtext. 2 (en lista). \\ ? 1965 Glossinotoechia kayseri (BARROIS); Schumann, Pl. 4 fig. 5.}

Origen del nombre: Especie que se encuentra en los alrededores del pueblo de La Vid (La Pola de Gordón, provincia de León) y del Grupo La Vid.

Material: 119 ejemplares. Holotipo DPO 38657 (Fig. 14.a), 10 Paratipos DPO 38654-38656 y 38658-38664 ( DPO 38660, Fig. 14.b; DPO 38664 seccionado para mostrar estructuras internas, Fig. 17) y otros 14 ejemplares en variable estado de conservación, pero, en general, bastante deformados y rotos, DPO 38665-38678, procedentes del estrato y localidad típicos. 60 ejemplares, DPO 38679-38716 y 38765-38786 procedentes de la localidad de Adrados (Boñar, provincia de León), del Grupo La Vid, parte baja de la Formación Vegacervera, Emsiense superior. 34 ejemplares, DPO 38717-38750, procedentes de Caldas de Luna (prov. de León) del Grupo La Vid, varios niveles de la parte baja de la Formación Vegacervera (Figurados DPO 38717: Fig. 14.d; DPO 38723, Fig. 15.a; DPO 38692, Fig. 15.b; DPO 38710, Fig. 15.c).

Localidad y estrato-tipo: Corte en la carretera La Vid-Vegacervera, aproximadamente $1 \mathrm{~km}$ al E del pueblo, cerca de una alberca, talud meridional de la carretera (Figs. 2, 9 y 10), 2 a 3 niveles decimétricos de calizas arcillosas muy fosilíferas, separados por pizarras marrones del Grupo La Vid, en la parte baja de la Formación Vegacervera, 31-32 m sobre la Fm La Pedrosa, nivel M-LV-35 (Figs. 9-10), de la parte baja del Emsiense
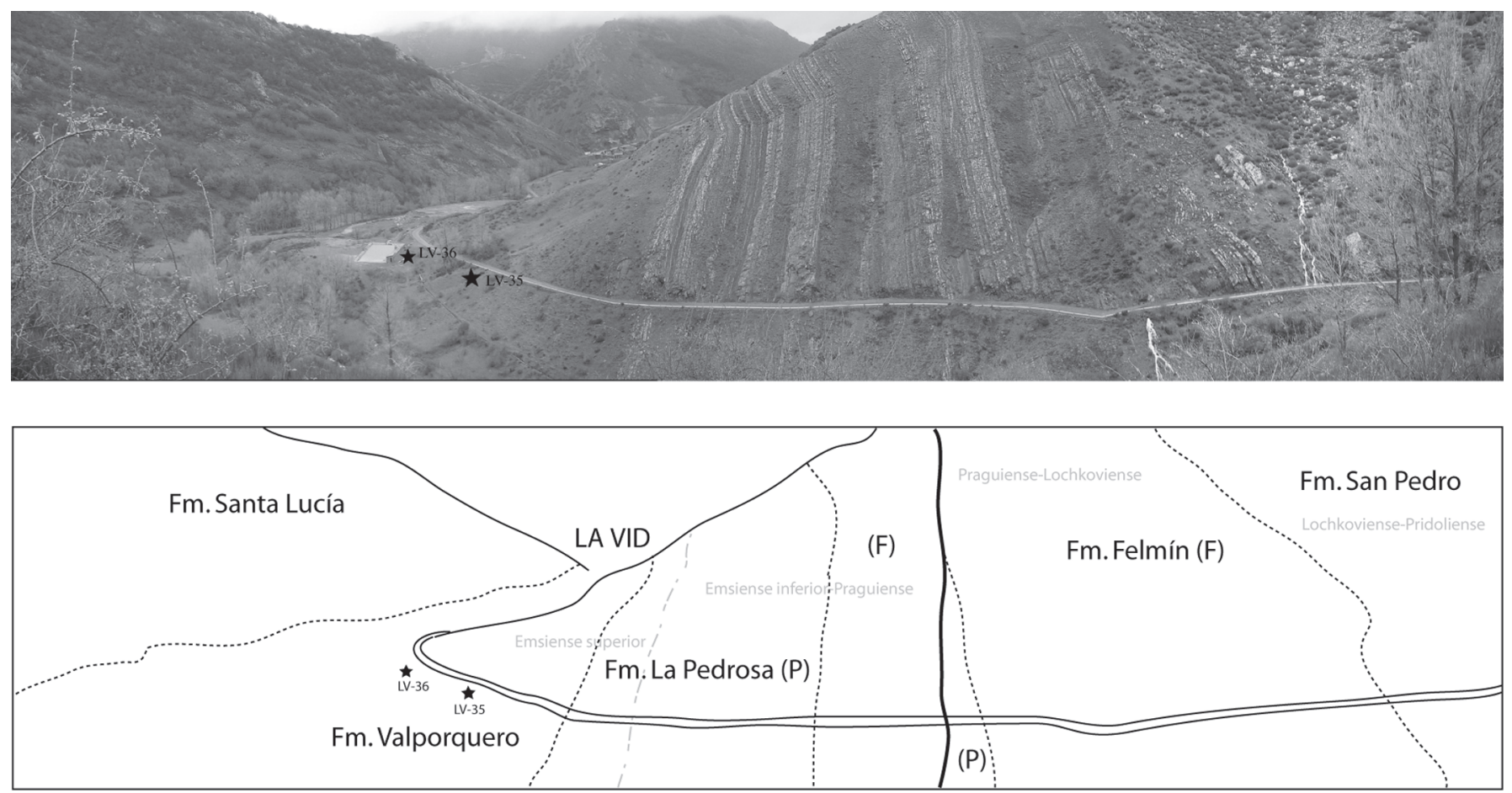

Figura 9. Localidad típica de Chlupacitoechia lavidana n. sp. en la carretera de La Vid a Vegacervera (provincia de León), cerca del depósito de agua, y estrato típico en el nivel LV-35 del Grupo La Vid, Formación Valporquero. El nivel LV-36 del mismo grupo y formación anteriores y los niveles próximos encierran una fauna importante de Chlupacitoechia intermedia (Brice, 1981). Situación del nivel operativo Emsiense inferior/Emsiense superior.

Chlupacitoechia lavidana $n$. sp. type-locality, at the La Vid-Vegacervera road (province of Leon), near the water reservoir, and species stratotype at the level LV-35 of the La Vid Group, Valporquero Formation. In the level LV-36 and close layers abundant Chlupacitoechia intermedia (Brice, 1981) occur. Setting of the working lower Emsian-upper Emsian boundary. 
superior, Biozona de dacrioconáridos Nowakia cancellata y de conodontos Polygnathus laticostatus. Intervalo Faunístico 10 (García-Alcalde, 1996).
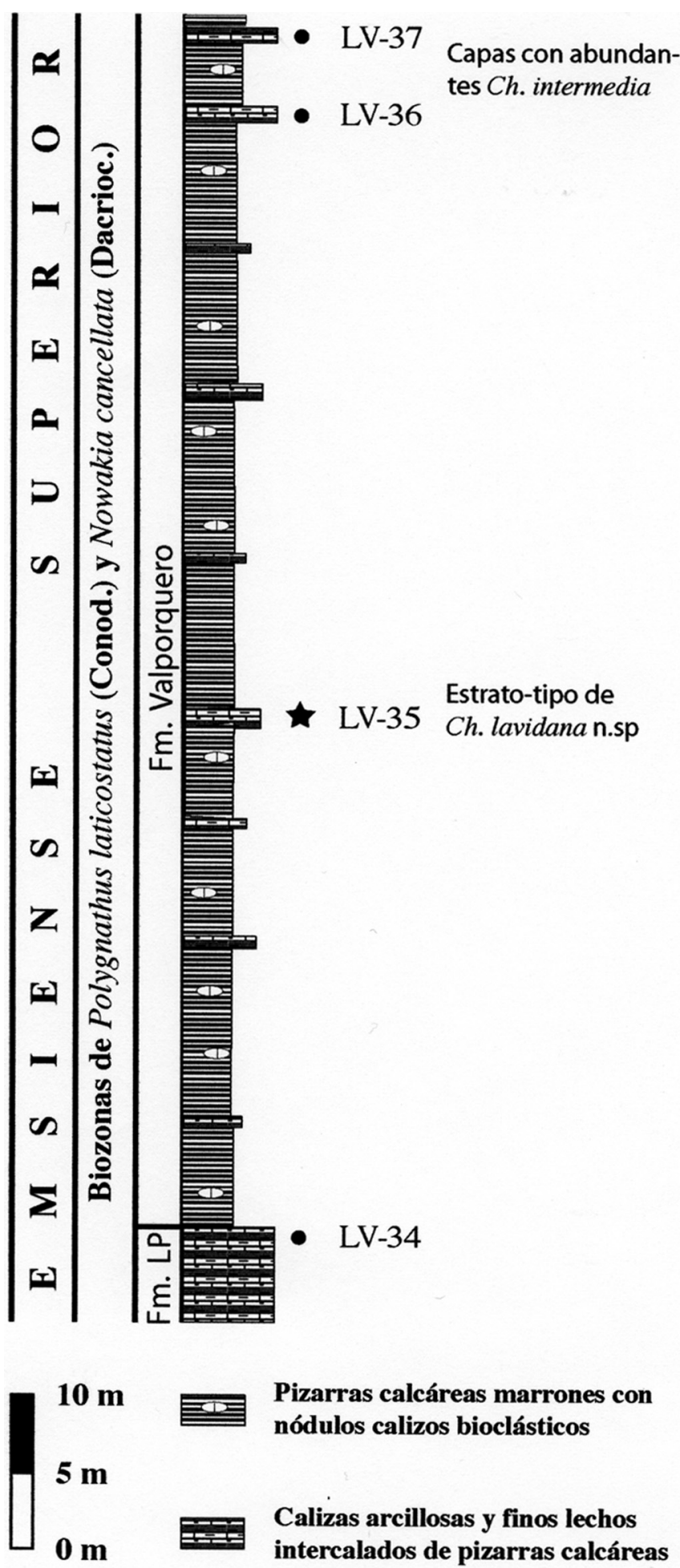

Figura 10. Estrato-tipo de Chlupacitoechia lavidana n. sp. y niveles donde aparece Ch. intermedia (Brice, 1981) en la misma localidad.

Chlupacitoechia lavidana n. sp. stratotype, and levels where Ch. intermedia (Brice, 1981) occurs in the same locality.
Diagnosis: Shell tall for the genus. More long than wide, sub-pentagonal, high, sometimes very high, strongly dorsi-biconvex shell, maximum width at the anterior quarter of the length. Evenly convex, geniculate shell valves with truncated, rounded edges in adult growth stages. Ventral sinus and dorsal fold, lacking or faint, antero-lateral ventral margins first bend faintly in ventral direction and then abruptly in dorsal direction (double geniculation) developing the paries geniculatus. Sub-erect, narrow ventral beak; apical angle less than $70^{\circ}$; circular, minute, permesothyrid pedicle foramen; strong, medially folded deltidium. Entirely ribbed shell; fine, rounded, unbranched ribs, exceptionally bifurcating at the posterior half part, starting at the apex of valves, flattened and longitudinally grooved to accommodate marginal spines and covered by minute chevron-like striae, on paries geniculatus. 45 ribs at the commissure (9/8
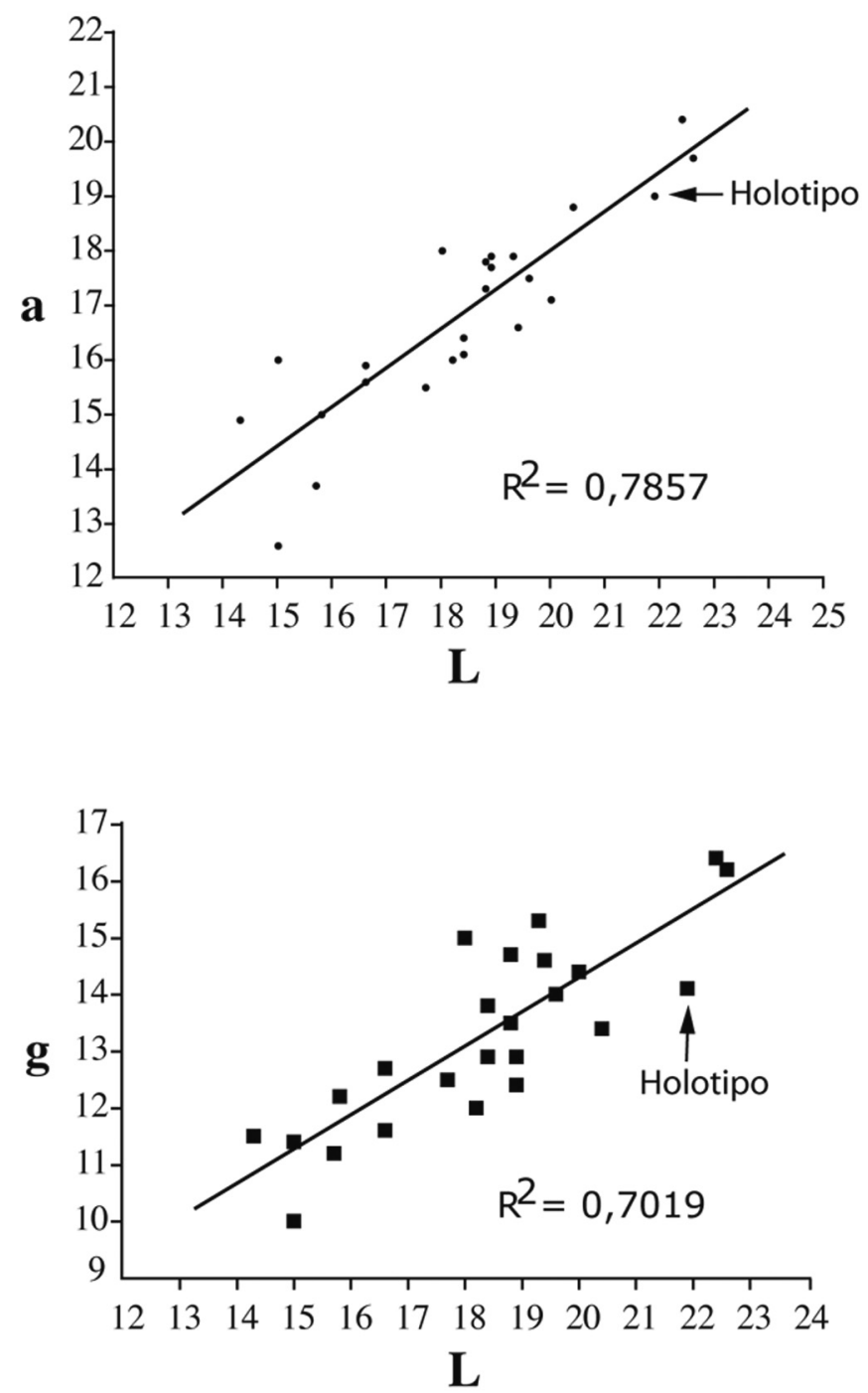

Figura 11. Diagramas de dispersión longitud/anchura (L/a) y longitud/grosor (L/g) de Chlupacitoechia lavidana n. sp.

Chlupacitoechia lavidana n. sp. Length/Width (L/a) and Length/Thickness $(\mathrm{L} / \mathrm{g})$ dispersion diagrams. 
in the mid part, 17-18 in each side). B-type, marginal spines (Westbroek, 1967), faintly denticulate commissures, the anterior uniplicate; convex, rather high, sub-rectangular, dorsal- to postero-dorsally directed tongue. Parallel, strongly concave dental plates. Long, high dorsal median septum; small septalium filled posteriorly by a high, bilobed, longitudinally striated cardinal process, roofed over by a free, flattened to faintly convex connectivum.

Diagnosis: Conchas grandes para el género, alargadas, de contorno sub-pentagonal con la máxima anchura en el cuarto anterior de la longitud; conchas altas, a veces muy altas, acusadamente dorsi-biconvexas; valvas regularmente convexas pero con bordes laterales y frontales truncados y aristas redondeadas, sin seno ventral ni pliegue medio dorsal desarrollados; los márgenes antero-laterales de la valva ventral se curvan más o menos en dirección ventral antes de doblarse abruptamente hacia la valva dorsal; Gancho sub-erecto, foramen circular permesotírido, ángulo apical menor de $70^{\circ}$; deltidio robusto, plegado en su parte media. Concha cubierta de costillas finas (alrededor de 45 en la comisura, con fórmula costal media $9 / 8$ y 17 a 18 costillas en cada flanco), convexas, que nacen en los ápices de las valvas, en su mayor parte simples, aunque en la mitad posterior algunas son bifurcantes; en los paries geniculatus ensanchan, se aplanan y presentan hendiduras longitudinales medias y fina ornamentación de estrías en zigzag; espinas marginales largas de tipo B (Westbroek, 1967).

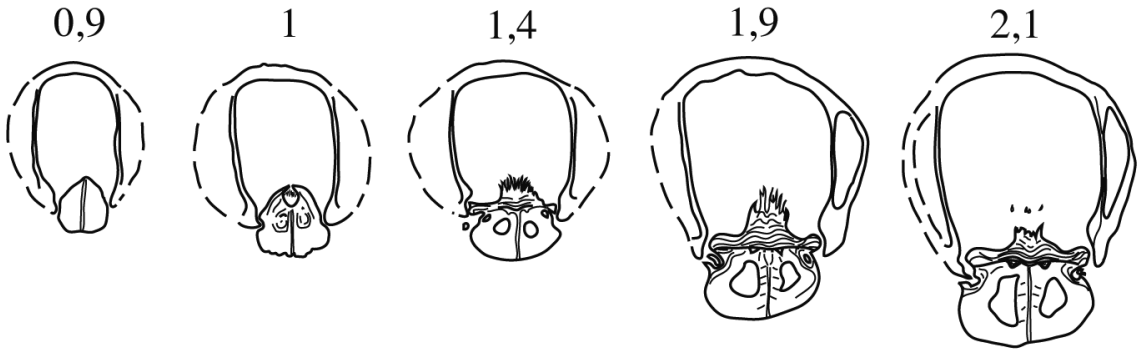

3,1 3,6
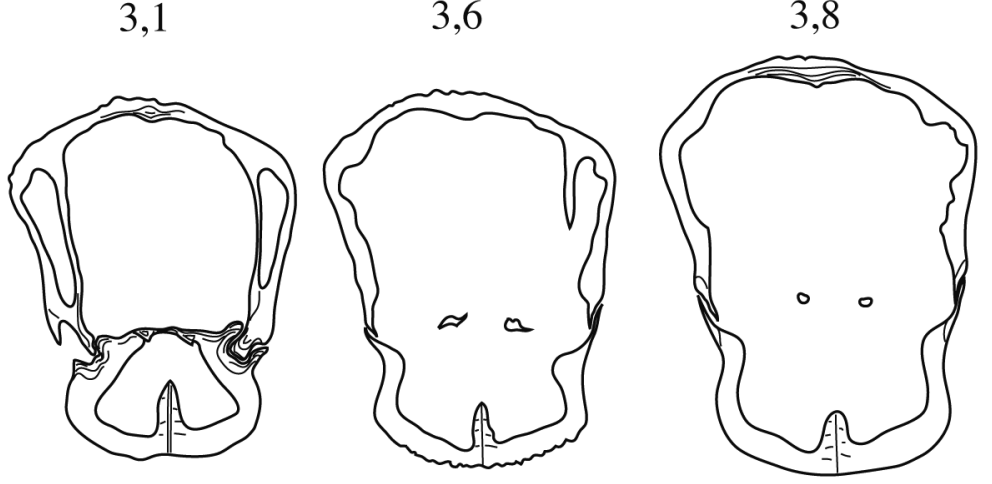

$5 \mathrm{~mm}$
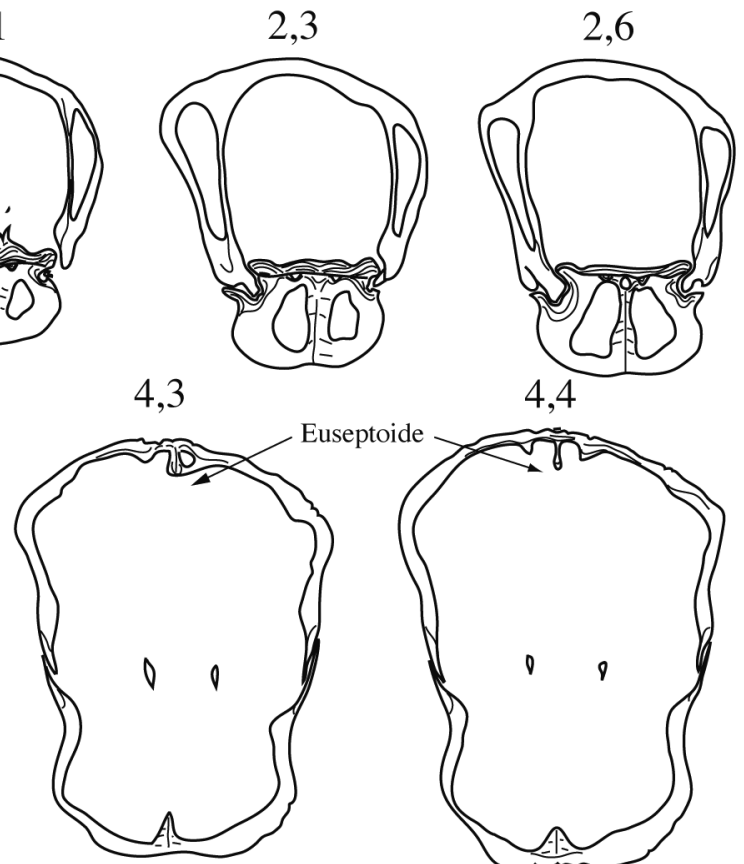

4,4

5,5
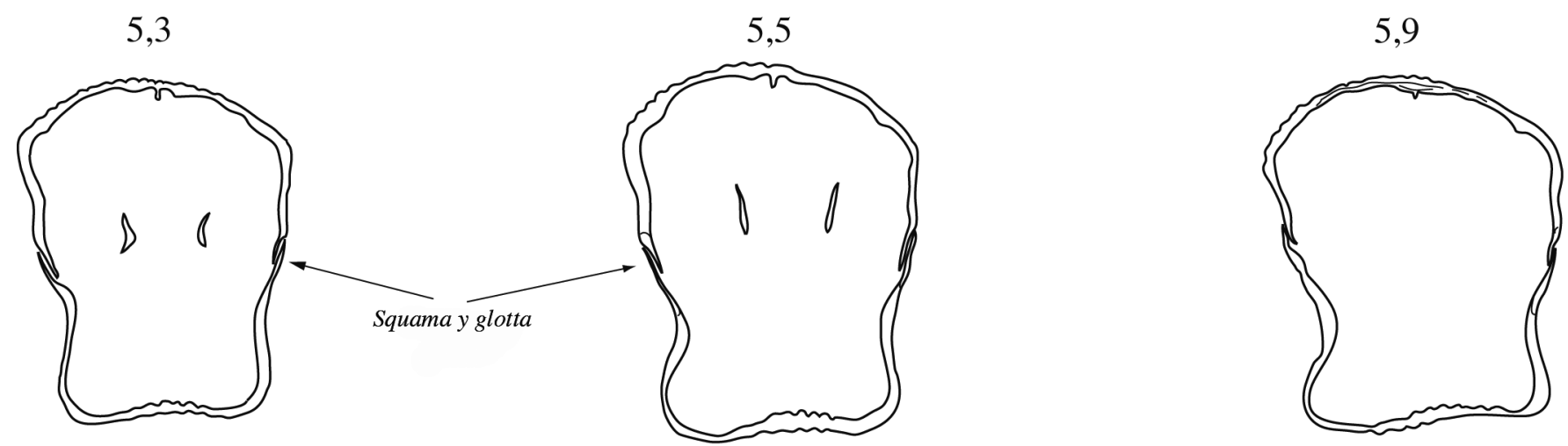

$5 \mathrm{~mm}$

Figura 12. Secciones seriadas de Chlupacitoechia lavidana n. sp. DPO 38664. Distancias medidas al ápice ventral. Chlupacitoechia lavidana n. sp. DPO 38664 serial sections. Distances measured in mm from the shell apex. 

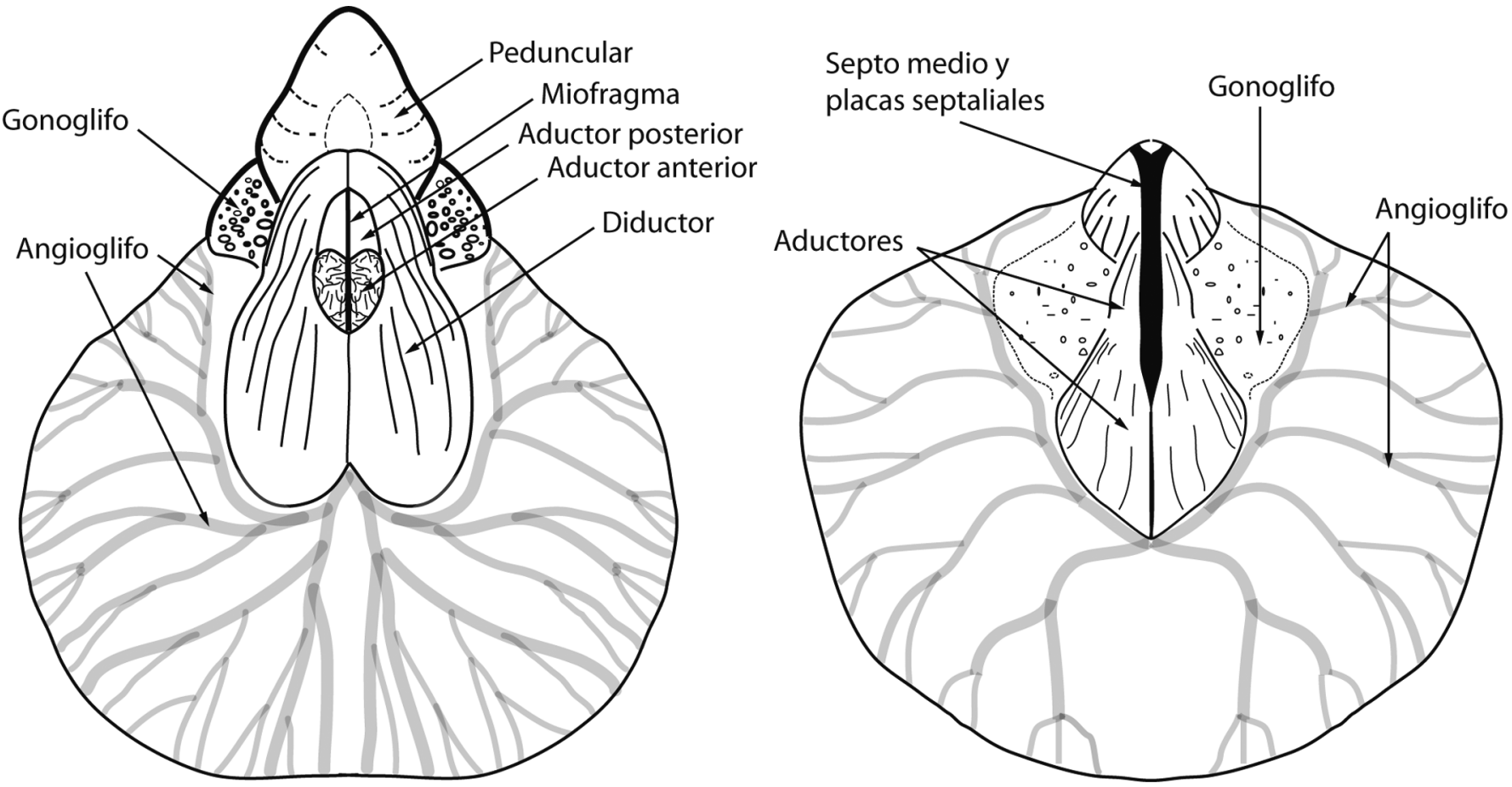

Figura 13. Chlupacitoechia lavidana n. sp. Estructura interna de las valvas ventral (izquierda) y dorsal (derecha), algo idealizadas, basadas la de la valva ventral, en los moldes internos fragmentarios, DPO 38703, 38692 y 38679, de Adrados (León), y la de la valva dorsal, en el molde interno DPO 38692 de la misma localidad. Chlupacitoechia lavidana $n$. sp. Draft of the internal structure of ventral (left), and dorsal (right) valves, based on fragmentary internal moulds DPO 38703, 38692, 38679, and 38679 coming from Adrados (Leon) (a little idealized).

Comisura moderadamente denticulada, la frontal uniplegada; lengüeta convexa, bastante alta, sub-rectangular, dorsal a postero-dorsalmente dirigida. Placas dentales paralelas; septo medio dorsal, alto y largo, soportando un septalio pequeño, posteriormente relleno por una apófisis cardinal alta y pectinada, bilobulada, que se extiende lateralmente sobre las placas cardinales, y cubierto anteriormente por un conectivo convexo libre de callotest.

Descripción: Conchas grandes (Lmax $>22 \mathrm{~mm}$; promedio para 48 ejemplares medidos: $18,9 \mathrm{~mm})$, principalmente alargadas (promedio a/L: 0,92; sólo $25 \%$ de los ejemplares medidos son equidimensionales o débilmente transversos) (Fig. 11), de contorno sub-pentagonal con la máxima anchura en el cuarto anterior de la longitud. Conchas gruesas (gmax: $19 \mathrm{~mm}$; promedio 13,8 para 44 ejemplares; promedio g/L: 0,73 ), fuertemente dorsi-biconvexas (Fig. 11), con la máxima altura de la valva peduncular hacia la mitad de L o antes y máxima altura de la braquial en el frente de la valva, en o cerca del nivel de truncamiento (Figs. 14.a3 y 14.d5). Valva ventral suave y regularmente convexa en perfil longitudinal y transversal, incluso en la propia lengüeta, con flancos doblados en ángulo recto hacia la comisura, pero con aristas redondeadas; los márgenes anterolaterales de la valva peduncular tienden a alzarse en dirección ventral, a veces fuertemente (la deformación suele acentuar, en ocasiones, éste carácter de manera artificial), antes de doblarse de manera abrupta dorsalmente (doble geniculación) (Figs. 14.b4-5, 14.c4-5 y 14.d3); esta alación suele iniciarse en una lamela de crecimiento más gruesa que las vecinas (Figs. 14.b1, 15.a1). No existe seno ventral propiamente dicho. Gancho estrecho, prolongado posteriormente, inclinado a sub-erecto (Fig. 14.a3), perforado por un foramen circular menudo, permesotírido, limitado por un deltidio completo y robusto, plegado en su

Figura 14. Chlupacitoechia lavidana $\mathrm{n}$. sp. (todas las figuras blanqueadas con óxido de magnesio. Las barras horizontales representan $10 \mathrm{~mm}$ ). a1-5: Holotipo DPO 38657, vistas ventral, dorsal, lateral, anterior y posterior. b1-5: Paratipo DPO 38660, vistas ventral, dorsal, lateral, anterior y posterior. c1-5: Ejemplar DPO 38679, molde interno parcial, vistas ventral, lateral, dorsal, anterior y posterior; obsérvese en c1 y c5 el campo muscular peduncular y el gonoglifo, y en c3 el campo muscular dorsal, dividido por un largo septo medio. d1-5: Ejemplar DPO 38717, vistas ventral, dorsal, anterior, posterior y lateral. Chlupacitoechia lavidana $n$. sp. (the figures have been whitened with magnesium oxide. Horizontal bars: 10 mm). a1-5: Holotype DPO 38659, ventral, dorsal, lateral, anterior, and posterior views. b1-5: Paratype DPO 38660, ventral, dorsal, lateral, anterior, and posterior views. c1-5: DPO 38679, fragmentary internal mould, ventral, lateral, dorsal, anterior, and posterior views; see in figures $\mathbf{c 1}$ and $\mathbf{c 5}$, the ventral muscle field and gonoglyphe, and in figure c3, the dorsal muscle field, divided by a long median septum. d1-5: DPO 38717, ventral, dorsal, anterior, posterior, and lateral views. 

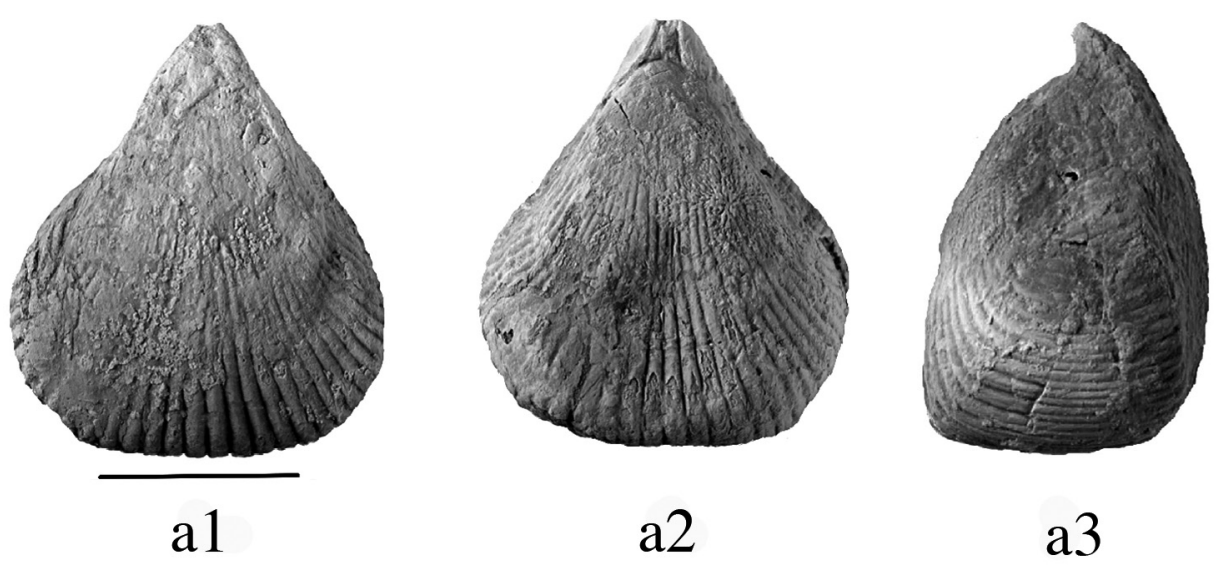

a3

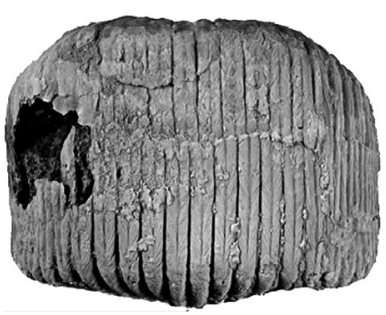

a2

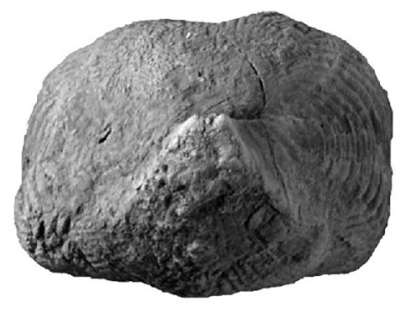

a5
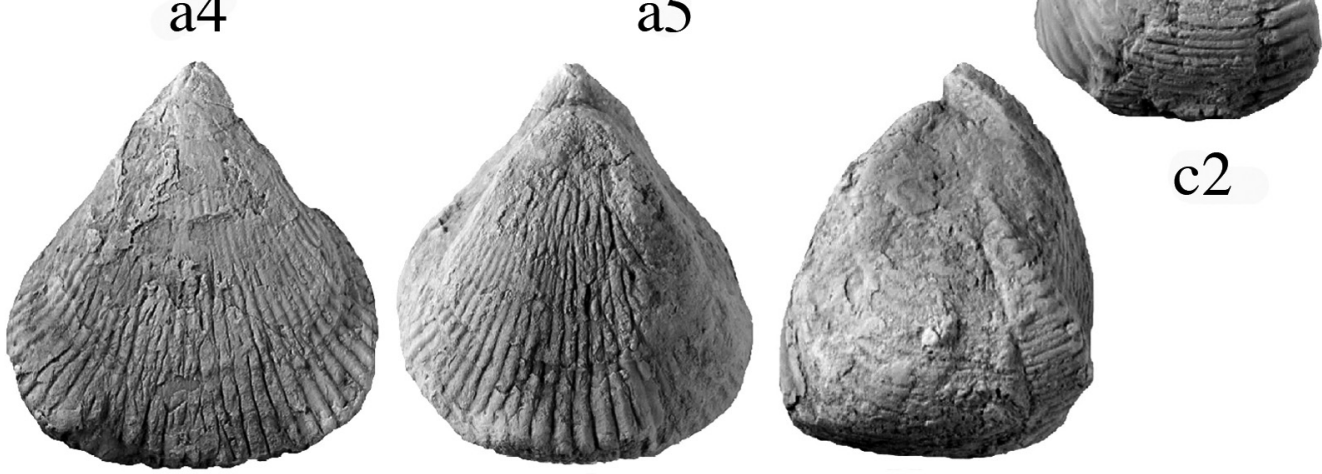

b1
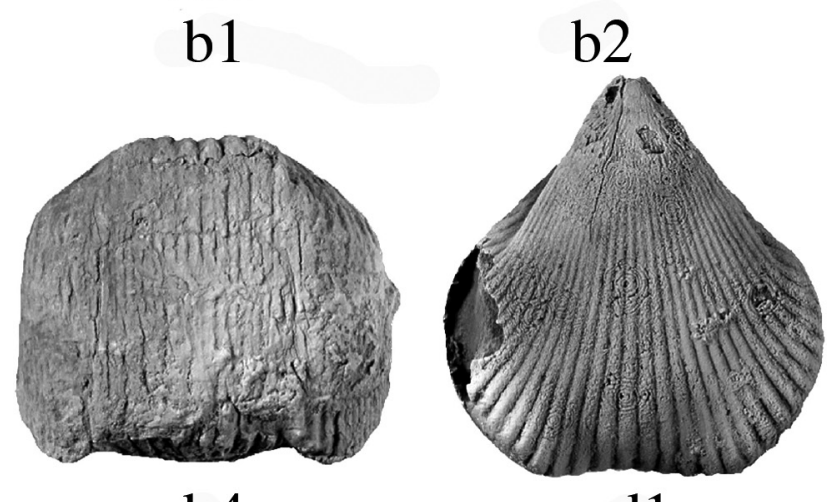

b4

d1

$\mathrm{c} 2$
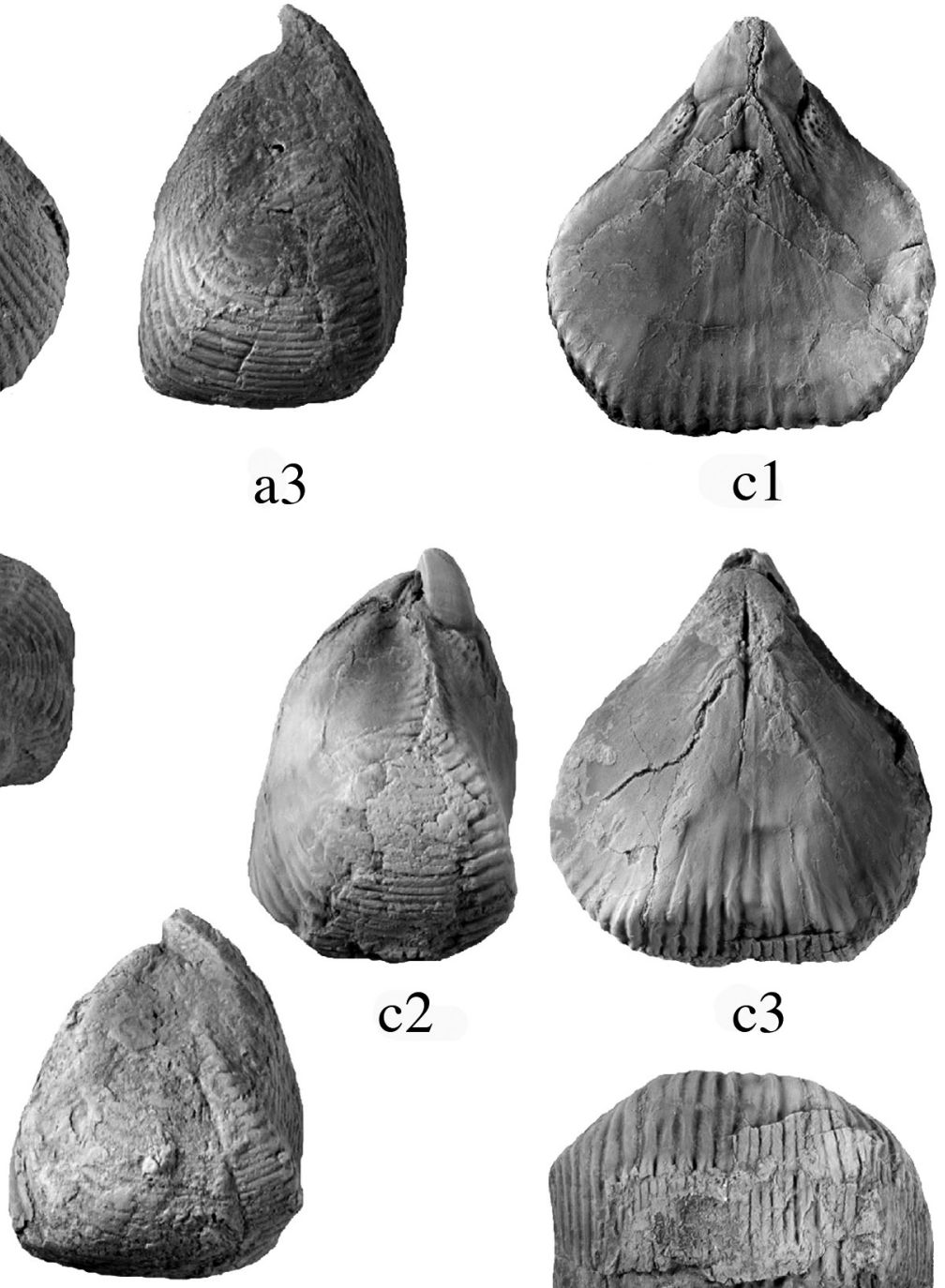

b3
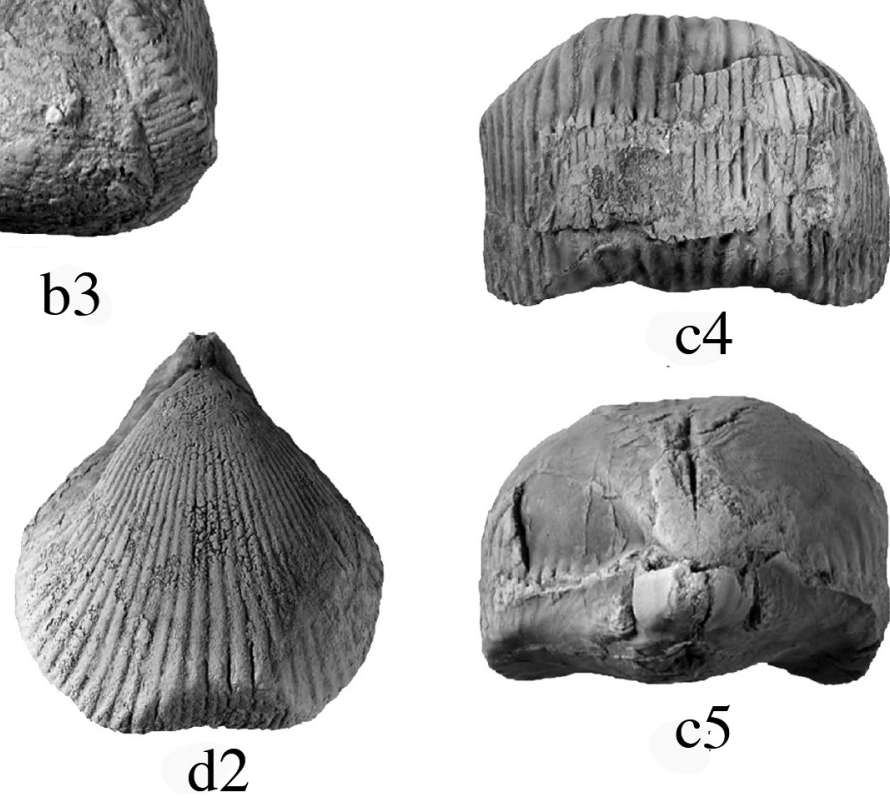

c3

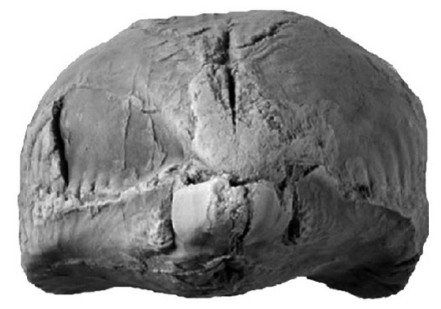

c5
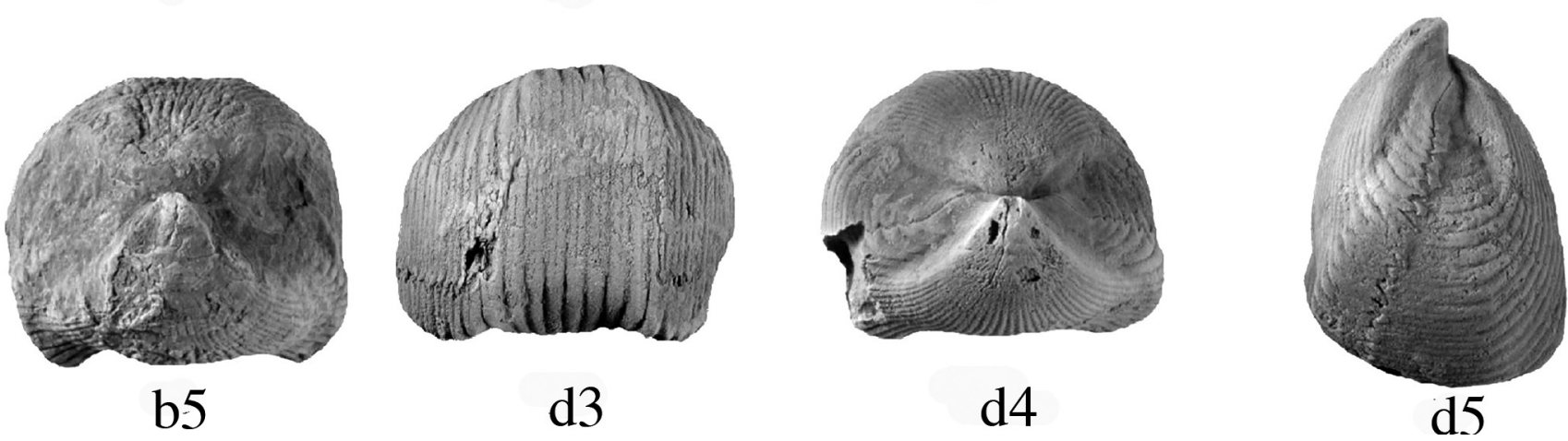
parte media (Fig. 14.d2); ángulo apical agudo (entre $56^{\circ}$ y $73^{\circ}$; promedio: $64^{\circ}$ para 12 ejemplares medidos); flancos umbonales acusados en ambas valvas, definiendo sendas áreas lunulares poco profundas. Valva dorsal muy convexa en la región umbonal y suavemente convexa luego, con los márgenes doblados abruptamente hacia las comisuras y aristas algo más vivas que la ventral, pero todavía redondeadas: techo de la valva aplanado o con una oscura depresión media en la región anterior; sin pliegue medio propiamente dicho, exceptuando un ligero desnivel respecto a los flancos, cerca del borde truncado. Paries geniculatus alto, bien desarrollado. La lengüeta es rectangular y alta, de fondo convexo, dirigida dorsal a postero-dorsalmente, de anchura superior a 1/3 de la anchura total (Figs. 14.d3 y 14.d5). Concha cubierta de costillas estrechas y bajas, convexas a sub-angulosas (cerca de los bordes truncados), simples en la región anterior y con uno o dos niveles de bifurcación poco importantes en la mitad posterior, coincidiendo generalmente con bordes engrosados de lamelas de crecimiento; costillas simétricas salvo en las regiones aladas, separadas por intervalos agudos mucho más estrechos que ellas. En los paries geniculatus, las costillas se aplanan y ensanchan considerablemente y presentan una hendidura media longitudinal (para el acoplamiento de espinas marginales internas largas) y el sistema de líneas de crecimiento se transforma en un modelo ornamental de finas estrías angulosas, en zigzag (Fig. 14.a4). Las espinas marginales son de tipo B (Westbroek, 1967), pero en ejemplares desgastados la comisura puede dar la impresión de una denticulación más acusada, simulando el tipo A. Las costillas de los flancos laterales y postero-laterales se doblan fuertemente hacia atrás en el nivel de truncamiento para alcanzar las comisuras; hay 28 a 57 costillas en cada valva (promedio para 56 ejemplares medidos; 43 a 47 costillas); fórmula costal en la parte media: 6-14/5-13, con frecuencia máxima para 9-11/8-10 (35 ejemplares, es decir, el $62 \%$ ); en los flancos hay 10 a 22 costillas (promedio: 17 a 18 en cada flanco).

Caracteres internos: Algunos moldes internos permitieron observar el interior de la concha. El campo muscular es muy extenso, aunque poco marcado en ambas valvas. El de la valva ventral comprende una región estriada y débilmente diferenciada en el fondo de la cavidad deltirial, que correspondería a la musculatura de los adjustores (Fig. 13 y 15.c1). Por delante se extiende el campo muscular principal hasta algo más allá de la mitad de la longitud, bilobulado y cordiforme, con huellas de los aductores pequeñas, diferenciadas en un par posterior reniforme, liso y un par anterior cordiforme recorrido por una fina red anastomosada de hendiduras, representando probablemente un sistema quick and catch (Rudwick, 1970) (Figs. 13, 14.c1, 15.b1, 15c); las huellas de los aductores están completamente rodeadas por las de los diductores, bilobuladas, extensas y estriadas radialmente; el área muscular de aductores y diductores está bisectada por un débil miofragma medio, algo más desarrollado entre las huellas de los aductores (Figs. 12, 13, 15.b1, 15c). En los márgenes de la zona de contacto de la musculatura peduncular y diductora, se extienden sendas zonas ovaladas y deprimidas, con fondo cubierto de pequeñas depresiones circulares, representando el gonoglifo (Figs. 13 y 14.c1-2). El angioglifo, poco evidente, es de tipo sacado, con vasos medios ramificados, relativamente más fuertes (Fig. 13). El campo muscular de la valva dorsal, parece dividido también en un campo umbonal sub-triangular, es- triado radialmente, bisectado por el septo medio, que se abre hacia delante a ambos lados del septalio y un campo aductor anterior, romboidal y alargado, con nervaduras paralelas a los lados posteriores que son los mayores, embutido por su extremo proximal en el campo umbonal y bisectado igualmente por el septo medio, que alcanza la mitad de la longitud (Figs. 13, 15.7); gonoglifo extendiéndose a ambos lados del área muscular, entre los dos campos descritos; angioglifo sacado, con vasos muy tenues (Fig. 13).

Placas dentales relativamente largas, paralelas, algo cóncavas, definiendo cavidades apicales estrechas, bien diferenciadas; dientes cardinales denticulados encajados en cavidades glenoideas no muy profundas, con crestas internas que sobresalen un poco sobre la plataforma cardinal. Apófisis cardinal pectinada, alta y bilobulada, con laminillas verticales numerosas (en torno a 14), ocupando la superficie de la plataforma cardinal (Fig. 12). El septalio, estrecho y somero, está relleno por depósitos conchíferos de la apófisis cardinal, salvo en su extremo distal donde está cubierto por un conectivo estrecho, más o menos convexo, que se prolonga más allá de la cavidad septalial (Fig. 12). Bases crurales fuertes, originando cruras que se prolongan en el plano de la comisura un corto trecho antes de curvarse acusadamente en dirección ventral (Fig. 12). Septo medio dorsal, alto y fuerte, cortante, extendiéndose mas allá de la mitad de la longitud de la concha, delimitando en la región cardinal sendas cavidades apicales laterales. Squamae y glottae bien desarrollados.

Observaciones ontogenéticas: El crecimiento en las conchas de Ch. lavidana n. sp. parece, igual que en otros Uncinuloideos, bicíclico, aunque no se dispone de ejemplares juveniles para demostrarlo. A partir de observaciones sobre conchas adultas, la frontera entre las fases neánica y efébica, donde se produciría la transición concha plana-concha alta (Westbroek, 1967) suele marcarse por breves interrupciones del desarrollo que provoca la aparición de una o unas pocas lamelas de crecimiento próximas, más gruesas que las vecinas, donde se dividen algunas costillas. La fase neánica comprende conchas bajas claramente alargadas, mientras que la relación a/L tiende a acercarse a la unidad en fases posteriores. La doble geniculación ventral es un fenómeno que se produce en la etapa efébica y se inicia también en una breve interrupción del desarrollo marcada por una lamela de crecimiento más fuerte que las vecinas.

Discusión: García-Alcalde $(1995,1996)$ agrupó los Glossinotoechiidae de la parte baja del Emsiense superior bajo la denominación Tridensilis intermedia, en razón de la presencia constante de alas, más o menos desarrolladas, en los márgenes antero-laterales de la valva ventral. En realidad, el material estudiado pertenece a dos niveles próximos de la Formación Valporquero (Fig. 10), el del inferior asignable a la nueva especie, Ch. lavidana, y el del superior a Chlupacitoechia intermedia. Por otra parte, Tridensilis Su, 1976, género al que Havlíček (1983) y García-Alcalde $(1995,1996)$ asignaron dichas formas es, en realidad, un Uncinulidae, posiblemente sinónimo de Uncinulus (Havlíček, 1992; Savage, 2002, in Treatise). 
Ch. lavidana n. sp. difiere de Ch. chlupaci (Havlíček, 1956), tipo del género, en el contorno más alargado, menor desarrollo de la doble geniculación, perfil transversal del pliegue medio dorsal plano, incluso algo deprimido (convexo en $\mathrm{Ch}$. chlupaci), truncamiento menos marcada de la valva ventral en el frente y costillas más finas y numerosas. Las diferencias con Ch. intermedia se exponen en la descripción de dicha especie.

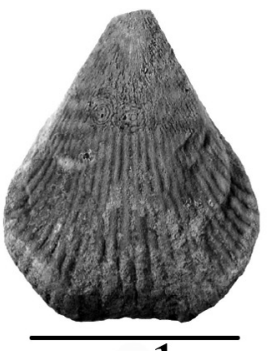

a1

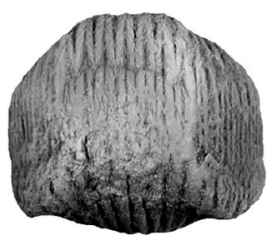

a4
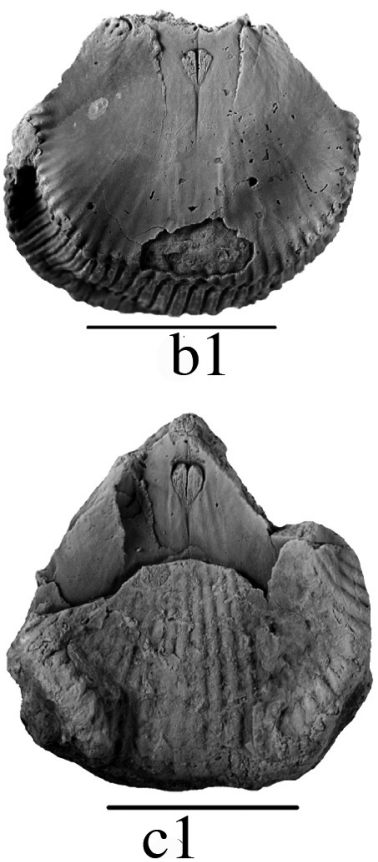

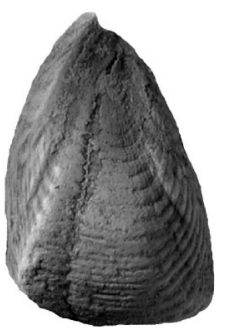

a2

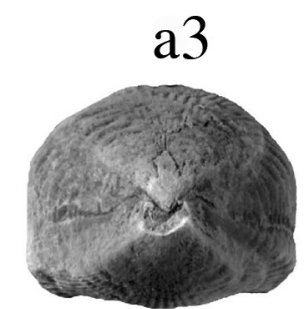

a5
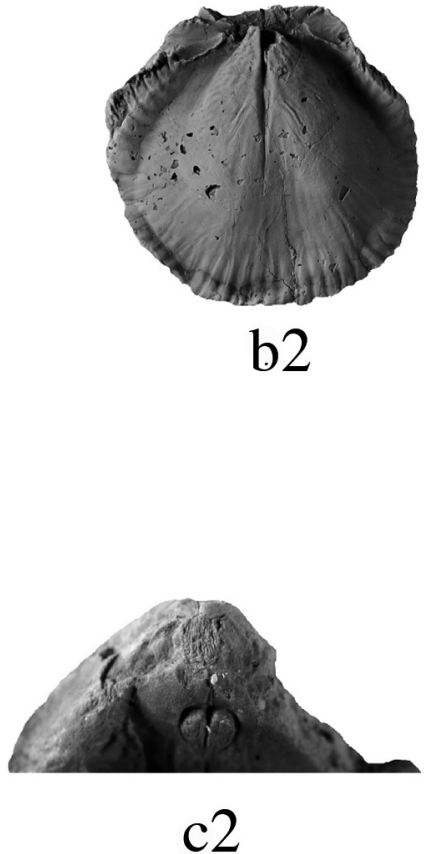

Brice (1981: 199) comparó su nueva especie Glossinotoechia intermedia con Eoglossinotoechia marocanensis, encontrando que la suya era más pequeña, menos espesa, más alada, con ganchos más estrechos y costillas menos numerosas que ésta. Por las características referidas, $E$. marocanensis se aproximaría, más bien, a nuestra nueva especie, aunque la ausencia de doble geniculación, seno ventral y pliegue medio dorsal son rasgos propios del género donde se incluyó y la separan de todas las especies de Chlupacitoechia.

\section{Chlupacitoechia intermedia (Brice, 1981)}

Figs. 9-10, 16-18

\begin{tabular}{|c|c|c|}
\hline & 959 & $\begin{array}{l}\text { Uncinulus henrici Barrande; Comte, Tab. II, } \\
394 .\end{array}$ \\
\hline & 1965 & $\begin{array}{l}\text { Glossinotoechia henrici (Barrande, 1847); Schu- } \\
\text { mann, } 70, \mathrm{Pl} .4 \text { fig. } 1 .\end{array}$ \\
\hline & 1965 & $\begin{array}{l}\text { Glossinotoechia sanctimichaelis (Kayser, 1889); } \\
\text { Schumann, } 72 \text {, P1. } 4 \text { fig. } 9\end{array}$ \\
\hline pars & 1965 & $\begin{array}{l}\text { Glossinotoechia kayseri (Barrois, 1882); Schu- } \\
\text { mann, } 80 \text {, Fundpunkt } 1 \text { Schichtglied } 16 .\end{array}$ \\
\hline ars & 1965 & $\begin{array}{l}\text { Glossinotoechia kayseri (BARROIS): Schumann, } \\
\text { Pl. } 4 \text { fig. } 4 .\end{array}$ \\
\hline & 1967 & $\begin{array}{l}\text { Glossinulus (Glossinotoechia) latus; Westbroek, } \\
\text { 11, 41-42, 44-45, 61, 67-68, 70-71, Figtext. 44, } \\
\text { 65, 74, 78, 80-81, Pl. } 1 \text { fig. 8, Pl. } 3 \text { fig. 6, Pl. } 11 \\
\text { fig. 3, Pl. } 13 \text { fig. 4, Enclosures I-II. }\end{array}$ \\
\hline & 1981 & $\begin{array}{l}\text { Glossinotoechia intermedia nov. sp.; Brice, } 198 \text {, } \\
\text { pl. } 26 \text { figs. 1-16, fig.text. 2-3. }\end{array}$ \\
\hline & 1981 & $\begin{array}{l}\text { cf. Glossinotoechia lata SCHUMANN 1965; Bri- } \\
\text { ce, 202, pl. } 26 \text { fig. 19a-b. }\end{array}$ \\
\hline & 1006 & $\begin{array}{l}\text { Tridensilis intermedia; García-Alcalde, Figtext. } 2 \\
\text { (en lista). }\end{array}$ \\
\hline & 2001 & Chlupacitoechia intermedia; García-Alcalde, Fig. \\
\hline
\end{tabular}

Material: 60 ejemplares, DPO 38751-38764, 38787-38832, generalmente en mal estado de conservación, aplastados y colonizados por epizoos. DPO 38751-38764 y 38816-38826 (DPO 38755, Fig. 18.a; DPO 38809, Fig. 18.b; DPO 38817, Fig. 18.c; DPO 38827, Fig. 18.e mostrando la morfología y extensión de las espinas marginales; DPO 38758 seccionado para mostrar estructuras internas, Fig. 17), del corte de la carretera de La Vid a Vegacervera (León), parte baja de la Fm. Valporquero, nivel M-LV-36/37, del Emsiense Superior. DPO 38787-38800 (DPO 38791, Fig. 18.d), de niveles y edad similares de Colle (León), yacimientos C-19 e I-104. DPO 38801-38805, de ni-

Figure 15. Chlupacitoechia lavidana n. sp. (todas las figuras blanqueadas con óxido de magnesio. Las barras horizontales representan $10 \mathrm{~mm}$ ). a1-5: DPO 38723, vistas ventral, lateral, dorsal, anterior y posterior. b1-2: Molde interno fragmentario DPO 38692, vistas ventral y dorsal; obsérvense los campos musculares, el miofragma medio ventral y el septo medio dorsal. c1-2: Molde interno fragmentario DPO 38710, vistas ventral (obsérvese el campo muscular) y postero-ventral, ampliado para mostrar el molde de la apófisis cardinal, comprendiendo numerosas laminillas y el campo de los aductores ventrales. Chlupacitoechia lavidana $n$. sp. (the figures have been whitened with magnesium oxide. Horizontal bars: 10 mm). al-5: DPO 38723, ventral, lateral, dorsal, anterior, and posterior views. b1-2: Fragmentary internal mould DPO 38692, ventral, and dorsal views; see the muscle fields, the ventral median myophragm, and the dorsal median septum. c1-2: Fragmentary internal mould DPO 38710, ventral and postero-ventral views. In the ventral view the muscle field is clearly visible. Postero-ventral view enlarged to show the cardinal process vertical platelets and the ventral adductor muscle field. 
veles y edad similares de Caldas de Luna (León), M-CAL 9 y 10. DPO 38806-38815, de niveles y edad similares de Abelgas (León). DPO 38827 de niveles y edad similares, de Lumajo (León). DPO 38828-38832 de niveles y edad similares, de Felmín (León).

Distribución estratigráfica y edad: $C h$. intermedia, aparece en la Cordillera Cantábrica algo por encima de los niveles con $C h$. lavidana n. sp. e inmediatamente debajo de las capas con Triblyocrinus flatheanus, en el Intervalo Faunistico 10 de GarcíaAlcalde (1996) dentro de la Biozona de dacrioconáridos Nowakia cancellata y de la de conodontos Polygnathus laticostatus; parte baja del Emsiense superior (Figs. 9-10).

Descripción: Las características de la especie coinciden notablemente con las de la especie nominada descrita por Brice (1981:
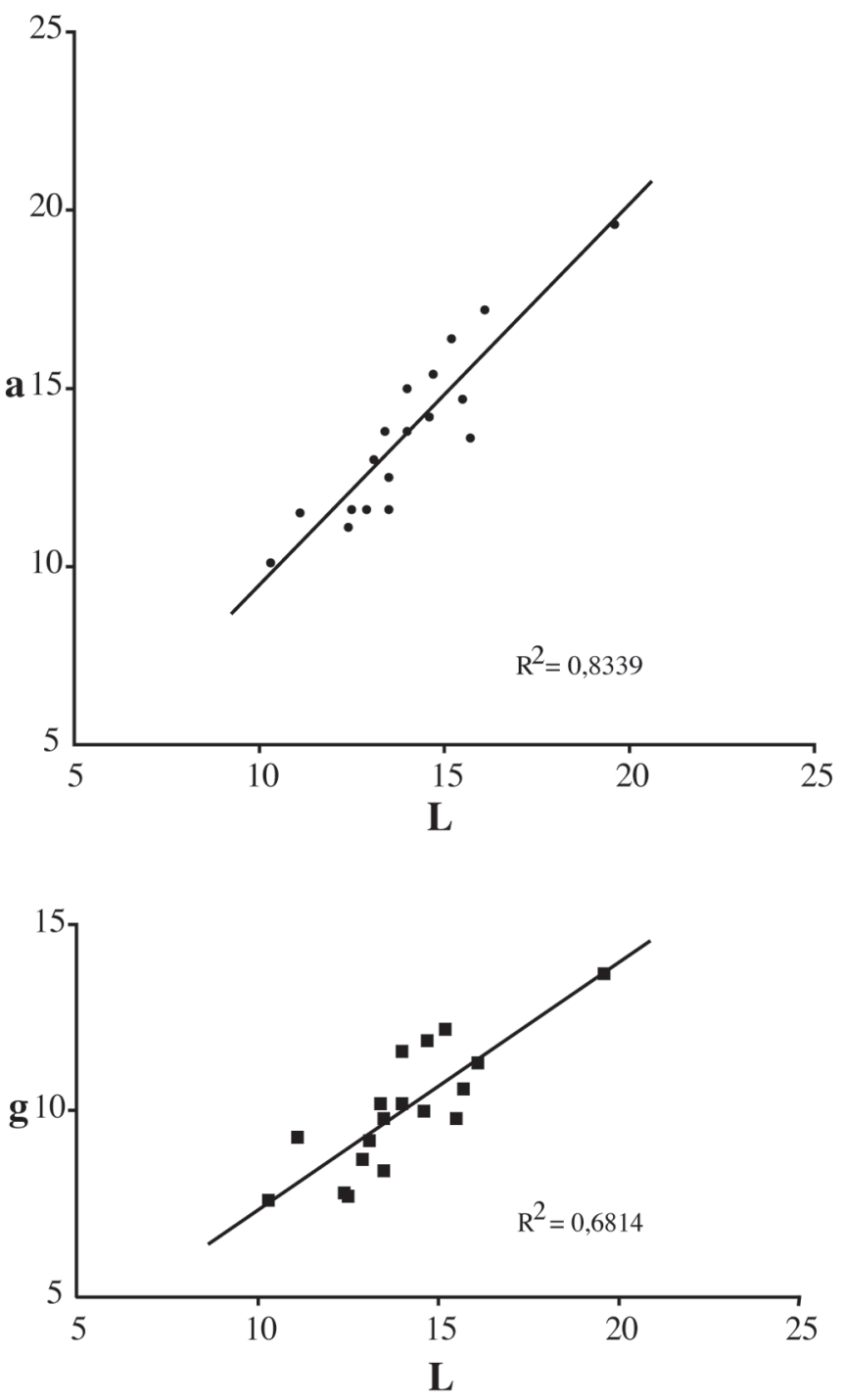

Figura 16. Diagramas de dispersión longitud/anchura (L/a) y longitud/grosor (L/g) de Chlupacitoechia intermedia (Brice, 1981).

Chlupacitoechia intermedia (Brice, 1981)Length/ Width $(L / a)$ and Length/Thickness $(L / g)$ dispersion diagrams.
198-202) y son próximas también a las de Ch. lavidana n. sp. descrita antes. Los parámetros propios del material cantábrico son los siguientes. Lmax $<20 \mathrm{~mm}$; promedio para 31 ejemplares medidos: 14,4. Conchas alargadas a transversas (promedio a/L: 0,$98 ; 44 \%$ de los ejemplares medidos equidimensional o transverso) (Fig. 16); contorno sub-pentagonal irregular, con la máxima anchura a los 2/3 de la longitud o un poco antes; concha bastante alta (gmax<14; promedio para 25 ejemplares medidos: 10,1; promedio g/L: 0,71) (Fig. 16), muy dorsi-biconvexas, con la valva dorsal 2 a 3 veces más alta que la ventral; máxima altura de la peduncular por detrás de la mitad de L; máxima altura de la braquial en el frente de la valva (Fig. 18). Alas bastante bien desarrolladas en los márgenes antero-laterales de la valva ventral (Fig. 18.c1 y 18.c3). Lengüeta rectangular, de fondo plano, bastante alta, dorsal a postero-dorsalmente dirigida, de anchura superior a $1 / 3 \mathrm{de}$ la de la concha (Figs. 18.a2, 18.c3 y 18.c5). Gancho inclinado a sub-erecto con ángulo apical relativamente abierto (entre 52 y $82^{\circ}$; promedio para 18 ejemplares medidos; 66 $6^{\circ}$ (Fig. 18.c1 y 18.d2). 31 a 51 costillas en cada valva (promedio: 41 para 30 ejemplares medidos). Fórmula costal para más del $80 \%$ de los ejemplares medidos: med8-9/7-8, lat14-16/15-17.

Caracteres internos: Parecidos a los de Ch. lavidana n. sp. aunque con placas dentales más cóncavas, cavidades laterales ventrales más amplias, miofragma menos desarrollado, campo muscular más débil, plataforma cardinal aplanada con rebordes internos de las cavidades glenoideas a nivel con el resto de la plataforma, apófisis cardinal reducida y conectivo sub-horizontal (Fig. 17).

Discusión: Brice (1981) propuso una nueva especie de la Formación Marettes, en la localidad de La Lezais (Francia) de la parte baja del Emsiense superior, con el nombre de Glossinotoechia intermedia, señalando, en cualquier caso la presencia de alas en los márgenes antero-laterales de la valva ventral. Este rasgo, junto con la altura media de las conchas (promedio g/L: 0,77 ) son características propias del género Chlupacitoechia Havlíček, 1992, donde incluimos aquí a la especie francesa. En Glossinotoechia (tipo: G. henrici) las alas de la valva ventral se unen en el sector medio de la misma para formar una elevación continua sub-marginal (Havlíček, 1992) y, además, las conchas son muy altas.

El contorno, perfil, proporciones, ornamentación y estructura interna del material cantábrico, son similares a los de las colecciones francesas de $G$. intermedia de la trinchera de La Lezais, descritas por Brice (1981), lo que justifica la asignación que aquí se realiza.

Ch. intermedia es también próxima a la nueva especie, Ch. lavidana n. sp, descrita antes, incluso en el desarrollo ontogenético, lo que sugiere, junto con la distribución paleogeográfica y estratigráfica, que aquella pudo derivar de ésta. Hay, sin embargo, diferencias en la forma y dimensiones de ambas especies: Ch. lavidana n. sp. es mucho más grande y alta que Ch. intermedia, de contorno más triangular y con un número de costillas mayor (cerca de 60 como máximo en Ch. lavidana, por unas 50 en Ch. intermedia), con fórmula costal diferente; además, la lengüeta 
es convexa en $C h$. lavidana y plana en $C h$. intermedia y aunque las alas ventrales son débiles en ambas especies, se acentúan más en Ch. intermedia.

La referencia de Schumann (1965) a Glossinotoechia henrici corresponde, con toda probabilidad, a Ch. intermedia, como ya señaló en su día Brice (1981, en lista de sinonimias). Las diferencias fundamentales entre Glossinotoechia y Chlupacitoechia se expusieron más arriba.

Glossinotoechia lata Schumann, 1965, podría comprender uno de los extremos de la variabilidad de Ch. intermedia, que abarca conchas equidimensionales a transversas; de todos modos, la mala conservación del escaso material descrito por el autor de la especie, no permite asegurarlo. En caso de que se pudiera confirmar, Ch. intermedia sería sinónima de Ch. lata.

La referencia a la especie en García-Alcalde (2001: Fig. 2) se basa en formas que, por causa de la deformación, presentaban una depresión media en el pliegue dorsal y una ele- vación media en el seno ventral muy atenuadas que corresponderían, en realidad, a Glossinulus kayseri (Barrois).

\section{Género Glossinulus Schmidt, 1942}

Especie tipo: Rhynchonella adolphi mimica Barrande, 1879: 178. Emsiense superior.

\section{Glossinulus kayseri (Barrois, 1882) \\ Figs. 19-23}

1882 Rhynchonella Kayseri, C.B. nov. sp.; Barrois, 266, P1. 11 fig. 23.

1952 Uncinulus kayseri Barrois; Le Maítre, 116, pl. 21 fig. 35-39.

- pars 1959 Uncinulus kayseri Barrois; Comte, 394, Tab II.

- 1964 Uncinulus kayseri Barrois 1882; Sougy, 460, pl. 35 figs-4-5.

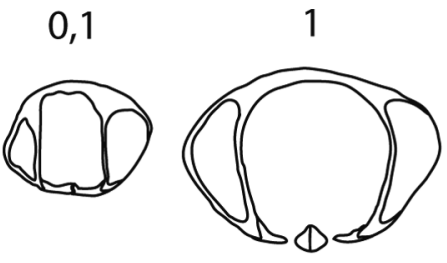

1,4

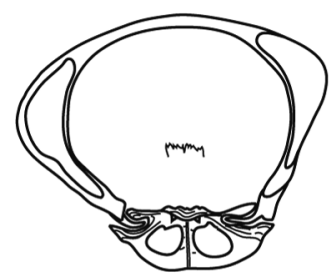

2,4
1,05

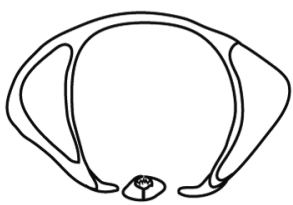

1,8

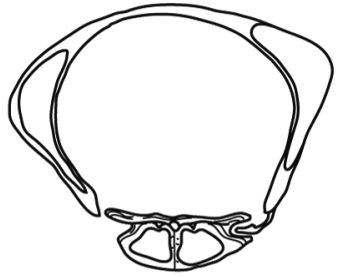

1,2

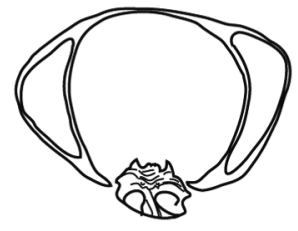

1,3

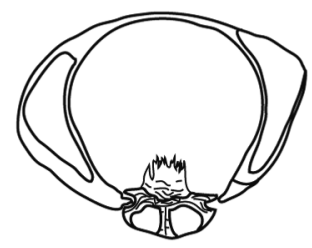

1,9

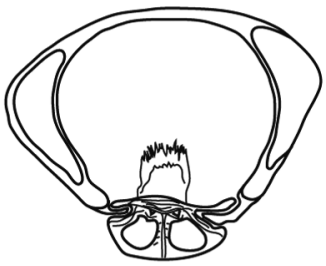

2,1

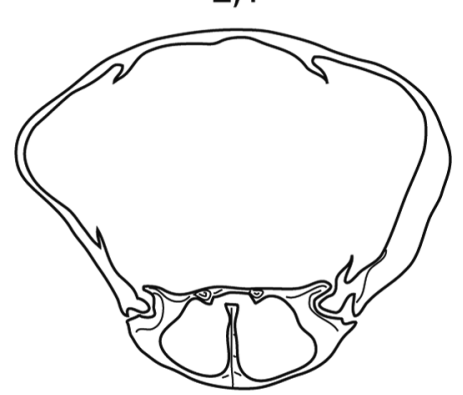

3,7
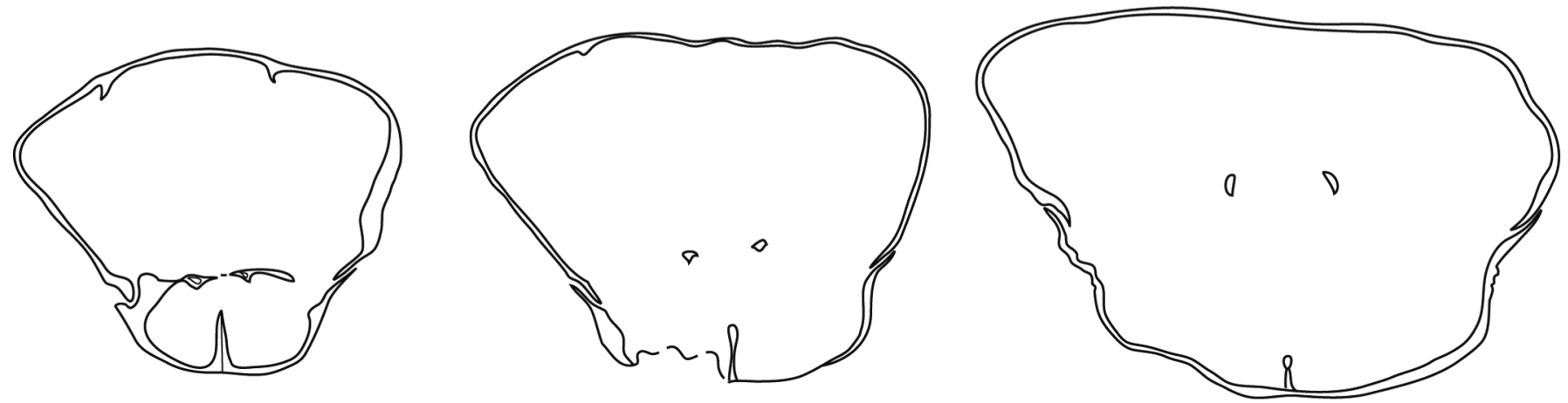

Figura 17. Secciones seriadas de Chlupacitoechia intermedia (Brice, 1981), DPO 38758. Distancias medidas al ápice ventral (barra horizontal $5 \mathrm{~mm}$ ).

Chlupacitoechia intermedia (Brice, 1981), DPO 38758 serial sections. Distances measured in mm from the ventral apex (horizontal bar $5 \mathrm{~mm}$ ). 


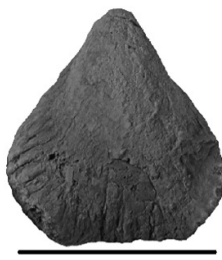

a1

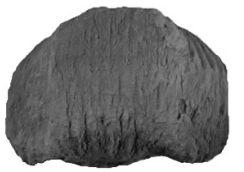

a4

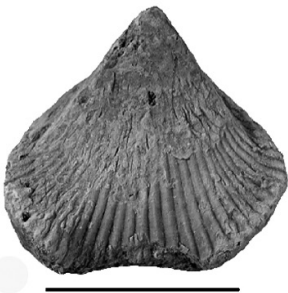

c1

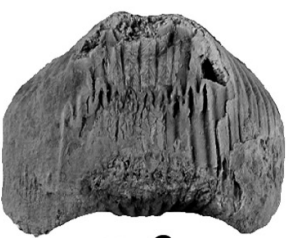

c3

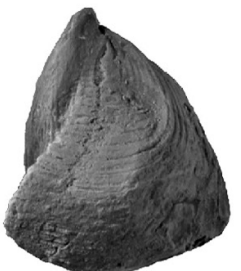

c5

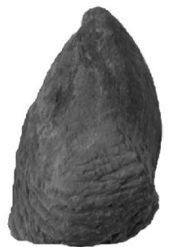

a2

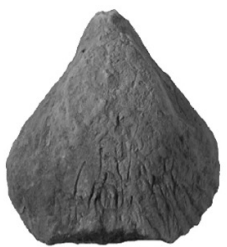

a3

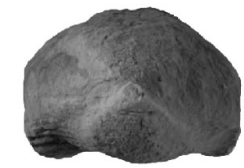

a5

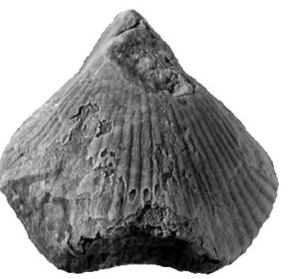

c2

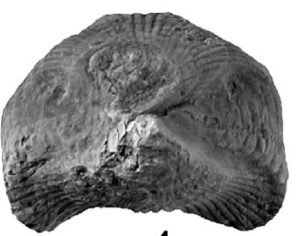

c4

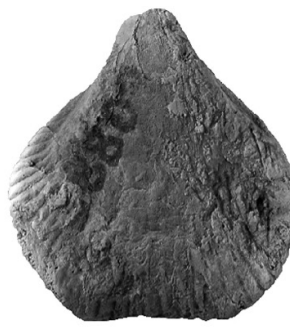

b1

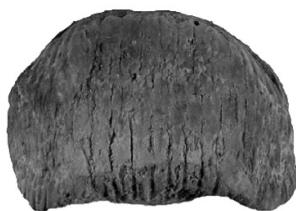

b4
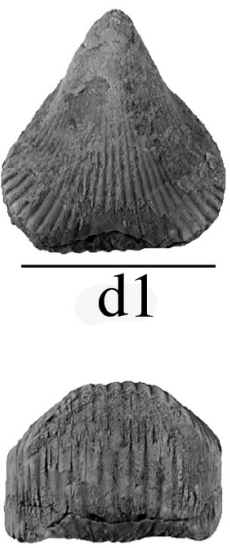

d4

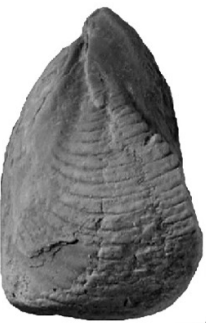

b2

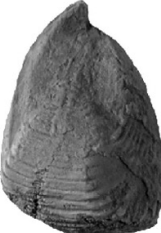

d2
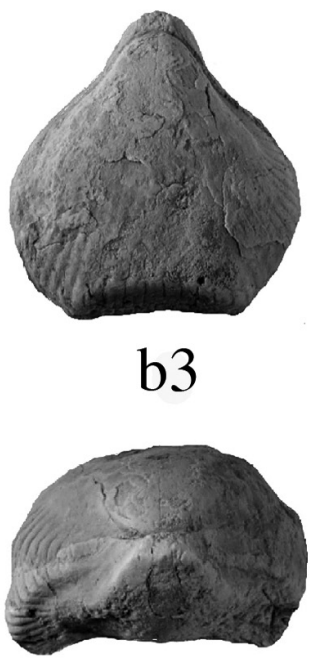

b5
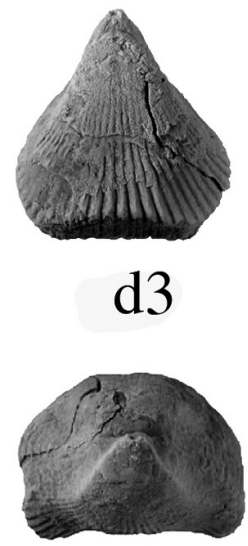

d5

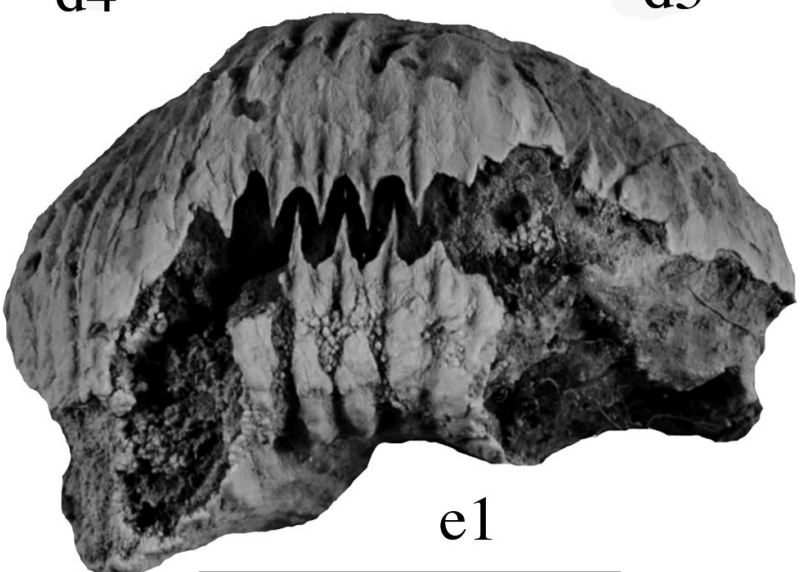

Figura 18. Chlupacitoechia intermedia (Brice, 1981) (Todas las figuras blanqueadas con óxido de magnesio. Las barras horizontales representan $10 \mathrm{~mm}$ ). a1-5: DPO 38755, vistas ventral, lateral, dorsal, anterior y posterior. b1-5: DPO 38809, vistas ventral, lateral, dorsal, anterior y posterior. c1-5: DPO 38817, vistas ventral, dorsal, anterior, posterior y lateral. d1-5: DPO 38971, vistas ventral, lateral, dorsal, anterior y posterior. e1: DPO 38827, vista anterior de un ejemplar algo deformado y roto, muy ampliada, para mostrar la estructura de la comisura con el enrejado típico de espinas marginales.

Chlupacitoechia intermedia (Brice, 1981) (the figures have been whitened with magnesium oxide. Horizontal bars: 10 mm). a1 -5: DPO 38755, ventral, lateral, dorsal, anterior, and posterior views. b1-5: DPO 38809, ventral, lateral, dorsal, anterior, and posterior views. c1-5: DPO 38817, ventral, dorsal, anterior, posterior, and lateral views. d1-5: DPO 38971, ventral, lateral, dorsal, anterior, and posterior views. e1: DPO 38827, very enlarged anterior view of a crushed specimen, showing the typical marginal spine grille at the commissure. 


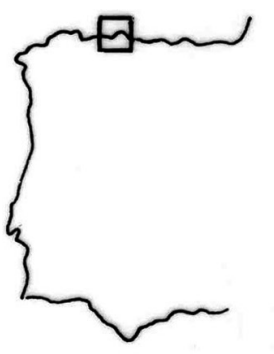

\section{MA R C A N T Á B R I C O}
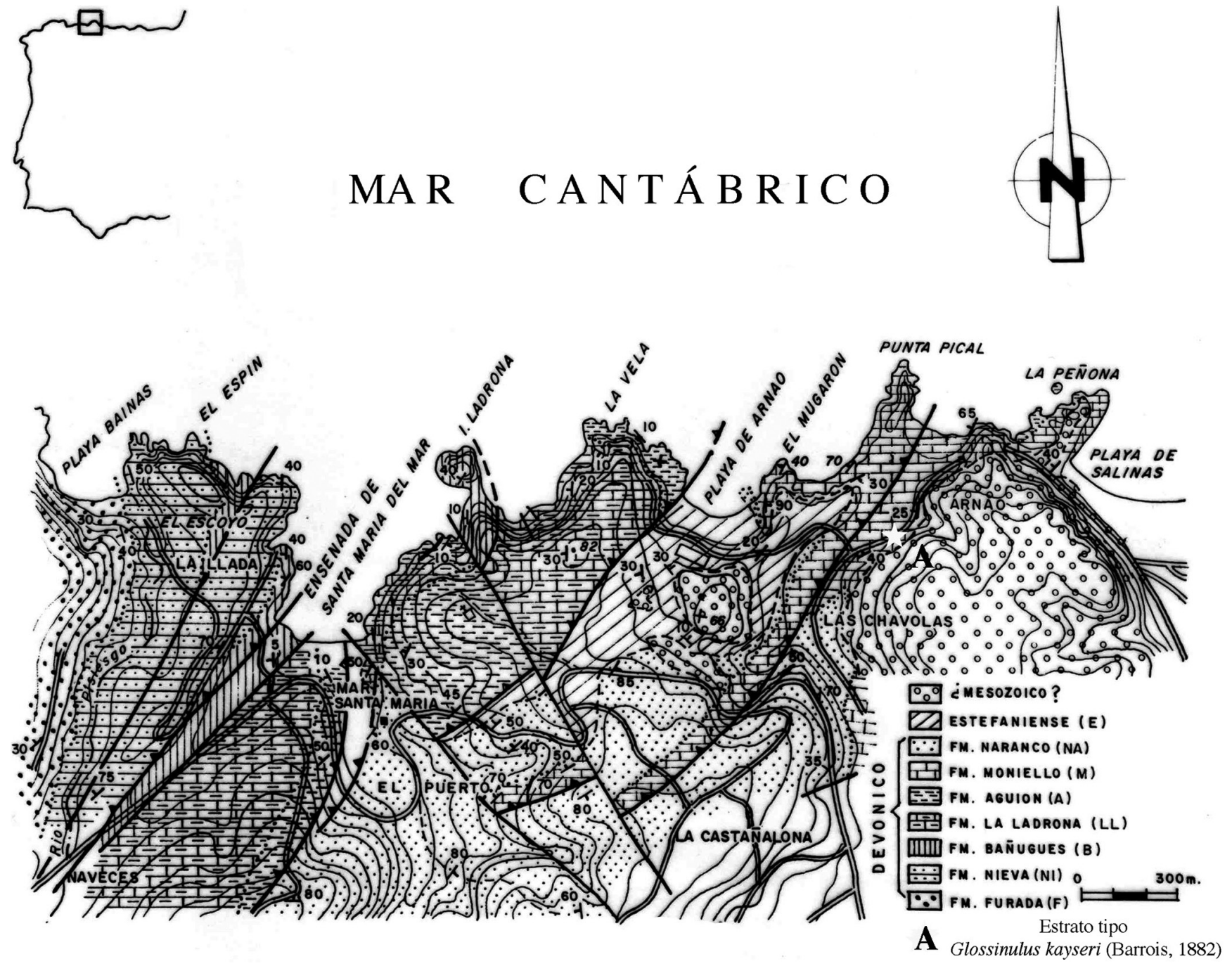

Figura 19. Mapa geológico del área costera en los alrededores de Arnao (Castrillón, Asturias) con la situación de la localidad típica de Glossinulus kayseri (modificado de García-Alcalde, 1992: Fig. 1).

Geological map of Arnao (Castrillón, Asturias) area. Situation of the Glossinulus kayseri type-locality (modified from García-Alcalde, 1992: Fig. 1).

? 1964 Glossinulus mimicus (Barrande, 1879); Drot, 143, pl. 16 figs. 1-2 14-17.

pars 1965 Glossinotoechia kayseri (Barrois, 1882); Schumann, 80, Fundpunkt 5 (coet excl).

v. 1979 Glossinulus mimicus; García-Alcalde et al., 6, 14, Figs. 6711 .

v. 1979 Glossinulus mimicus (Barrande, 1879); Arbizu et al., 112, P1. 2 figs. 17-19.

v. 1995 Glossinulus mimicus; García-Alcalde, Fig. 7 (en lista).

v. 1996 Glossinulus mimicus; García-Alcalde, Fig. 2 (en lista).

v. 2001 Glossinulus mimicus; García-Alcalde, Fig. 2 (en lista)

Lectotipo (primera designación): Se designa, provisionalmente, como lectotipo de la especie, al ejemplar sobre el que se basó el dibujo en Barrois (1882: Pl. XI fig. 2), procedente de la caliza de Moniello, en Arnao. La localización de dicho ejemplar, después de varias gestiones en centros franceses relacionados con el autor de la especie, se desconoce. Se seguirá intentando, en el futuro próximo, hallar dicho ejemplar, antes de proceder, eventualmente, a proponer un neotipo.

Estrato-tipo (primera designación): Barrois (1882: 266) propuso la nueva especie Rhynchonella Kayseri, señalando que se trataba de una forma que se encontraba en la Caliza de Moniello, en Moniello y en la Caliza de Arnao, en Moniello y Arnao, junto con Rhynchonella Orbignyana, sin mayores precisiones. La alusión a la Caliza de Arnao es errónea, como demostraron, en su día, Comte (1959: 287-289) y Arbizu et al. (1979: 103 y siguientes). De hecho, en términos actuales, la especie sólo aparece en la Caliza de Moniello y nunca en la Caliza de Arnao s.s. La procedencia del lectotipo provisional, designado más arriba 


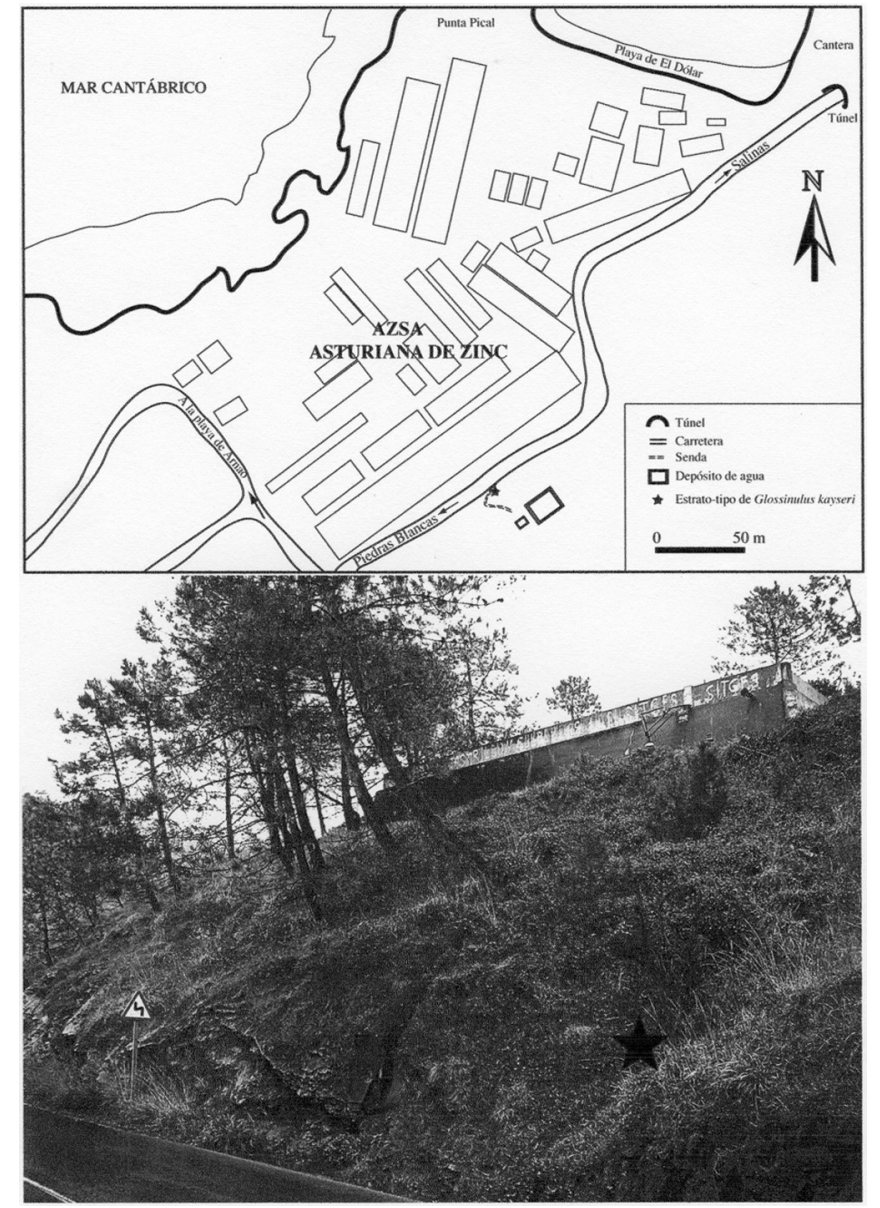

Figura 20. Esquema geográfico (arriba) y fotografía (abajo) de la situación de la localidad y estrato-tipo de Glossinulus kayseri.

Geographical scheme (above) and picture (below) showing the Glossinulus kayseri type-locality and stratotype setting.

es, con gran probabilidad, de un yacimiento situado detrás de las instalaciones de la Fábrica de Arnao, en la carretera local de Salinas a Piedras Blancas, antes de llegar a la desviación hacia las oficinas de la Fábrica de Arnao y playa de baños de la localidad (Figs. 19-20), donde la especie es particularmente abundante y fue incluso analizada desde el punto de vista estadístico por Martínez-Chacón (1969). Por esa razón, se designa aquí como localidad-tipo de la especie. El estrato-tipo se encuentra en dicha localidad, en una alternancia de calizas arcillosas arrecifales y débiles intercalaciones de margas de la parte media de la Fm. Moniello (Fig. 20). La situación del estrato-tipo dentro de la Formación Moniello no es evidente, al no existir una continuidad suficiente de afloramiento, debido a los edificios y cierre de la Fábrica de Arnao y al trazado de la discordancia del Jurásico Superior que recubre las formaciones devónicas en el área (Fig. 19). Sin embargo, el detallado conocimiento que se tiene sobre la estratigrafía de la caliza de Moniello en la zona costera, permite co- rrelacionar con gran precisión, merced al conjunto de la fauna de braquiópodos, corales y ostrácodos, dicho nivel con el M.929-930 en el borde occidental de la ensenada de Moniello (Méndez-Bedia, 1976: Fig. 13; Arbizu et al., 1979: Figs. 1-5), en el primer tercio del Miembro Superior de la Formación, de edad Emsiense superior Terminal (Fig. 21). Este nivel representa el extremo superior de la distribución estratigráfica de la especie que comienza, en el corte de Moniello, bastante más abajo, en el Miembro Inferior (capa M.838 de Méndez-Bedia, 1976), aunque es rara antes del Miembro Superior (Arbizu et al., 1979). La fauna presente en el estrato-tipo y niveles correlativos de la ensenada de Moniello, es abundante y variada, pertenece al Intervalo Faunístico 16 (García-Alcalde, 1996) y comprende numerosas formas de braquiópodos (no menos de 34 especies), briozoos (varias especies de fenestélidos dominantes y otras), trilobites, ostrácodos (no menos de 14 especies, $c f$. Becker \& Sánchez de Posada, 1977), corales y tabulados (no menos de 15 especies, entre ellas, Calceola sandalina), gasterópodos, serpúlidos, escamas de peces, crinoideos, conodontos (Biozona de Icriodus corniger corniger, $c f$. García-López \& Sánz-López, 2002: Fig. 7), espículas de esponjas e icnofósiles.

En la provincia de León y, mas concretamente, en las áreas de los ríos Luna, Bernesga y Curueño la especie sólo aparece esporádicamente en el miembro inferior (Mb I) de la Fm. Santa Lucía, en la localidad del Arroyo de El Puerto, cerca del pueblo de Santa Lucía (Fig. 2) mientras hacia arriba es substituida por Eoglossinotoechia puertoana $\mathrm{n}$. sp.

Material: Más de 250 ejemplares. DPO 38855-38898 procedentes del estrato y localidad típicos (DPO 38855-38857 figurados en Fig. 24). DPO 38921-38927, 39463-39476 de diferentes yacimientos del área tipo, en su parte costera, de la misma Fm. Moniello y niveles del Emsiense Superior. DPO 39339-39415, 39421-39430 y 39436, 39456 y 39457-39461, procedentes de los niveles correlativos del estrato-tipo y otros próximos, en la ensenada de Moniello (Luanco, Asturias), M.928 a 932; DPO 38928, 39416-39420, 39431-39435, 39437-39455 y 39462, de diferentes niveles de la misma localidad y formación, pertenecientes al Emsiense superior. DPO 38899 (seccionado para mostrar estructuras internas, Fig. 22) y 39309-39337 de la parte media de la caliza de Moniello, en la cantera de El Valle, Pravia (Asturias), nivel C-37. DPO 38900-38920 de dos niveles de la Formación Moniello, en La Planadera, al S de Cornellana (Asturias).

Emended diagnosis: Dorsi-biconvex, sub-pentagonal shell, as long as wide or nearly so (mean a/L: 0,96), relatively thick (mean $\mathrm{g} / \mathrm{L}: 0,66$ ), with postero-lateral sides longer than antero-lateral. Bycyclic growth developing great, flattened to concave paries geniculatus. Shell entirely ornate by mainly simple ribs (mean: 42) starting at apexes of valves, with some divisions, especially at the middle part of the shell. Ventral sinus and dorsal fold barely developed. In the ventral sinus a strong, rounded, 


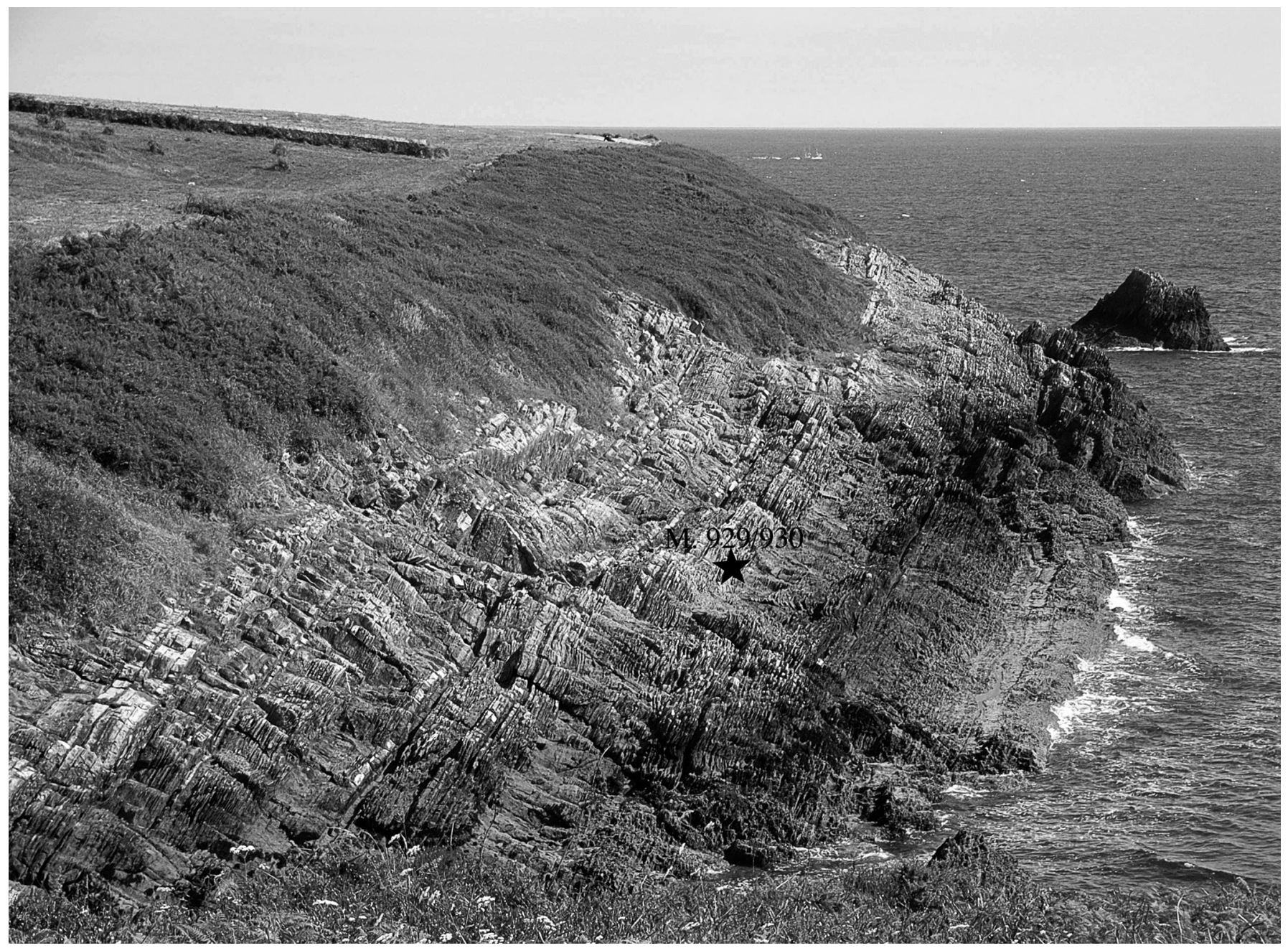

Figura 21. Niveles equivalentes del estrato-tipo de Glossinulus kayseri en el borde occidental de la ensenada de Moniello, cerca de Luanco (provincia de Asturias) en torno al nivel M. 929/930 de la Formación Moniello.

Correlative levels of the Glossinulus kayseri stratotype in the Moniello (Luanco, Asturias) inlet section, near the level M.929/930 of the Moniello Formation.

costulate median fold raises; this elevation lost importance anteriorly and disappears before the tongue base or at the tongue itself. Dorsal fold excavated by a sharp, median depression, reaching the maximum depth before the truncated border and ending at the border itself. The valve ventral develops a clear double geniculation at the antero-lateral sides. Straight or sometimes dorsally curved, uniplicate anterior commissure. More or less posteriorly prolonged, inclined, relatively open (mean apical angle: $63^{\circ}$ ) ventral beak. Fine, concave, parallel dental plates, bound narrow, free, lateral cavities; massive, denticulate cardinal teeth. Thick, high and long dorsal median septum, supporting a small septalium; septalium filled by a very high, linguiform, bilobed, longitudinally striated cardinal process posteriorly, free and roofed over by a convex connectivum anteriorly. Denticulate dental cavities; inner socket ridges overhang a little the cardinal plate. Squamae and glottae well developed.
Diagnóstico enmendado: Conchas casi equidimensionales (promedio a/L: 0,96), relativamente gruesas (promedio g/L: 0,66), de crecimiento bicíclicico, paries geniculatus extenso, plano o algo cóncavo, contorno sub-pentagonal con lados postero-laterales más largos que los antero-laterales, dorsi-biconvexas, ornadas por completo por cóstulas finas, principalmente simples (promedio: 42), pero con algunas bifurcaciones, sobre todo en la parte media de ambas valvas. Seno ventral y pliegue dorsal poco diferenciados; el seno ventral lo ocupa una elevación ancha, redondeada y bastante alta, costulada como el resto de la valva, que termina hacia la base de la lengüeta o algo antes; pliegue dorsal surcado por una depresión media acusada, que termina al nivel de truncación. Doble geniculación desarrollada en los márgenes antero-laterales de la valva ventral. Comisura frontal uniplegada y recta, a veces débilmente curvada en dirección dorsal. Gancho ventral más o menos estirado y curvado, relativamente abierto (promedio ángulo 


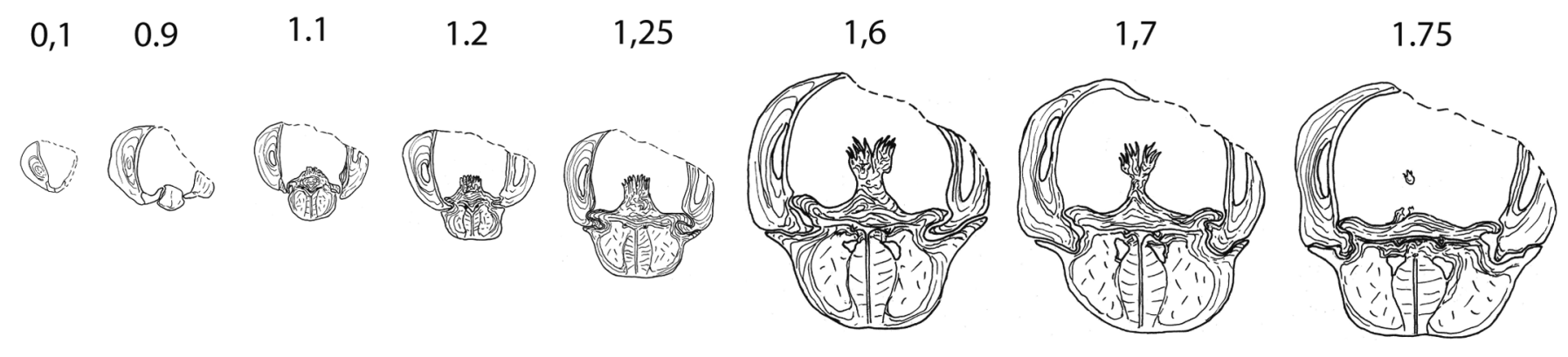

1,8

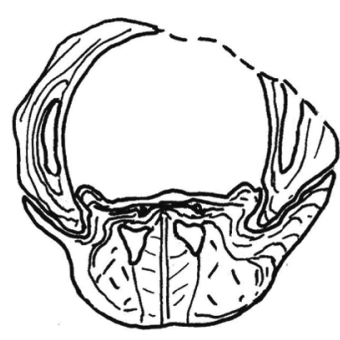

1,85

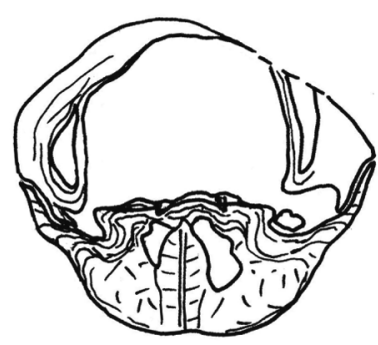

1,9

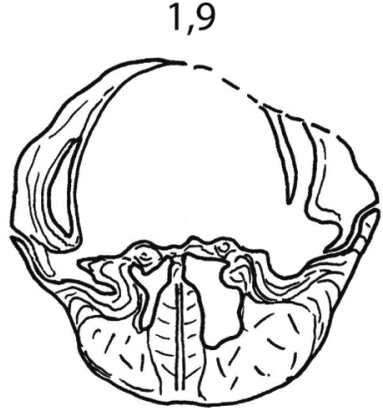

2,1

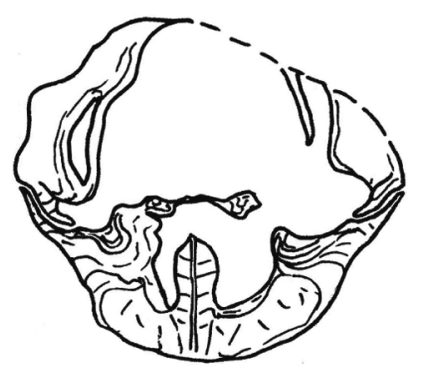

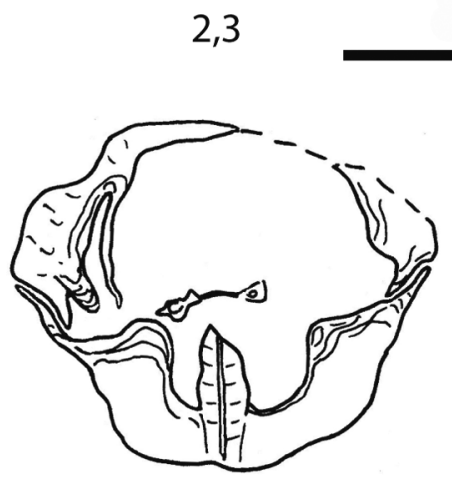

2,55

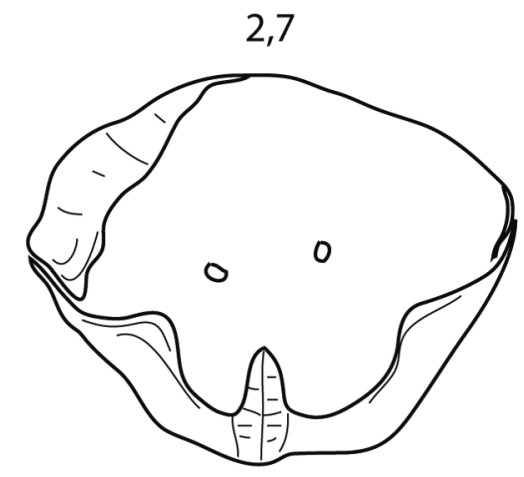

Figura 22. Secciones seriadas de Glossinulus kayseri (Barrois, 1882), DPO 38899. Distancias medidas al ápice ventral (barra horizontal $5 \mathrm{~mm}$ ).

Glossinulus kayseri (Barrois, 1882), DPO 38899 serial sections. Distances measured in mm from the shell apex (horizontal bar $5 \mathrm{~mm}$ ).

apical: $63^{\circ}$ ). Placas dentales finas, cóncavas y paralelas, delimitando cavidades laterales reducidas pero libres; dientes cardinales masivos, denticulados. Septo medio dorsal alto, largo y fuerte, soportando un septalio menudo, ocupado posteriormente por una apófisis cardinal muy alta, bilobulada, con numerosas laminillas, y cubierto anteriormente por un conectivo convexo. Cavidades glenoideas denticuladas, rebordes internos algo elevados sobre la plataforma cardinal. Squamae y glottae bien desarrollados.

Descripción: Conchas de tamaño normal para el género (Lmax: 17,7 mm; promedio: 13,4), de contorno sub-pentagonal, con los lados postero-laterales más largos que los antero-laterales, casi equidimensionales (a/L entre 0,71 y 1,32 ; promedio: 0,96 para 113 medidas) y gruesas ( $\mathrm{g} / \mathrm{L}$ entre 0,48 y 0,98 ; promedio: 0,66 para 113 medidas) (Fig. 23), con la máxima anchura situada en el cuarto anterior de la longitud y la máxima altura en el nivel de truncación de las valvas (Fig. 24). Valvas regularmente convexas, pero con bordes laterales y frontales truncados (crecimiento bi- cíclico), con aristas redondeadas salvo la antero-dorsal que es aguda. Paries geniculatus extenso, plano o, incluso, algo cóncavo. Comisuras denticuladas con dentículos débiles (Fig. 24.a3, 24.c4) aunque el desgaste puede simular dentículos mucho más agudos (Fig. 24.b3); comisura frontal uniplegada, recta o raras veces curvada en dirección dorsal (Fig. 24). Lengüeta trapezoidal, alta, dorsal a postero-dorsalmente dirigida. Valvas cubiertas de cóstulas radiales bajas, que nacen en los ápices de las valvas, finas y convexas en los discos y anchas, planas, hendidas longitudinalmente (para el acoplamiento de espinas marginales largas) y ornadas por finas estrías en zizzag en las paredes truncadas; espacios intercostulares agudos, mucho más estrechos que las costulas. Cóstulas rectas, salvo en los flancos donde se vuelven hacia atrás, principalmente simples pero presentando siempre algunas divisiones, sobre todo en la parte media de la concha. En la comisura el número de cóstulas varía de 30 a 55 (promedio 42 para 98 medidas); la fórmula costal media va de 7/6 a 16/15, con frecuencia máxima para 10/9-12/11, que comprende casi el $66 \%$ de las 76 medidas efectuadas); en los flancos el número de cóstulas oscila de 7 a 16, con frecuencia máxima 10 

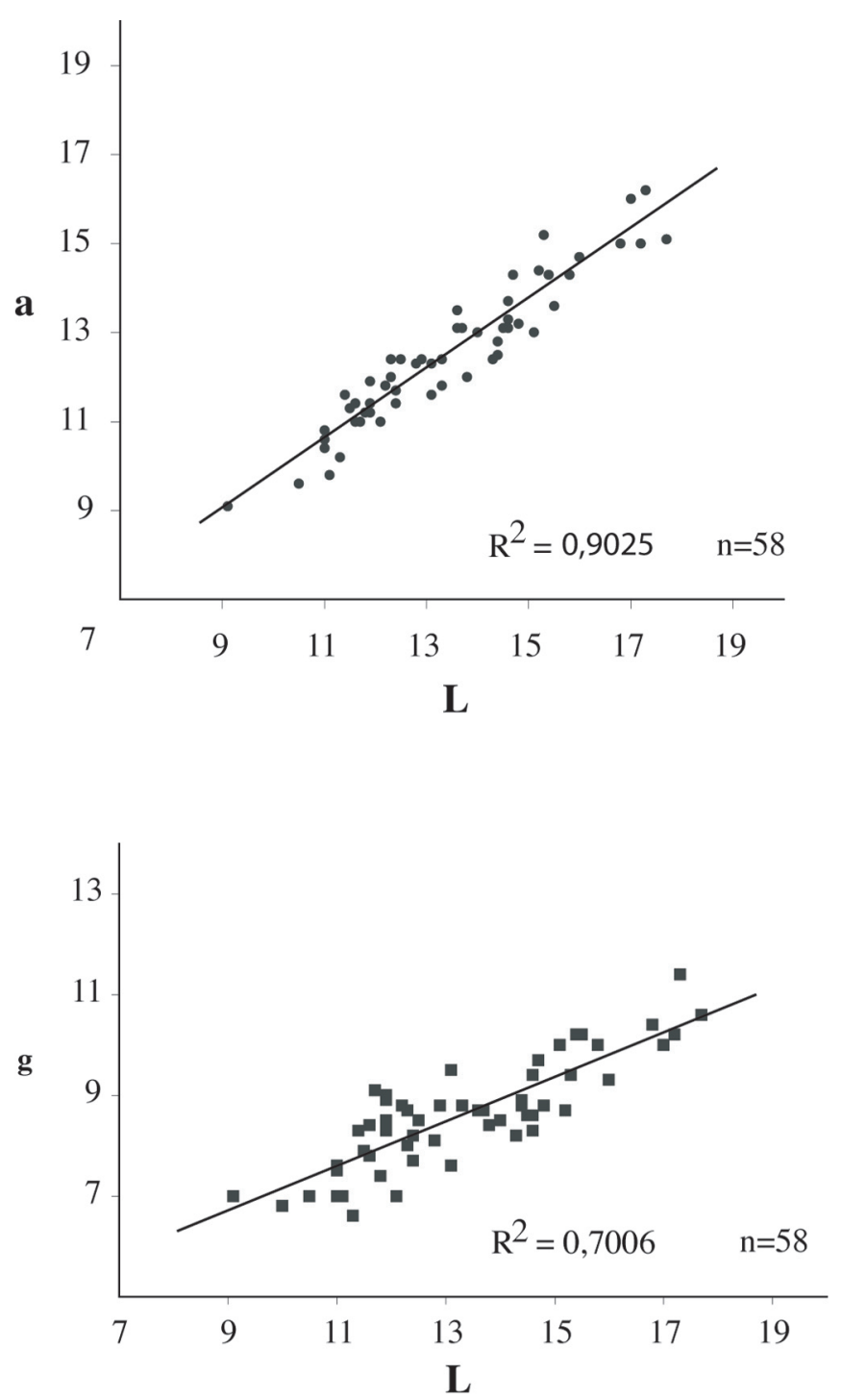

Figura 23. Diagramas de dispersión longitud/anchura (L/a) y longitud/grosor (L/g) de Glossinulus kayseri (Barrois, 1882).

Glossinulus kayseri (Barrois, 1882) Length/Width (L/a) and Lengtht/Thickness $(\mathrm{L} / \mathrm{g})$ dispersion diagrams.

a 14, para más del $60 \%$ de los ejemplares observados. Es difícil observar la presencia de costillas parietales. Las cóstulas se prolongan en el frente en espinas marginales internas muy largas, de tipo B (Westbroek, 1967). Lamelas de crecimiento muy débiles, casi inapreciables.

Umbo ventral estirado posteriormente, gancho inclinado a suberecto, con ángulo apical relativamente abierto (44 a $78^{\circ}$; promedio: $63^{\circ}$ para 88 medidas), truncado por un foramen peduncular menudo, circular, mesotírido a permesotírido, limitado basalmente por un deltidio fuerte, completo, plegado a lo largo de la sutura deltidial. Flancos umbonales algo cóncavos, delimitando superficies más o menos lunulares, muy someras (Fig. 24.c5).

El perfil longitudinal de ambas valvas, es muy convexo en la región umbonal y mucho más suave en el resto del disco. La valva ventral cambia el sentido de la curvatura cerca de los bordes antero-laterales, doblándose primero de manera suave en sentido ventral hasta alcanzar el borde de truncación, y luego abruptamente en dirección opuesta (doble geniculación); las aristas de las alas así formadas son redondeadas. El borde anterior de la valva dorsal tiende también a la doble geniculación doblándose, a veces, muy suavemente, en sentido dorsal para volverse, más tarde, de manera abrupta en dirección ventral en el paries geniculatus (Fig. 24.c1).

Seno ventral, iniciándose hacia la mitad de la longitud, poco profundo, ocupando en el frente 2/3 o más de la anchura de la concha. Dicha depresión está prácticamente ocupada por una elevación acusada, que llega a alcanzar la altura de los bordes de la valva, destacando incluso de ellos, en vistas anterior y posterior (Figs. 24.a4, 24.b3-4, 24.c4-5), la cual desaparece rápidamente algo antes de alcanzar la base de la lengüeta o en la propia base. La elevación comprende un haz de cóstulas, más o menos numerosas, entre las que aparecen con mayor frecuencia elementos bifurcantes. El pliegue dorsal se marca débilmente sólo en el cuarto anterior de la longitud y está recorrido por una depresión ancha, bastante acusada, cuya máxima profundidad se alcanza antes de llegar al borde truncado, donde desaparece por completo, sin prolongarse en el paries geniculatus.

Caracteres internos (Secciones seriadas, Fig. 22): Placas dentales cóncavas, finas, paralelas, próximas a las paredes de la concha, definiendo cavidades apicales reducidas, pero libres. Dientes cardinales, denticulados, masivos, encajando en cavidades dentarias con rebordes internos débilmente elevados sobre la plataforma cardinal. Septalio muy pequeño, apoyado en un septo medio grueso, alto y largo, que alcanza la mitad o más de la longitud de la concha; cavidades apicales dorsales rellenas parcialmente de concha secundaria. Apófisis cardinal lingüiforme, bífida, muy alta, con numerosas laminillas verticales, ocupando buena parte de la cavidad septalial y terminando por detrás de la articulación de la concha. Septalio cubierto anteriormente por un fino conectivo convexo que se prolonga mas allá de la cavidad septalial. Squamae y glottae bien desarrollados.

Desarrollo ontogenético: Como sucede con otras especies de Uncinuloideos, las formas juveniles de la especie son extremadamente raras lo que unido al pobre desarrollo de las lamelas de crecimiento, impide describir el ciclo de concha plana. En el estadio de concha alta, las paredes truncadas crecen en altura con la edad de las conchas, y también lo hace el número total de cóstulas y el de cóstulas medias. Parece existir también una débil tendencia a la disminución del ángulo apical con la edad.

Discusión: García-Alcalde (1995, 1996, 2001, en Arbizu et al., 1979 y en García-Alcalde et al., 1979), incluyó las poblaciones de las formaciones Moniello y Santa Lucía, en Moniello y otras localidades cantábricas en Glossinulus mimicus. Las causas de esta sinonimia fueron el perfil general de la concha y el dibujo del lectotipo de la especie, una forma alargada y pinzada, con ángulo apical bastante agudo y comisura frontal débilmente denticulada, características próximas a las de la especie de Barrande. Sin embargo, en conjunto, el material de la localidad tipo, tiende a ser equidimensional, con ángulo apical relativamente abierto y to- 
dos los ejemplares tienen la comisura frontal recta o, raras veces, arqueada en dirección dorsal. El propio Barrois (op. cit.: 266) es contradictorio al describir la especie, de la que afirma que tiene ángulo apical entre $70-75^{\circ}$ y comisura recta, debido a que la depresión media dorsal y la elevación media ventral no alcanzan el frente de las valvas.

Con los datos obtenidos de las nuevas y abundantes colecciones de Glossinulus kayseri, la especie se diferencia de
G. mimicus por la menor elongación, umbo menos pinzado, costillas menos numerosas y más groseras y comisura frontal recta; en el interior se diferencia también en el mayor desarrollo de las placas dentales y cavidades apicales y escaso desarrollo del septalio con presencia constante de conectivo, cubriéndolo por delante de la apófisis cardinal.

Material africano del Emsiense superior, procedente de las colecciones de H. Hollard y de J. Sougy, lo incluyó

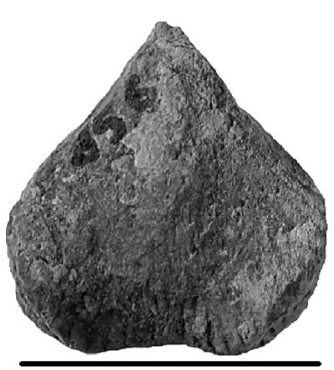

a1

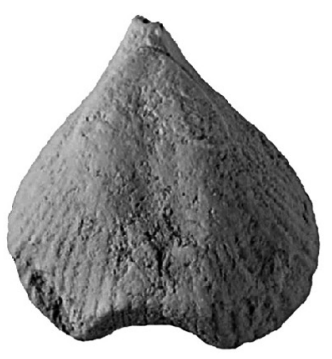

a2

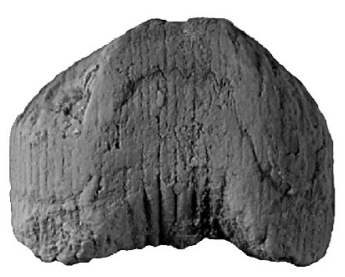

a3

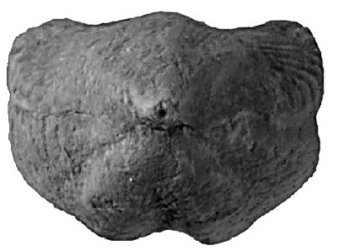

a4

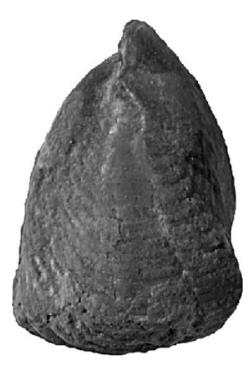

a5

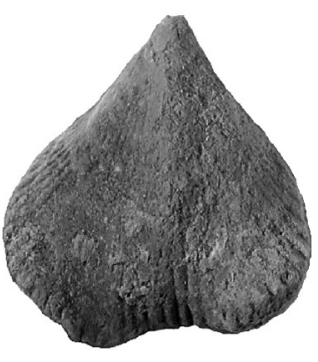

b1

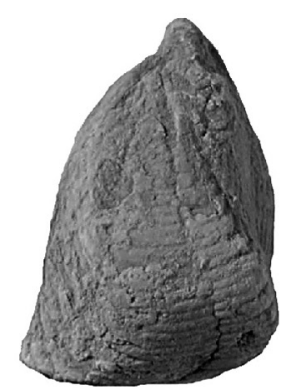

c1

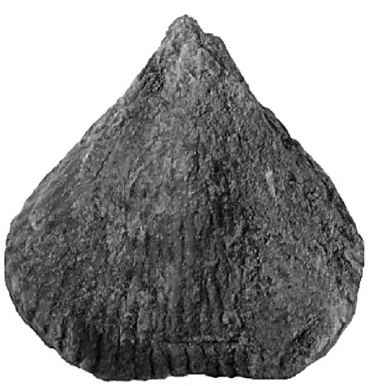

c2

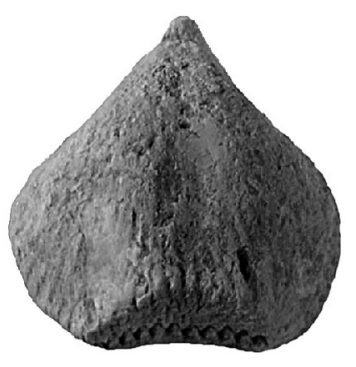

b2

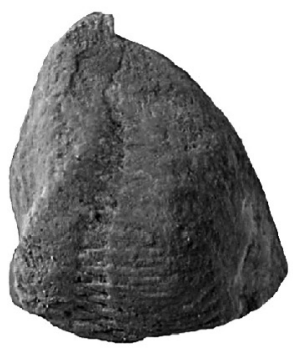

b5

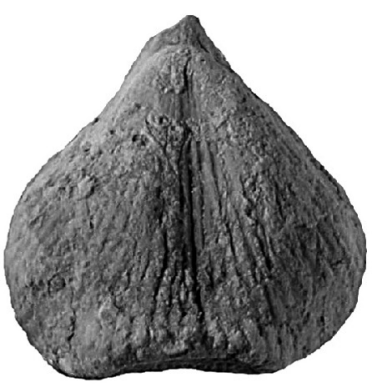

c3

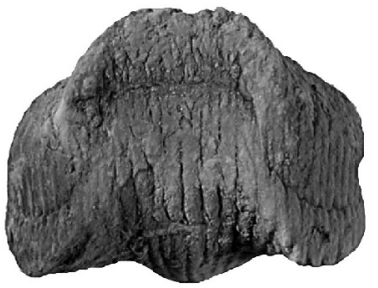

c4

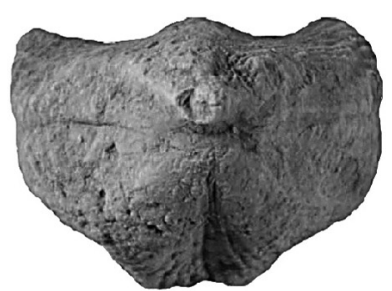

c5

Figura 24. Glossinulus kayseri (Barrois, 1882) (todas las figuras blanqueadas con óxido de magnesio. Las barras horizontales representan $10 \mathrm{~mm}$ ). a1-5: DPO 38855, vistas ventral, dorsal, anterior, posterior y lateral. b1-5: DPO 38856, vistas ventral, dorsal, anterior, posterior y lateral. c1-5. DPO 38857, vistas lateral, ventral, dorsal, anterior y posterior.

Glossinulus kayseri (Barrois, 1882) (the figures have been whitened with magnesium oxide. Horizontal bars: $10 \mathrm{~mm}$ ). a1 -5: DPO 38855, ventral, dorsal, anterior, posterior, and lateral views. b1-5: DPO 38856, ventral, dorsal, anterior, posterior, and lateral views. c1-5: DPO 38857, lateral, ventral, dorsal, anterior, and posterior views. 
Drot (1964) en G. mimicus. Sin embargo, los ejemplares figurados por dicha autora son también equidimensionales, con costillas relativamente groseras, ángulo apical abierto y comisura frontal recta o algo curvada en dirección dorsal y presentan también conectivo, caracteres que se amoldan mejor a los de G. kayseri, en cuya sinonimia los incluimos, con algunas dudas. El propio J. Sougy (1964) consideraba su material como perteneciente a la especie de Barrois. Y Le Maître (1952: 116) incluyó también el material africano de sus propias colecciones en dicha especie aunque igualándola a $G$. mimicus.

En nuestra opinión, G. mimicus pertenecería a un dominio paleobiogeográfico, el Báltico (Alemania), diferente que G. kayseri (Gondwana Septentrional: Península Ibérica y $\mathrm{N}$ de África).

Las formas denominadas Chlupacitoechia intermedia en García-Alcalde (2001: Fig. 2) son ejemplares deformados que corresponden, en realidad, a la especie nominada (ver antes).

\section{AGRADECIMIENTOS}

El presente trabajo fue auspiciado por el proyecto de investigación del Ministerio de Educación y Ciencia, MEC-05CGL2005-03715 y Fondos FEDER. Las fotografías originales se deben al fotógrafo del Departamento de Geología de la Universidad de Oviedo, D. Joaquín Varela. Mis agradecimientos más sincero a los revisores, profesores Denise Brice, de la Faculté Libre des Sciences et Technologies \& Institut Supérieur d'Agriculture de Lille (Francia) y Miguel V. Pardo Alonso, de la Universitat de València, y a los editores de la Revista por sus observaciones y correcciones.

\section{BIBLIOGRAFÍA}

Alekseeva, R.E. 1967. Brakhiopody Stratigraphiya Nichnego Devona Severo-Bostokka SSSR. Akademia Nauk SSSR, Sibirskoe Otdelenie Institut Geologii i Geofiziki, Izdatelstvo Akad. Nauk SSSR, 1-144.

Arbizu, M., García-Alcalde, J.L., García-López, S., MéndezBedia, I., Sánchez de Posada, L.C., Soto, F.M., Truyóls, M., Truyóls, J., Alvarez, F., Méndez, C. \& Menéndez, J.R. 1979. Biostratigraphical study of the Moniello Formation (Cantabrian Mountains, Asturias, NW Spain). Geologica et Palaeontologica, 13, 103-124.

Barrande, J. 1847. Über die Brachiopoden der silurischen Schichten von Böhmen. Naturwiss. Abhandlungen (Haidingers), 1, 357-475.

Barrande, J. 1879. Système silurien du Centre de la Bohême. 5, 1-226, Praga-Paris.

Barrois, C. 1882. Recherches sur les terrains anciens des Asturies et de la Galice. Mémoires de la Société Géologique du Nord, Lille, 2 (1), 1-630.

Becker, G. \& Sánchez de Posada, L.C. 1977. Ostracoda aus der Moniello-Formation Asturiens (Devon; N-Spanien). Palaeontographica, 158, 115-203.
Brice, D. 1981. Les brachiopodes Pentamerida, Rhynchonellida et Terebratulida. In: La tranchée de La Lezais. Emsien supérieur du Massif Armoricain. Sédimentologie, Paléontologie, Stratigraphie (eds. P. Morzadec, F. Paris \& P.R. Racheboeuf). Mémoires de la Société Géologique et Minéralogique de Bretagne, 24 (313), 193-217.

Comte, P. 1938. Brachiopodes dévoniens des gisements de Ferroñes (Asturies) et de Sabero (Leon). Annales de Paléontologie, 27, 41-87.

Comte, P. 1959. Recherches sur les terrains anciens de la Cordillère Cantabrique. Memorias del Instituto Geológico y Minero de España, 60, 1-440.

Chatterton, B.D.E. 1973. Brachiopods of the Murrumbidge Group, Taemas, New South Wales. Bulletin of Mineral Resources, Geology \& Geophysics, Australia, 137, 1-146.

Drot, J. 1964. Rhynchonelloidea et spiriferoidea SiluroDévoniens du Maroc pré-saharien. Notes et Mémoires du Service Géologique du Maroc, 178, 1-286.

García-Alcalde, J.L. 1992. El Devónico de Santa María del Mar (Castrillón, Asturias, España). Revista Española de Paleontología, 7, 53-79.

García-Alcalde, J.L. 1995. L'évolution paléogéographique pre-varisque de la zone Cantabrique septentrionale (Espagne). Revista Española de Paleontologia, 10, 9-29.

García-Alcalde, J.L. 1996. El Devónico del dominio AsturLeonés en la Zona Cantábrica (N de España). Revista Española de Paleontología, $\mathbf{n}^{\circ}$ extraordinario, 58-71.

García-Alcalde, J.L. 1999a. Nuevo género de braquiópodos rinconélidos del Praguiense (Devónico Inferior) de la región cántabro-celtibérica (España). Revista Española de Paleontologia, 14, 247-255.

García-Alcalde, J.L. 1999b. Terebratúlidos (Braquiópodos) del Emsiense superior de Colle (Sabero, León, $\mathrm{N}$ de España). Trabajos de Geologia, Universidad de Oviedo, 21 (homenaje a J. Truyols), 159-176.

García-Alcalde, J.L. 2001. Paleobiogeographical relationships between North Gondwana and South Baltica: The Ivanothyris havlíčeki fauna (Cantabrian Zone, latest Emsian). Journal of the Czech Geological Society, 46, 121-130.

García-Alcalde, J.L. (submitted). Voskopitoechia chlupaci n. sp. a Cantabrian (N Spain) Pragian Uncinulid brachiopod with Bohemian affinities. Bulletin of Geosciences.

García-Alcalde, J.L., Arbizu, M.A., García-López, S. \& Méndez-Bedia, I. (eds.) 1979. Meeting of the International Subcommission on Devonian Stratigraphy, Guidebook of the Field Trip. Servicio de Publicaciones de la Universidad de Oviedo, 1-41.

García-Alcalde, J.L. (coordinator), Carls, P., Pardo Alonso, M.V., Sanz López, J., Soto, F., Truyols-Massoni, M. \& Valenzuela-Ríos, J.I. 2002. Devonian. In: The Geology of Spain (eds. W. Gibbons \& T. Moreno). The Geological Society, London, 67-91.

García-López, S. \& Sanz-López, J. (with contributions by G.N. Sarmiento) 2002. The Palaeozoic sucession and conodont biostratigraphy of the section between Cape Peñas and Cape Torres (Cantabrian coast, NW Spain). Cuadernos del Museo Geominero, 1, 125-161.

Havlíček, V. 1956. Ramenonozci vapencu branckych a hlubo- 
cepskych z nejblizsiho prazskeho okoli. Sbornik Ustředniho Ústavu geologickych, Odd. paleont., 22, 535-665.

Havlíček, V. 1959. Rhynchonellacea im böhmischen älteren Paläozoikum (Brachiopoda). Věstnik Ustředniho Ústavu geologického, 34, 78-82.

Havlíček, V. 1960. Bericht über die Ergebnisse der Revision der böhmischen altpaläozoischen Rhynchonelloidea. Věstnik Ustředniho Ústavu geologickeho, 35, 241-244.

Havlíček, V. 1961. Rhynchonelloidea des böhmischen älteren Paläozoikums (Brachiopoda). Rozpravy Ustredni Ústavu Geologického, 27, 1-211.

Havlíček, V. 1982. New genera of rhynchonellid and camerellid brachiopods in the Silurian of Bohemia. Věstnik Ustředniho Ústavu geologického, 57, 365-372.

Havlíček, V. 1983. Gradual reduction of the septalium cavity in the Uncinulidae (Brachiopoda). Věstnik Ustředniho Ústavu geologického, 58, 149-157.

Havlíček, V. 1992. New Lower Devonian (Lochkovian-Zlichovian) rhynchonellid brachiopods in the Prague Basin. Sborník geologickych ved. Paleontologie, 32, 55-122.

Johnson, J.G., Boucot, A. J. \& Murphy, M.A. 1973. Pridolian and early Gedinnian age brachiopods from the Roberts Mountains Formation of Central Nevada. University of California Publications of Geological Sciences, 100, 1-75.

Kayser, E. 1889. Die Fauna des hauptquarzits und der Zorger Schiefer des Unterharzes. Abhandlungen Köning. Preussischen Geologische. Landensaltalst., N.F., 1, 1-139.

Le Maître, D. 1952. La faune du Dévonien Inférieur et moyen de La Saoura et des abords de l'erg El Djemel (Sud-Oranais). Materiaux carte géologique Algerie, ser. 1, Paléontologie, 12, 1-171.

Lenz, A.C. \& Jonson, J.G. 1985. Brachiopods of the Garra Formation (Lower Devonian), Wellington Area, New South Wales, Australia: Rhynchonellida, Spiriferida, Terebratulida. Palaeontographica, A, 188, 71-104.

Marek, L. \& Galle, A. 1976. The tabulate coral Hyostragulum, an epizoan with bearing on hyolithid ecology and systematics. Lethaia, 9, 51-64.

Martínez-Chacón, M.L. 1969. Revisión de algunas especies de Rhynchonellida de la base del Devónico Medio Asturiano. Tesis de Licenciatura, Facultad de Ciencias de la Universidad de Oviedo, 1-41 (inédito).

Méndez-Bedia, I. 1976. Biofacies y litofacies de la formación Moniello-Santa Lucia (Devónico de la Cordillera Cantábrica, NW de España). Trabajos de Geología de la Universidad de Oviedo, 9, 1-93.

Nikiforova, O.I. 1960. Novye podvidy Rannedevonskikh untsinulid arktiki. In: Novye Vidy Drevnikh Rastenii $i$ Bespozvonochnyukh SSSR (ed. B.P. Markowski), VSEGEI, Moscu, 1, 344-349.
Nikolaev, A.A. \& Rzhonsnitskaia, M.A. 1967. Devonian of northeastern USSR. In: International Symposium on the Devonian System (ed. D.H.Oswald). Calgary, 1, 483-502.

Rudwick, M.J.S. 1970. Living and fossil brachiopods. Hutchinson University Library, London, 1-199.

Rzhonsnitskaya, M.A. 1956. Nadsemeistvo Rhynchonellacea Gray, 1848. In: Materialy po Paleontologii, Novye Semeistva i Rody (eds. L.D. Kiparisova, V.P. Markovskii \& G.P., Radchenko), Vsesoiuznyi Nauchno-Issledovatel'skii Geologicheskii Institut (VSEGEI), Materialy (Paleontologii), 12, 53-56.

Savage, N. 2002. Uncinuloidea (pp. 1092-1131). In: Savage et al., Order Rhynchonellida (ed. R.L. Kaesler), Treatise on Invertebrate Paleontology, Part H, Brachiopoda (revised), Geological Society of America \& Paleontological Institute, Boulder, Colorado \& Lawrence, Kansas, 4, 1027-1376.

Schmidt, H. 1942. Die Rhynchonelliden des Wetteldorfer Richtschnittes. Senckenbergiana, 25, 389-404.

Schumann, D. 1965. Rhynchonelloidea aus dem Devon des Kantabrischen Gebirges (Nordspanien). Neues Jahrbuch Geologie und Paläontologie Abhandlungen, 123, 41-104.

Sougy, J. 1964. Les formations paléozoïques du Zemmour noir (Mauritania septentrionale). Étude stratigraphique, pétrographique et paléontologique. Annales de la Faculté des Sciences de Dakar, 15 (1-12), 1-695.

Stel, J. 1976. Clay diapirism in the lower Emsian La Vid Shales near Colle, Cantabrian Mountains, NW-Spain. Geologie en Mijnbouw, 55, 110-116.

Su, Y.-Z. 1976. Braquiópodos del Cámbrico-Devónico (en chino). In: Paleontological Atlas of North China, Nei Mongol. Geological Bureau Nei Mongol Autonomous Region \& Northeast Institute Geological Sciences, 1, 159-227.

Talent, J.A., Gratsianova, R.T. \& Yolkin, E.A. 2001. Latest Silurian (Pridoli) to middle Devonian (Givetian) of the Asio-Australia hemisphere: rationalization of brachiopod taxa and faunal lists; stratigraphic correlation chart. Courier Forschungsinstitut Senckenberg, 236, 1-221.

Tcherkesova, S.V. 1968. Rinkhonellidi podsemeistva Uncinulinae Rzonsnickaja iz tareiskogo opornogo razreza (Tsentralni Taimyr). Uchenie Zapiski. Paleontologiya $i$ biostratigrafiya, Nauchno-Issledovatelskii Institut Geologii Arktiki, Ministerstva Geologii SSR, 22, 89-124.

Westbroek, P. 1967. Morphological observations with systematic implications on some Palaeozoic Rhynchonellida from Europe, with special emphasis on the Uncinulidae. Leidse Geologische Mededelingen, 41, 1-82.

Manuscrito recibido: 18 de Febrero, 2008 Manuscrito aceptado: 15 de Septiembre, 2008 